Supporting Information

\title{
Topological Effects of Dendronized Polymers on their Thermoresponsiveness
} and Microconfinement

Gang Xu, Jiaxing Zhang, Ruitong Jia, Wen Li, * and Afang Zhang

International Joint Laboratory of Biomimetic \& Smart Polymers, School of Materials

Science and Engineering, Shanghai University, Shangda Road 99, Shanghai 20444, China 
Table of Contents

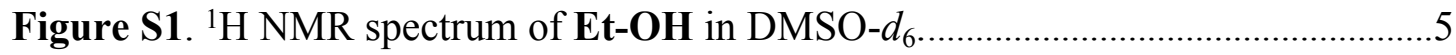

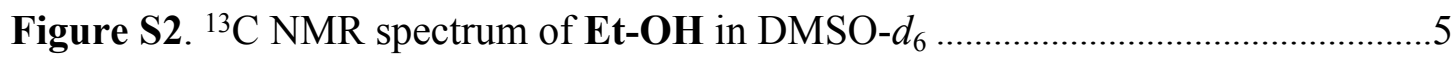

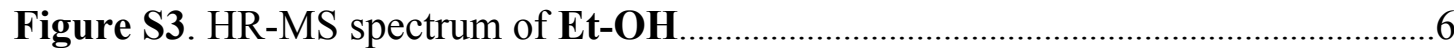

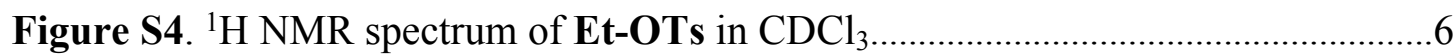

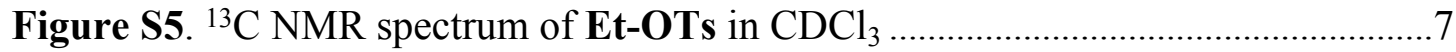

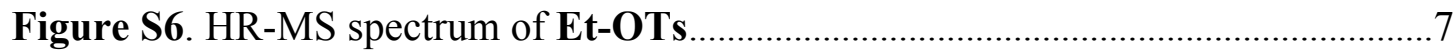

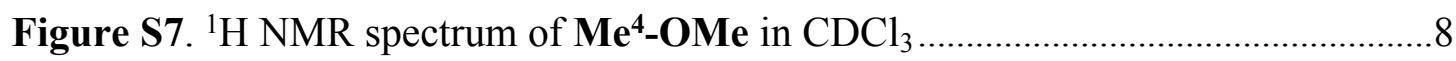

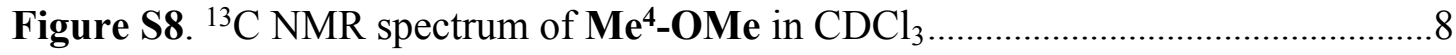

Figure S9. HR-MS spectrum of $\mathbf{M e}^{4}-\mathbf{O M e}$

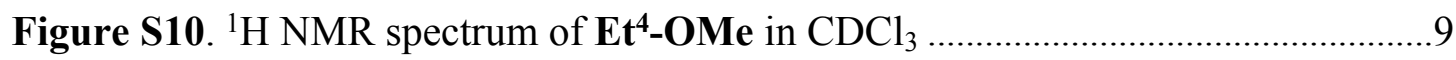

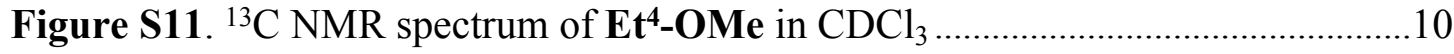

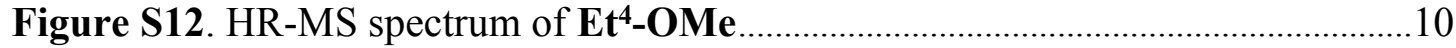

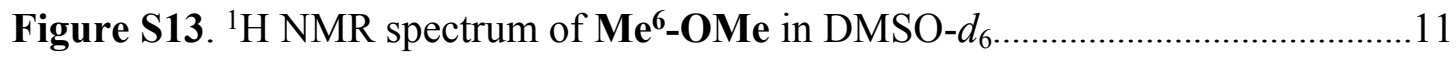

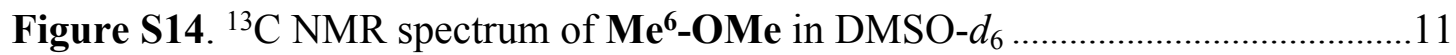

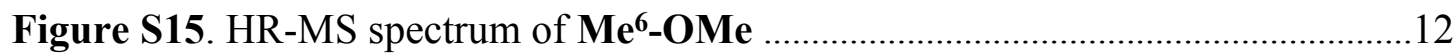

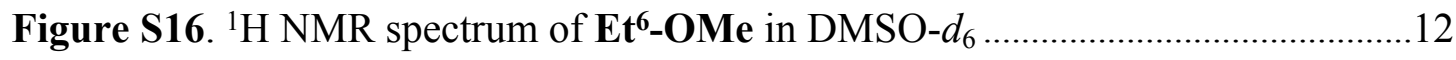

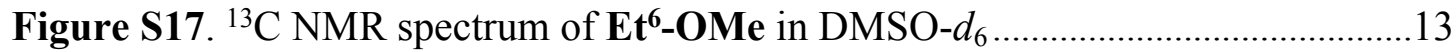

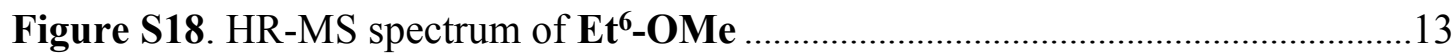

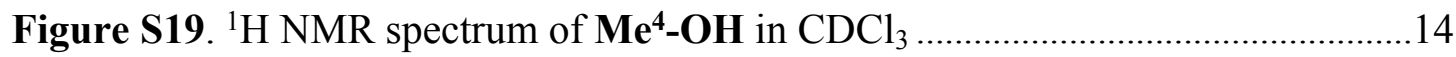

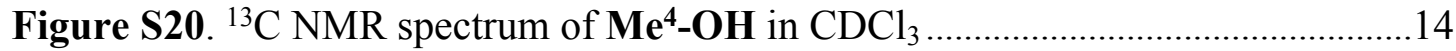

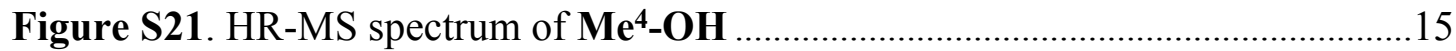

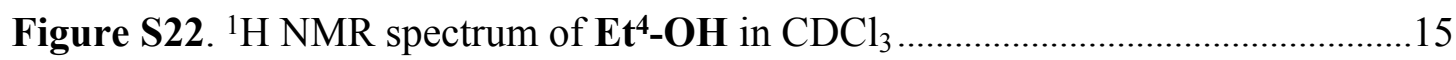

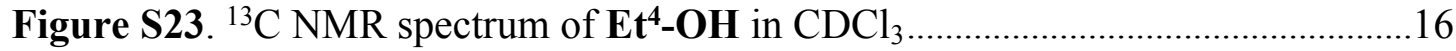

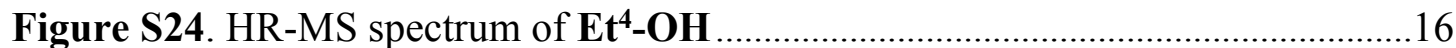

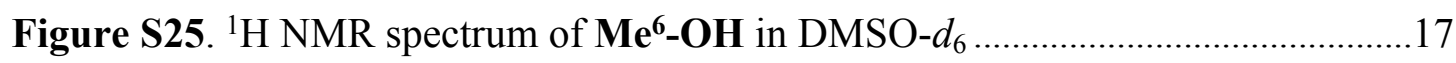

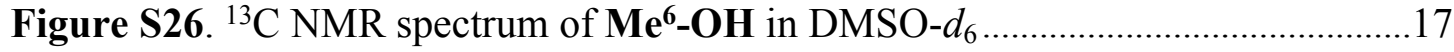

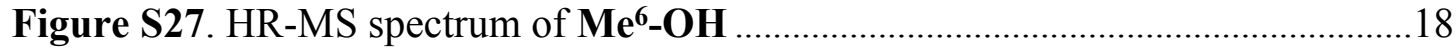

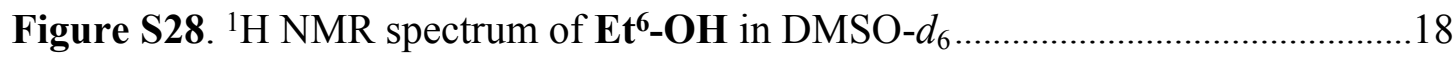

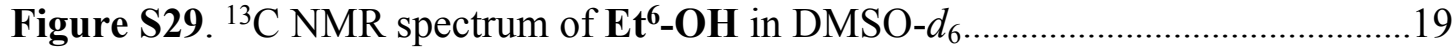




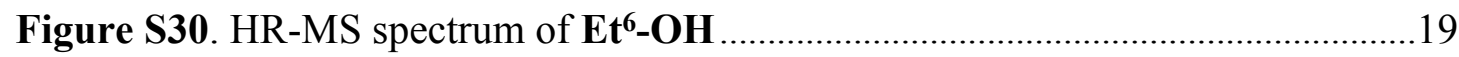

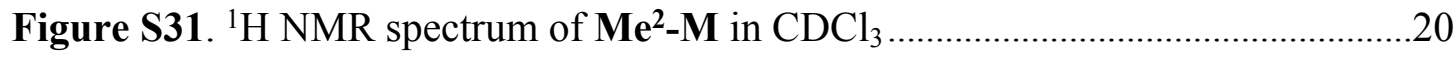

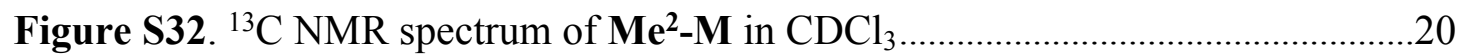

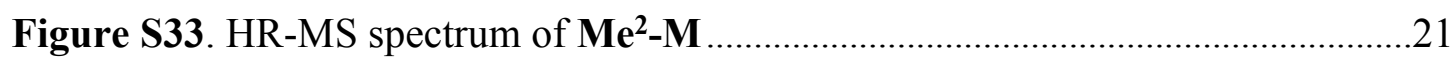

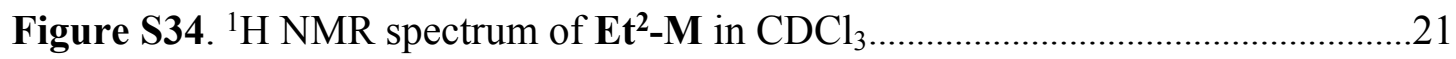

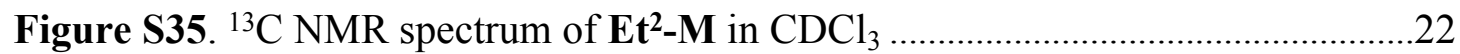

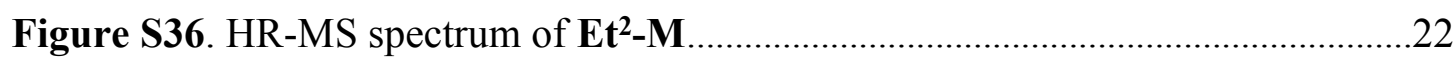

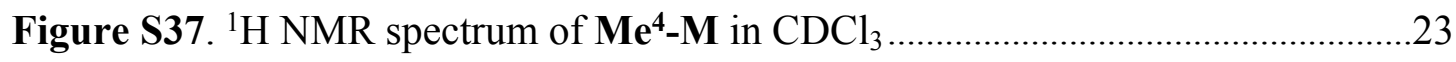

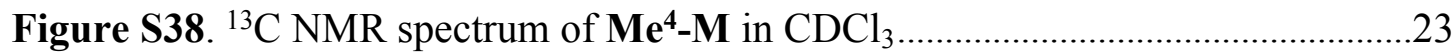

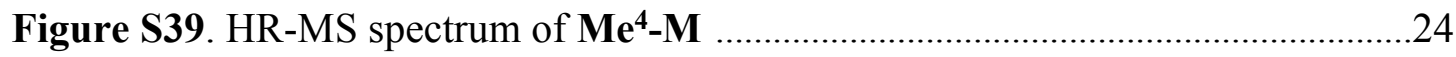

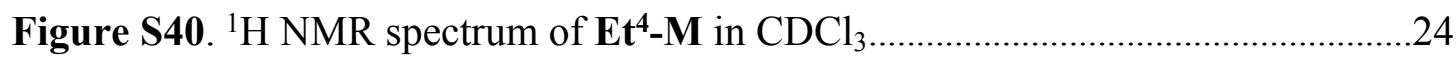

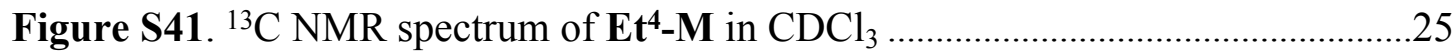

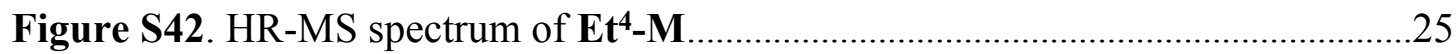

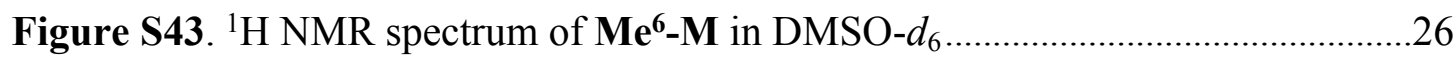

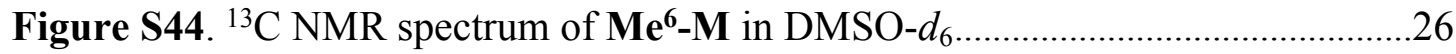

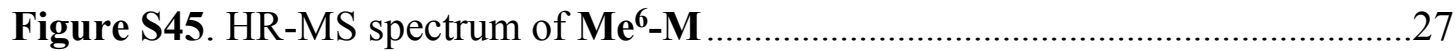

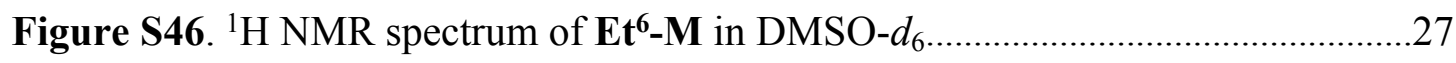

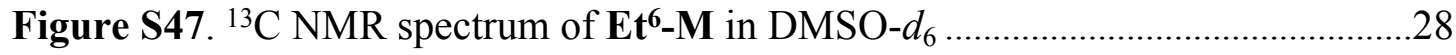

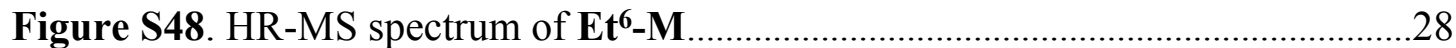

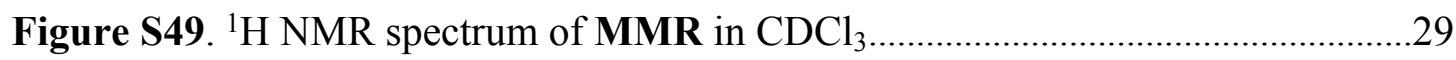

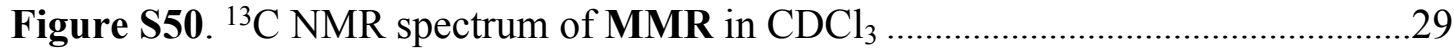

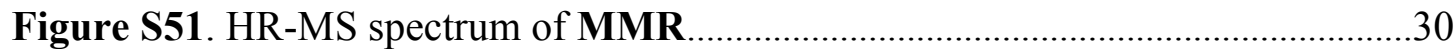

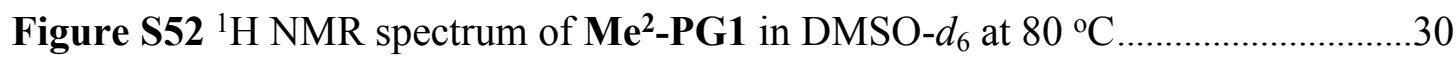

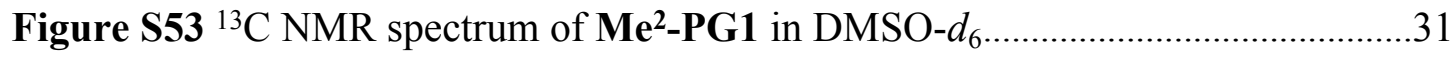

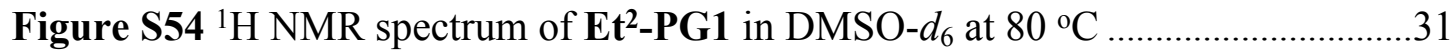

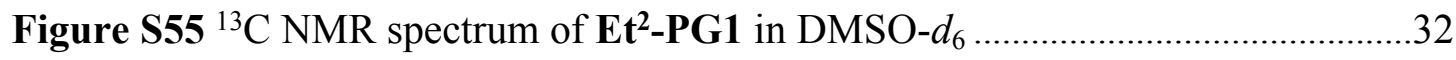

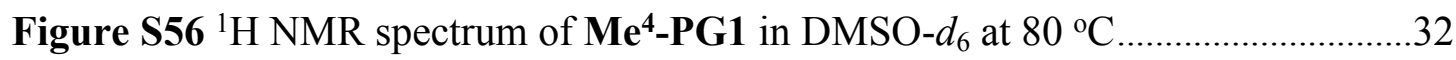

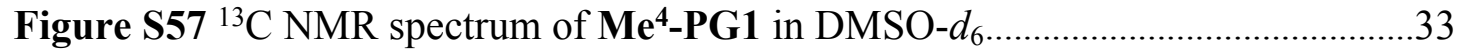

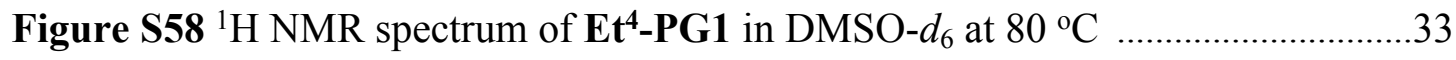

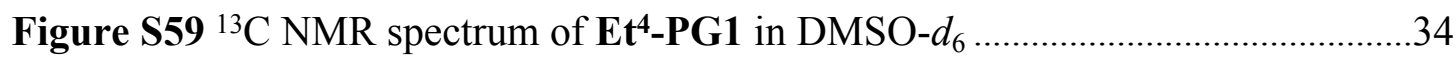

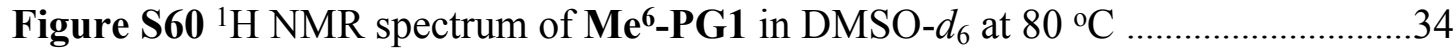

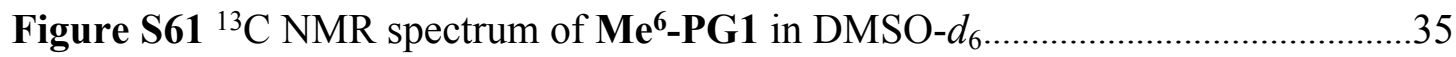


Figure S62. ${ }^{1} \mathrm{H}$ NMR spectrum of Et'-PG1 in DMSO- $d_{6}$ at $80{ }^{\circ} \mathrm{C}$

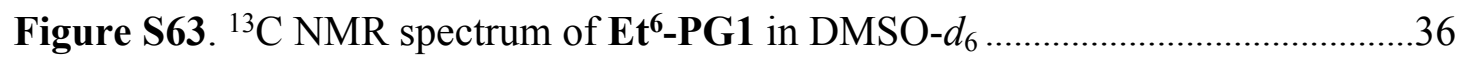

Figure S64. ${ }^{1} \mathrm{H}$ NMR spectrum of different dendronized polymers in DMSO- $d_{6}$ at 80 ${ }^{\circ} \mathrm{C}$.

Figure S65. ${ }^{1} \mathrm{H}$ NMR spectrum of Et $\mathbf{t}^{3}$-PG1MR in DMSO- $d_{6}$ at $80{ }^{\circ} \mathrm{C} \ldots \ldots \ldots \ldots \ldots \ldots \ldots . . . . . . . . . . . .37$

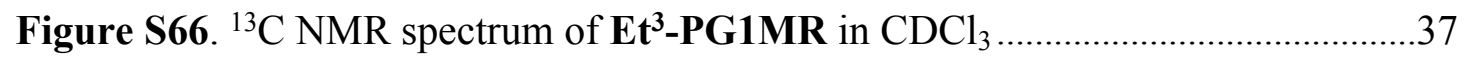

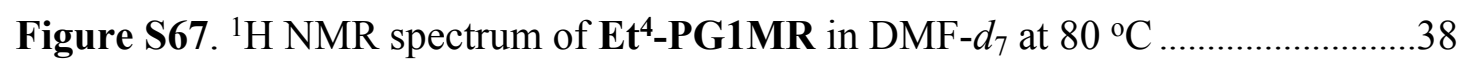

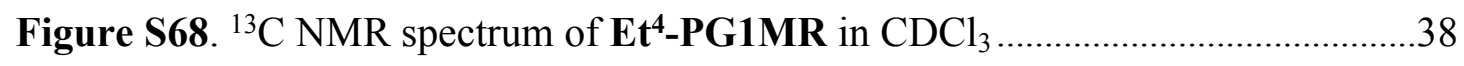

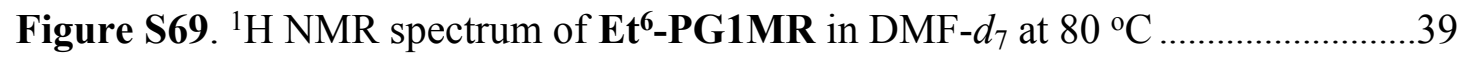

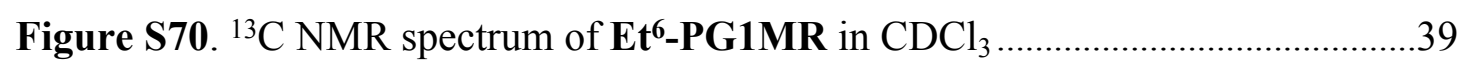

Figure S71. GPC elution curves of dendronized polymers ........................................... 40

Figure S72. Plots of transmittance $v s$ temperature for $0.25 \mathrm{wt} \%$ aqueous solutions of copolymers

Figure S73 Temperature-varied UV/vis spectra for $\mathbf{E t}^{\mathbf{3}}$-PG1MR (A), Et $\mathbf{t}^{\mathbf{4}}$-PG1MR (B), Et'-PG1MR (C)

Figure S74. Temperature-varied UV/vis spectra for $\mathbf{E t}^{3}$-PG1@MR (A), Et $\mathbf{t}^{4}$ PG1@MR (B), Et $\mathbf{t}^{6}$-PG1@MR (C).

Figure S75. Temperature-varied UV/vis spectra for Me $\mathbf{M e}^{3}$-PG1@MR (A), Me $\mathbf{M}^{4}$ PG1@MR (B), Mé-PG1@MR (C)..... 


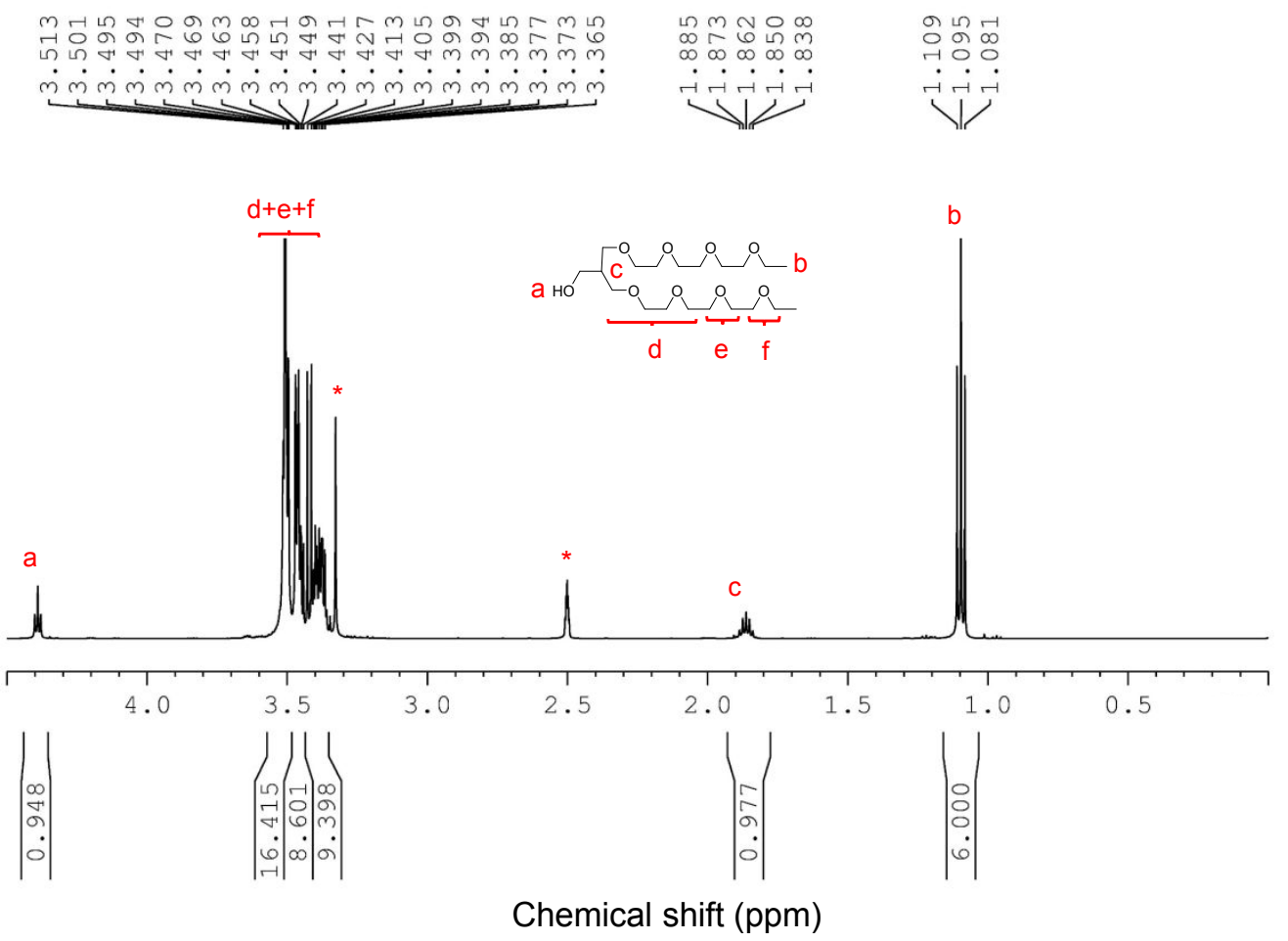

Figure S1. ${ }^{1} \mathrm{H}$ NMR spectrum of Et-OH in DMSO- $d_{6}$. The solvent peak is marked with asterisk $(*)$.
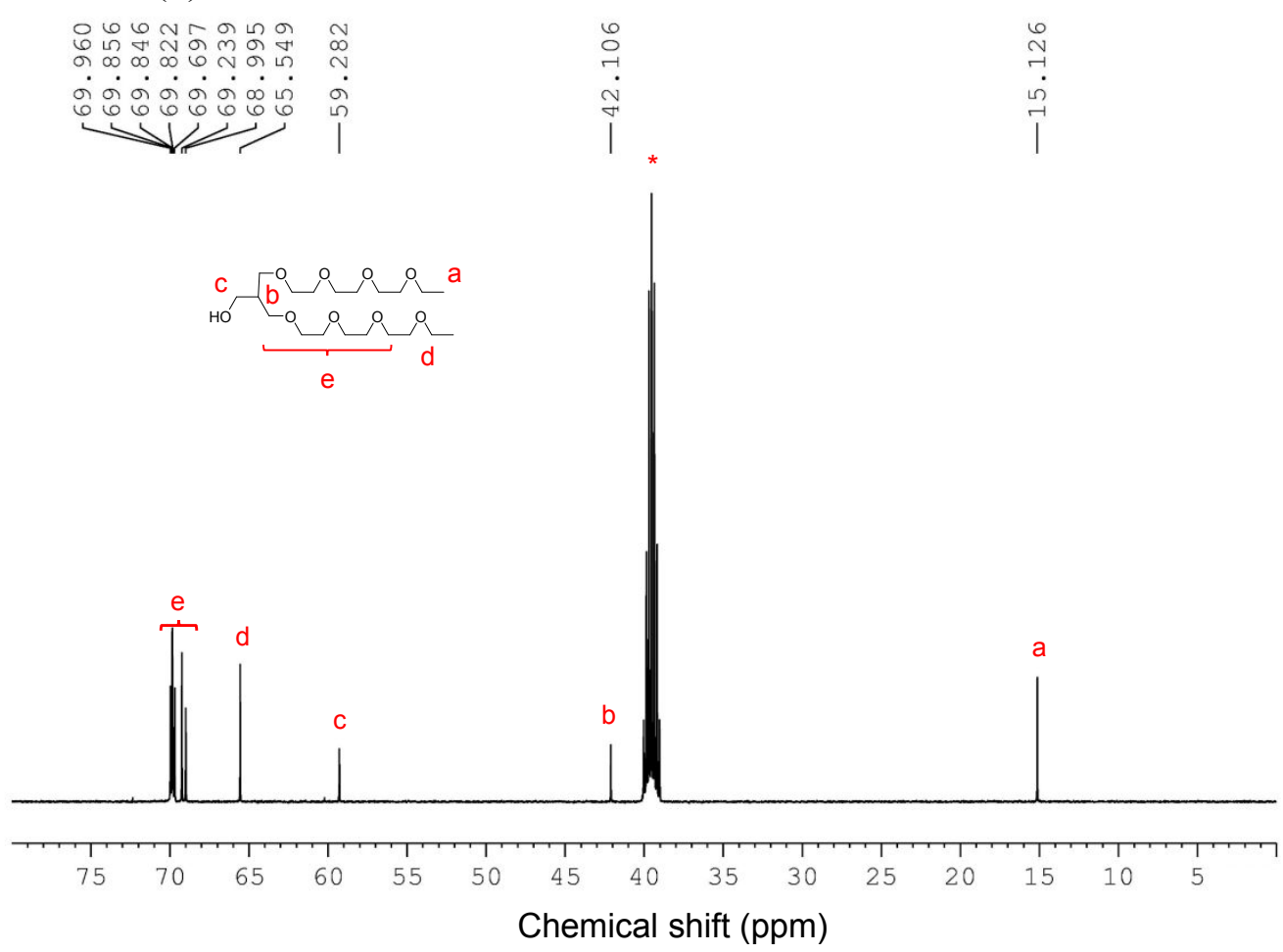

Figure S2. ${ }^{13} \mathrm{C}$ NMR spectrum of Et-OH in DMSO- $d_{6}$. The solvent peak is marked with asterisk $(*)$. 


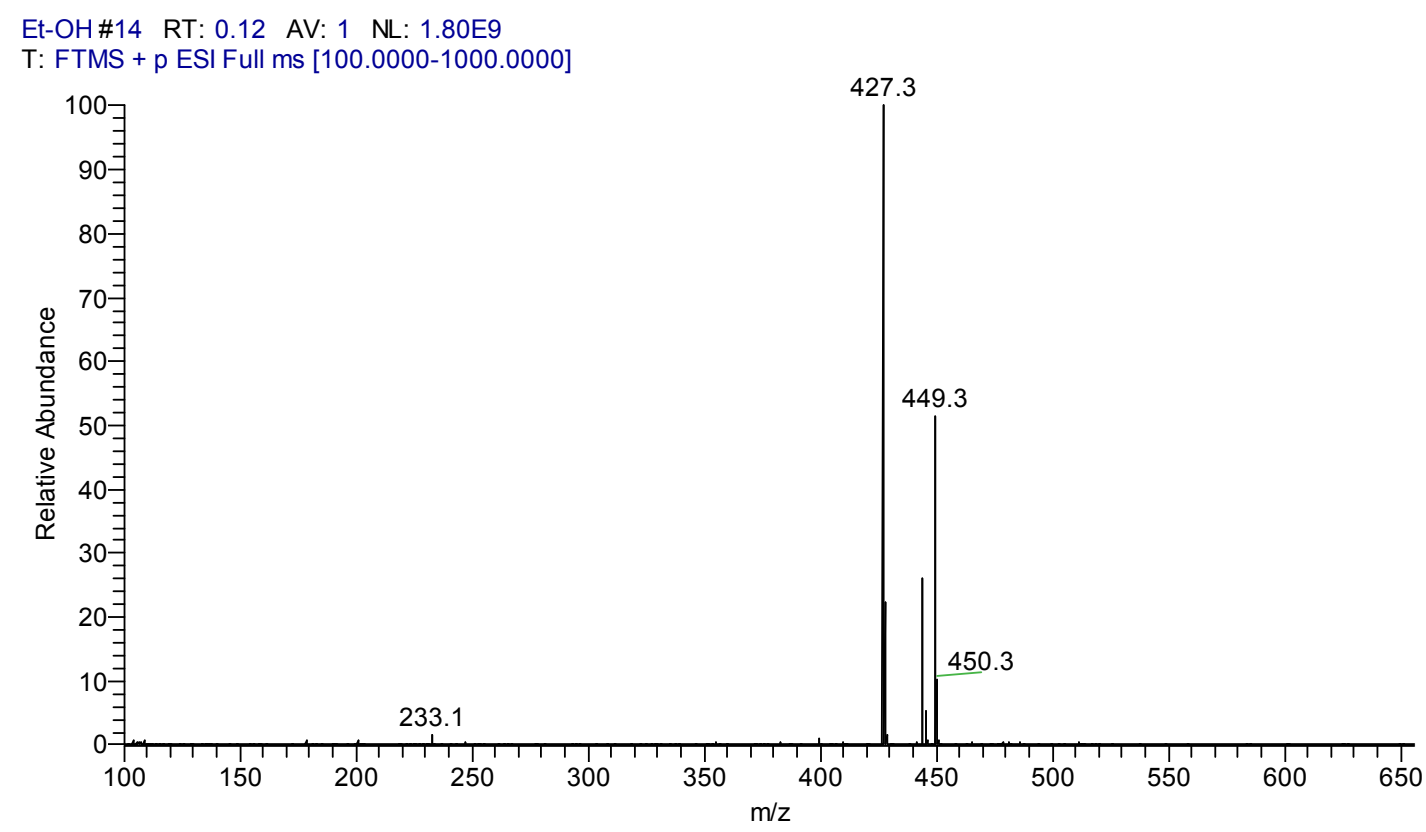

Figure S3. HR-MS spectrum of Et-OH.

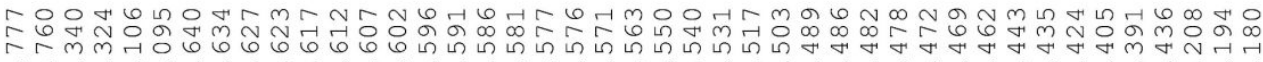

-

$\mathrm{VW}$

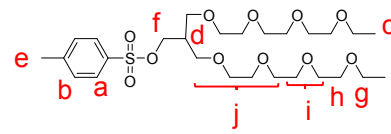

C

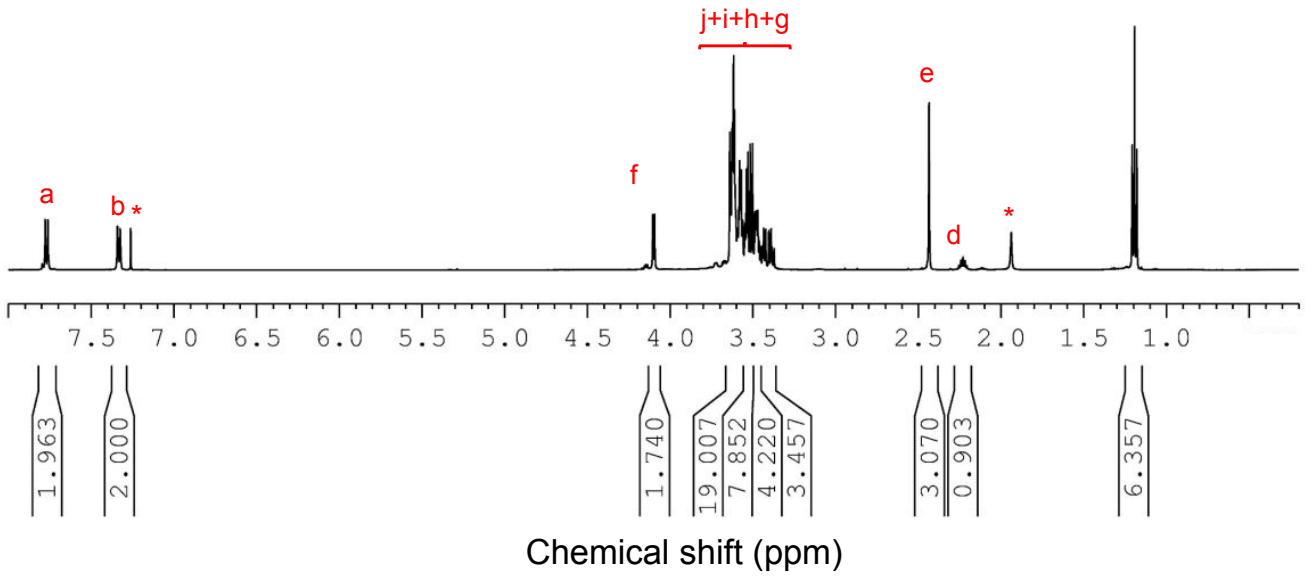

Figure S4. ${ }^{1} \mathrm{H}$ NMR spectrum of Et-OTs in $\mathrm{CDCl}_{3}$. The solvent peak is marked with asterisk $(*)$. 

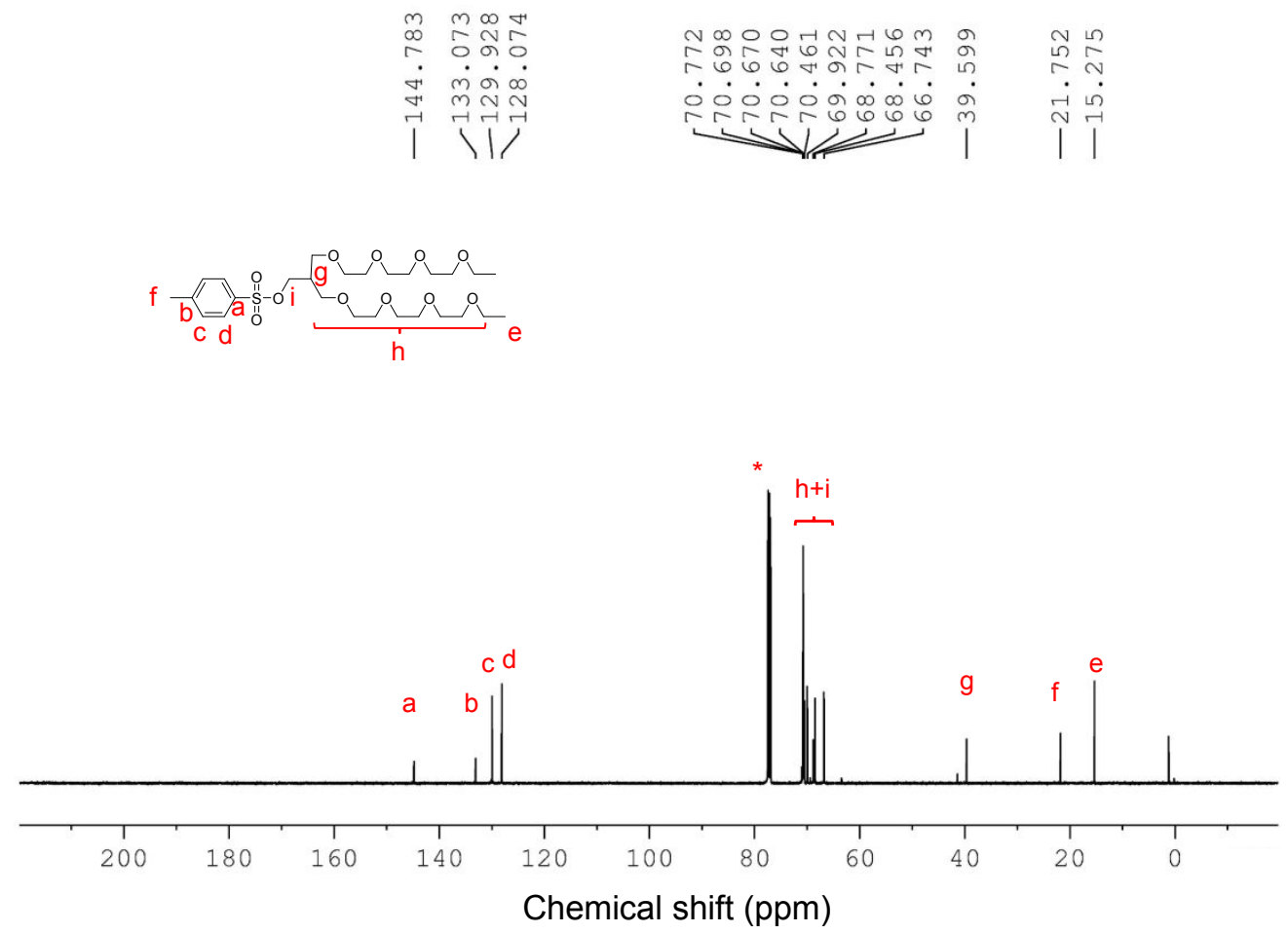

Figure S5. ${ }^{13} \mathrm{C}$ NMR spectrum of Et-OTs in $\mathrm{CDCl}_{3}$. The solvent peak is marked with asterisk (*).

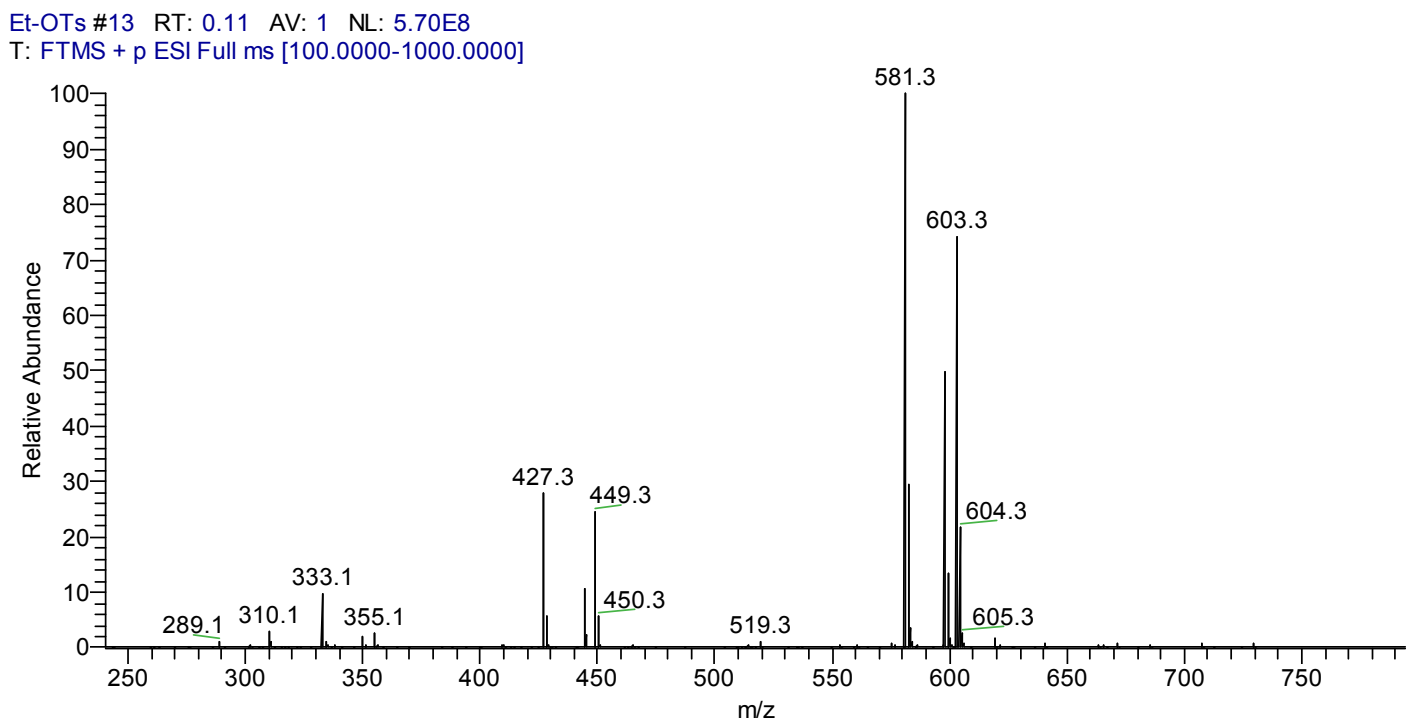

Figure S6. HR-MS spectrum of Et-OTs. 


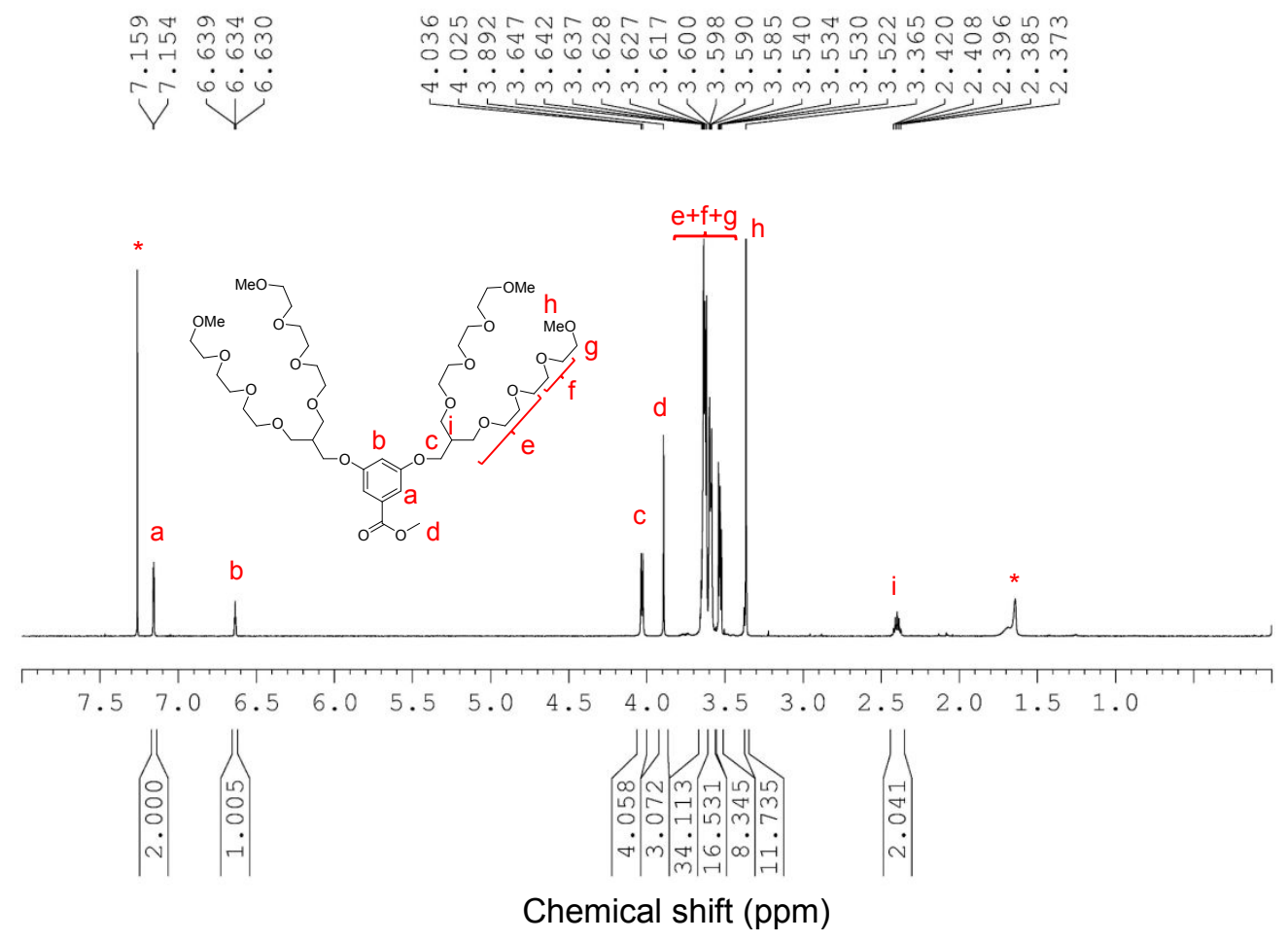

Figure S7. ${ }^{1} \mathrm{H}$ NMR spectrum of $\mathbf{M e}^{4}-\mathbf{O M e}$ in $\mathrm{CDCl}_{3}$. The solvent peak is marked with asterisk $(*)$.

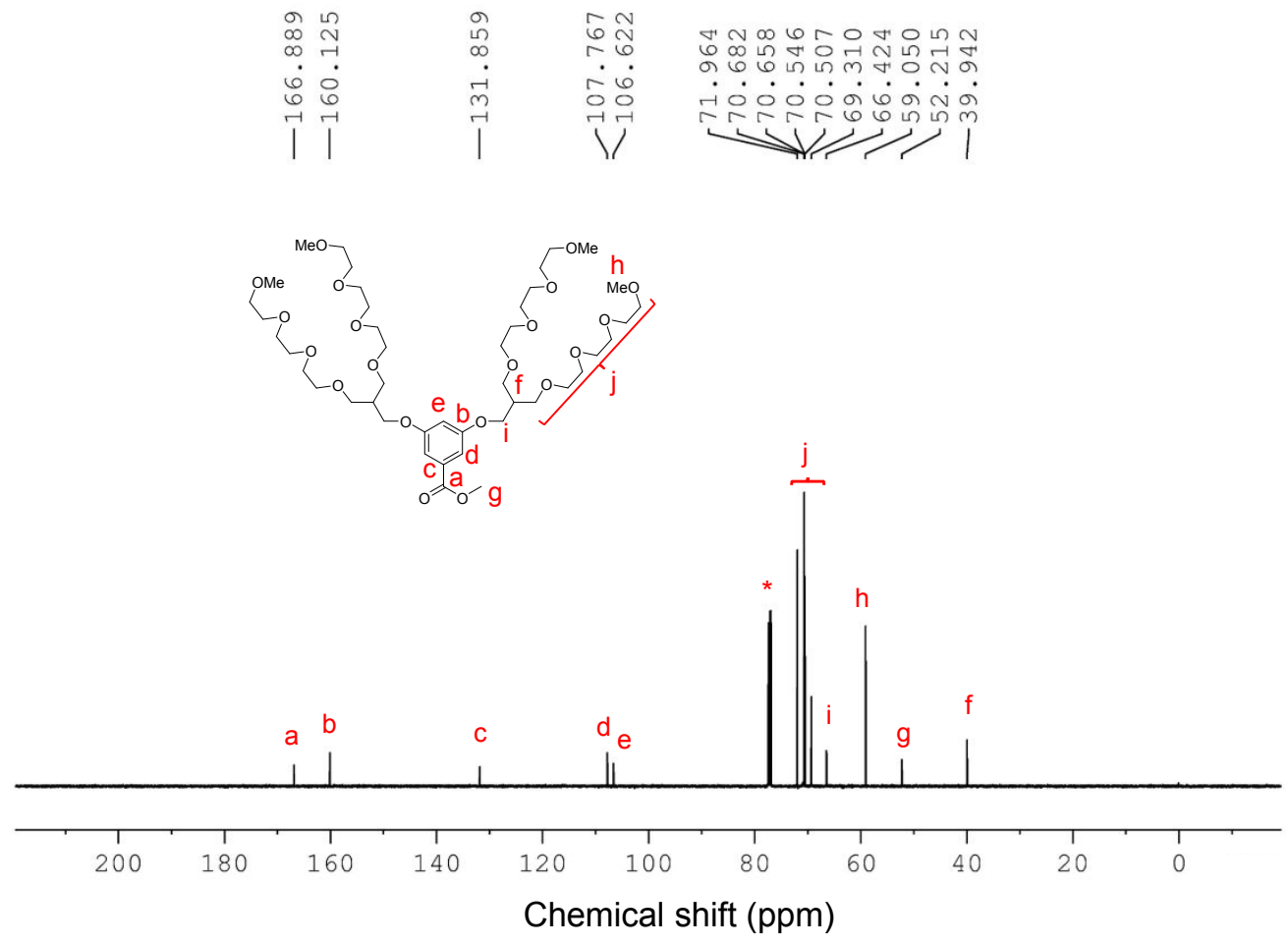

Figure S8. ${ }^{13} \mathrm{C}$ NMR spectrum of $\mathbf{M e}^{4}-\mathbf{O M e}$ in $\mathrm{CDCl}_{3}$. The solvent peak is marked with asterisk $(*)$. 
D190051 \#30 RT: 0.45 AV: 1 NL: $1.33 E 7$

T: FTMS + p NSI Full ms [100.00-1500.00]

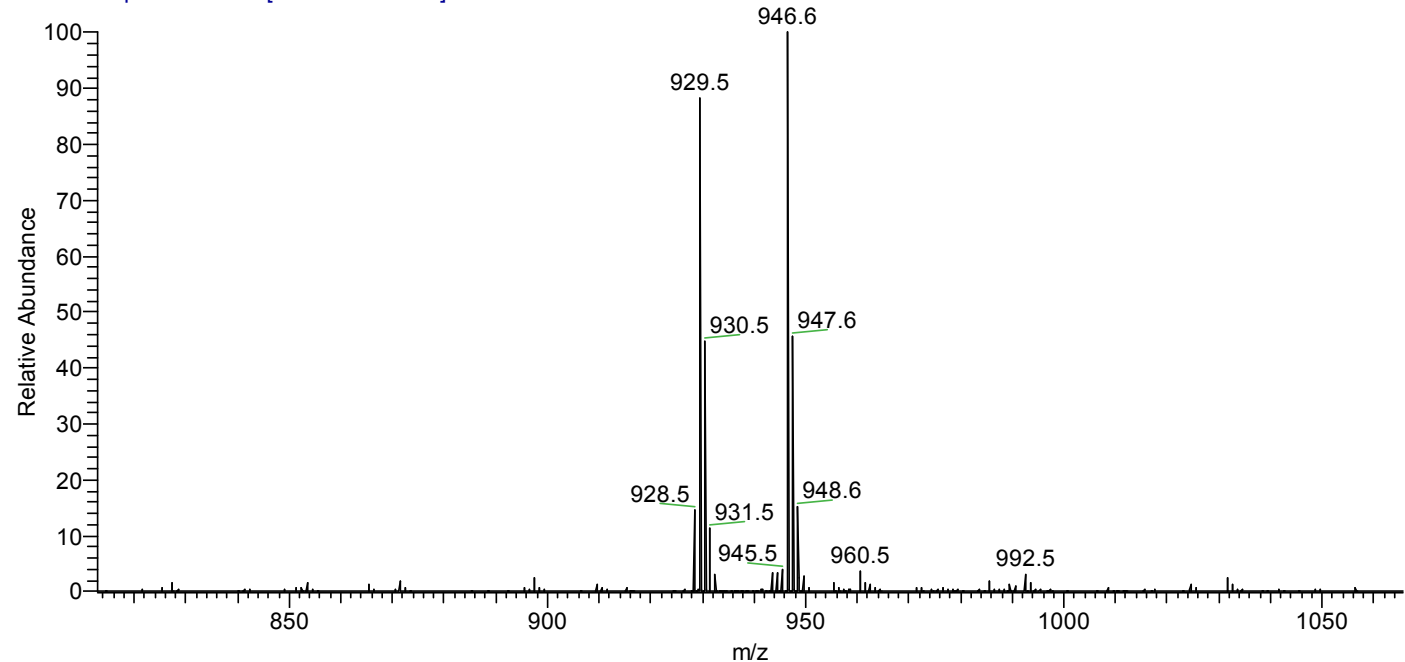

Figure S9. HR-MS spectrum of $\mathbf{M e}^{4}-\mathbf{O M e}$.

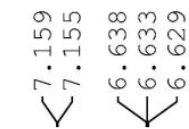

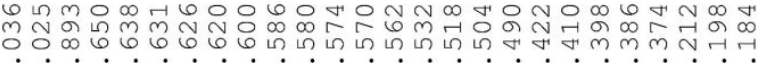
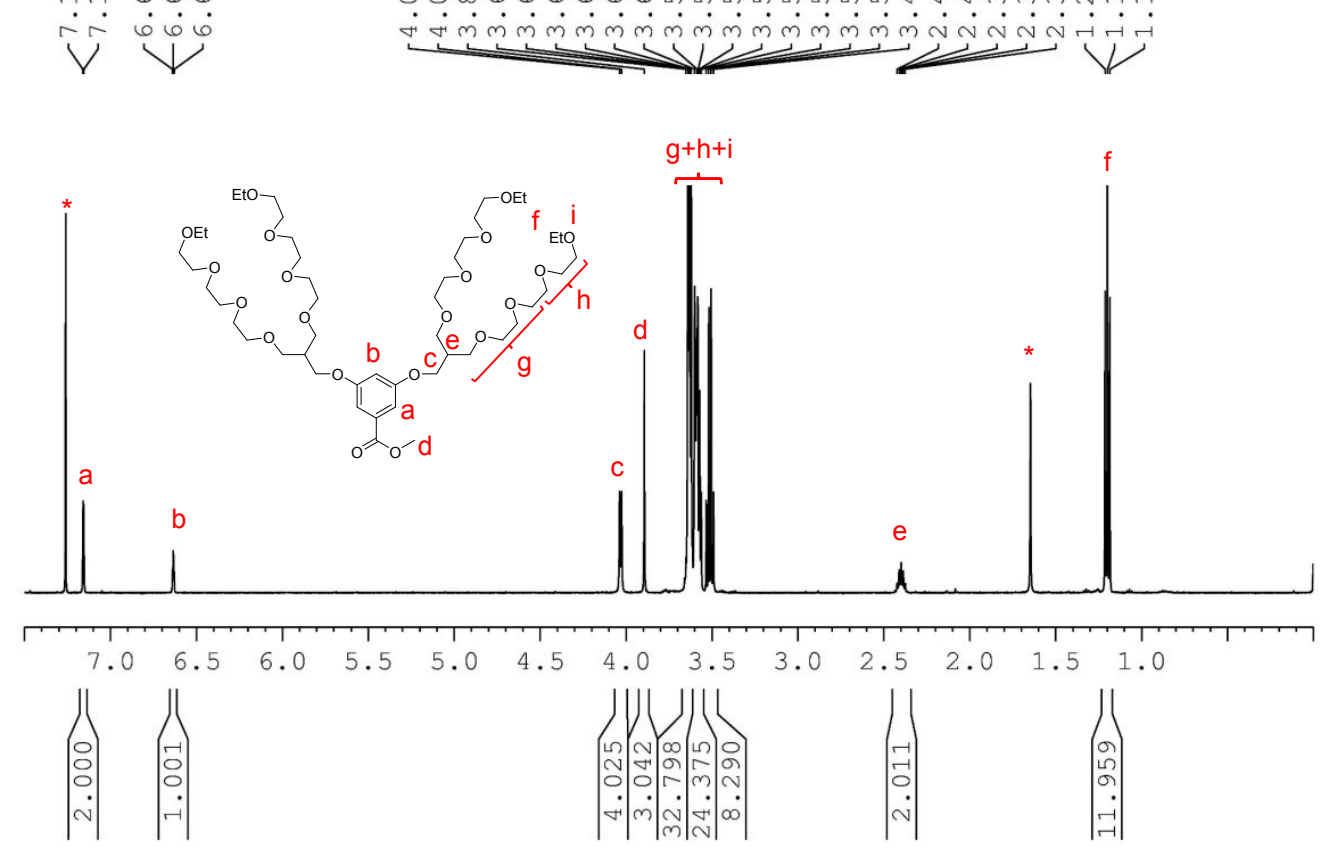

Chemical shift (ppm)

Figure S10. ${ }^{1} \mathrm{H}$ NMR spectrum of $\mathbf{E t}^{4}-\mathbf{O M e}$ in $\mathrm{CDCl}_{3}$. The solvent peak is marked with asterisk $(*)$. 


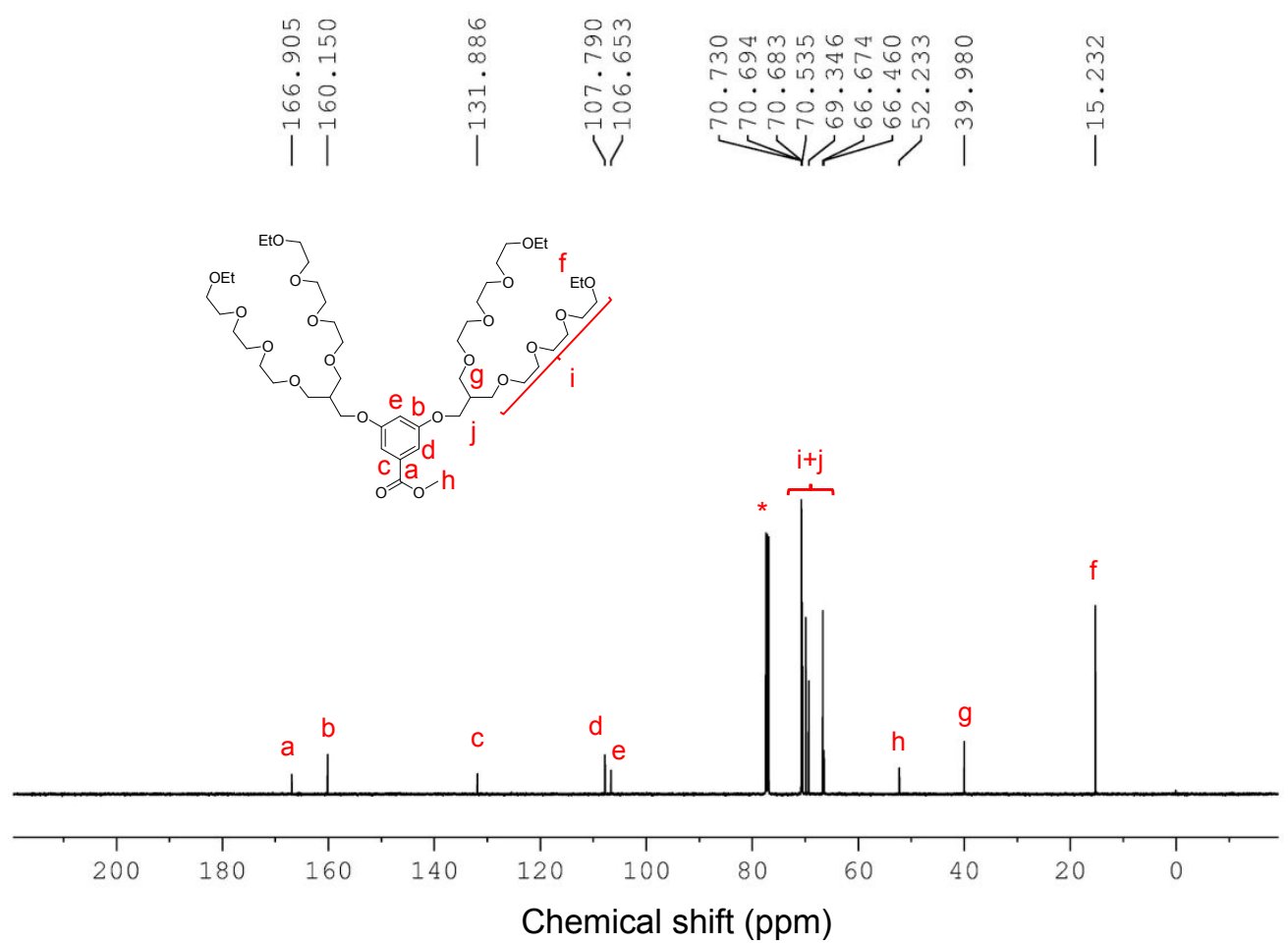

Figure S11. ${ }^{13} \mathrm{C}$ NMR spectrum of $\mathbf{E t}^{4}-\mathbf{O M e}$ in $\mathrm{CDCl}_{3}$. The solvent peak is marked with asterisk (*).

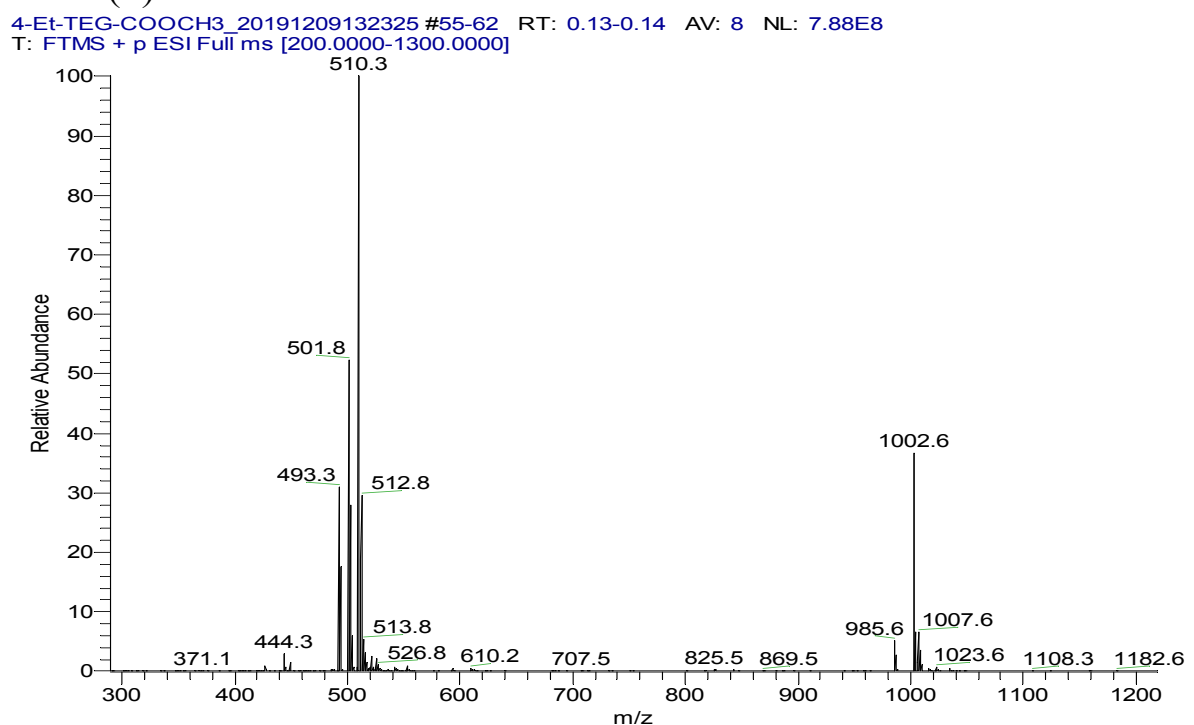

Figure S12. HR-MS spectrum of $\mathbf{E t}^{4}$-OMe. 

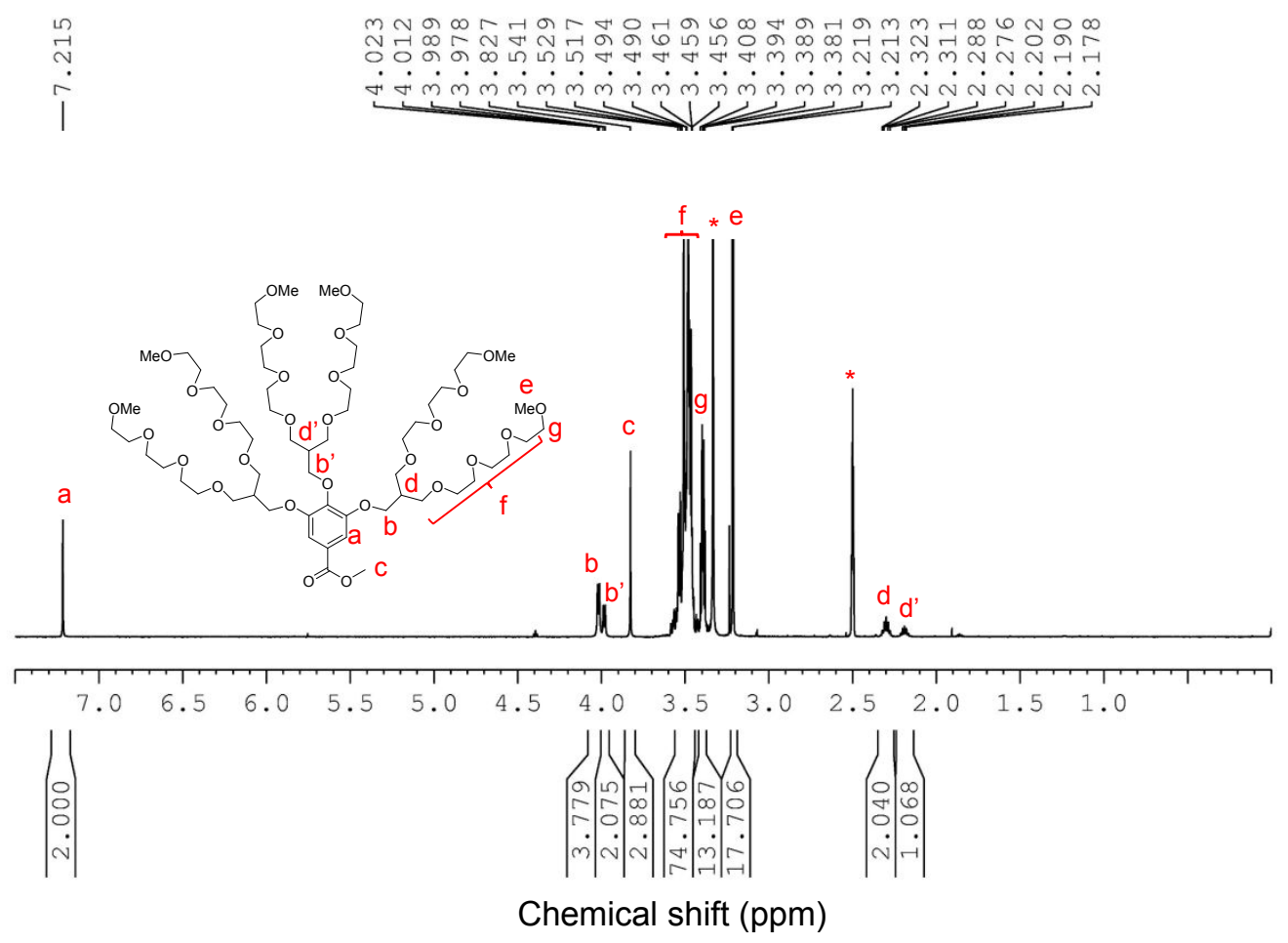

Figure S13. ${ }^{1} \mathrm{H}$ NMR spectrum of $\mathbf{M e}^{6}-\mathrm{OMe}$ in DMSO- $d_{6}$. The solvent peak is marked with asterisk (*).
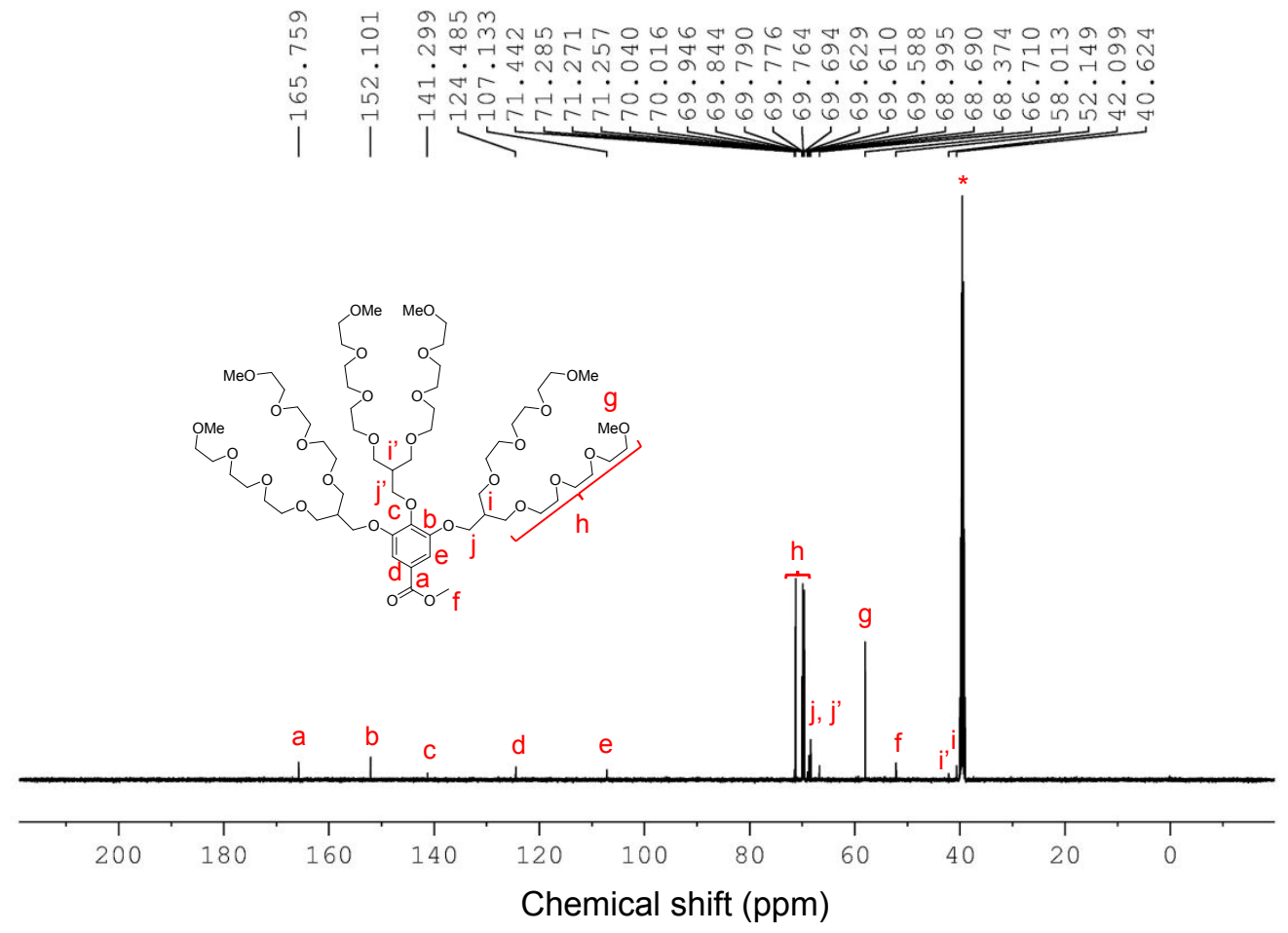

Figure S14. ${ }^{13} \mathrm{C}$ NMR spectrum of $\mathbf{M e}^{6}-\mathrm{OMe}$ in DMSO- $d_{6}$. The solvent peak is marked with asterisk (*). 
D190053 \#10 RT: 0.15 AV: 1 NL: 1.95E6

T: FTMS + p NSI Full ms [100.00-1500.00]

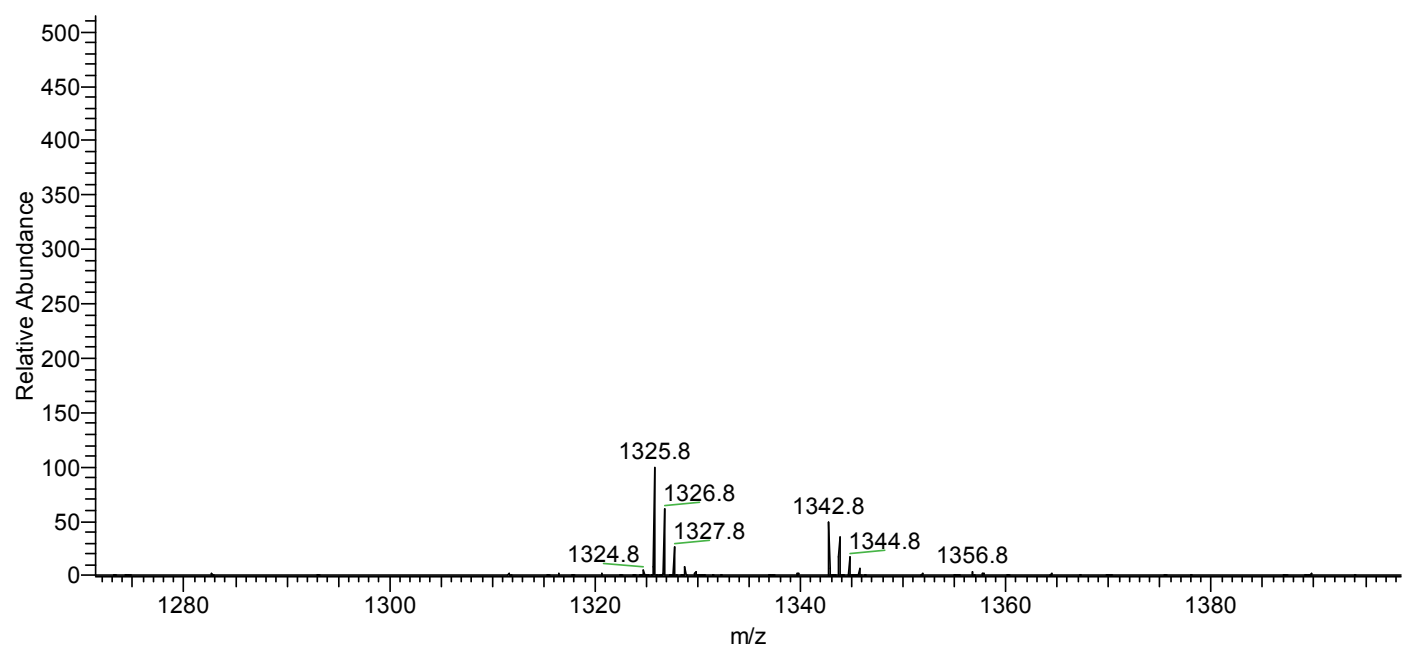

Figure S15. HR-MS spectrum of $\mathbf{M e}^{6}-\mathrm{OMe}$.
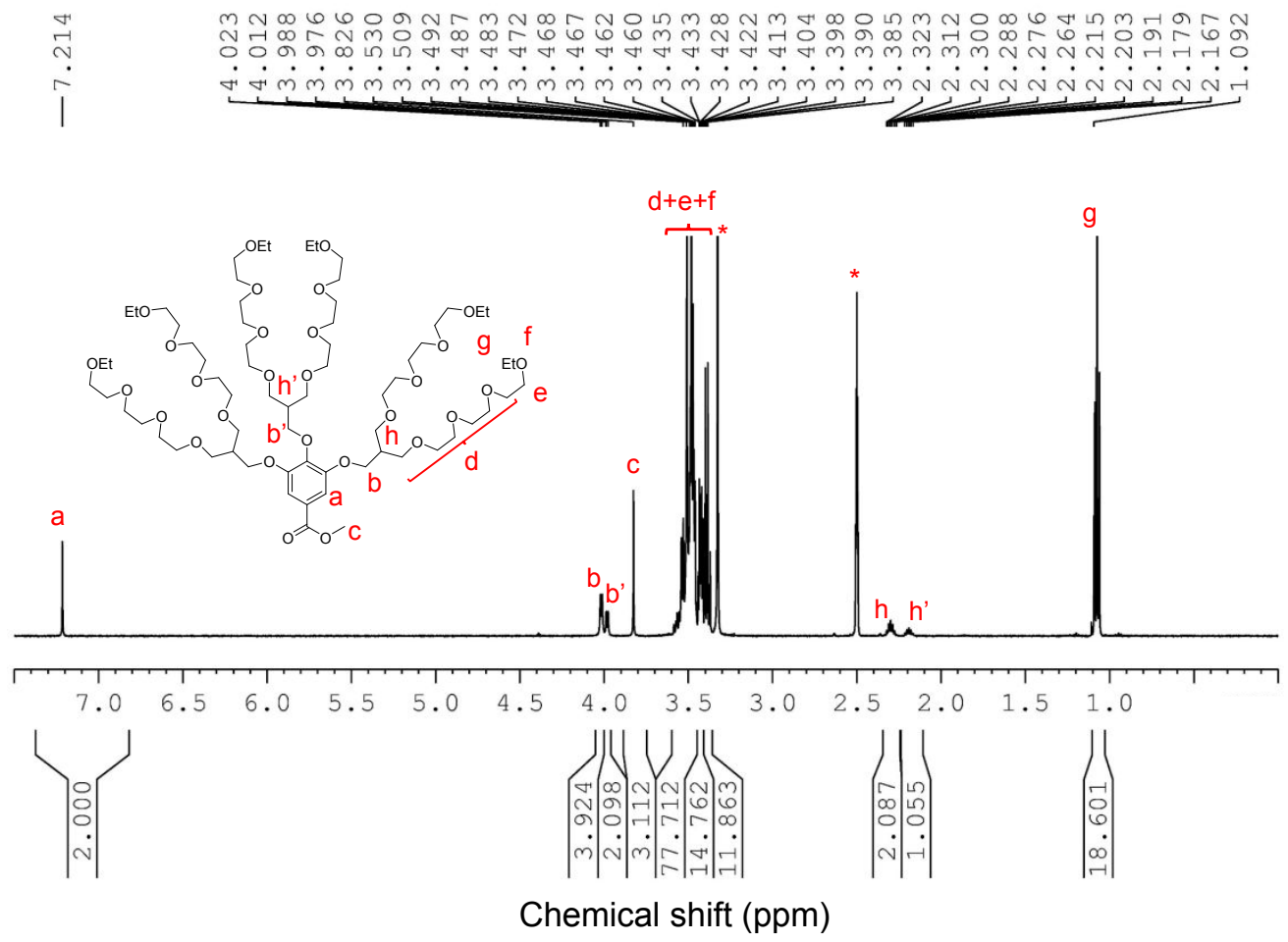

Figure S16. ${ }^{1} \mathrm{H}$ NMR spectrum of $\mathbf{E t}^{6}-\mathbf{O M e}$ in DMSO- $d_{6}$. The solvent peak is marked with asterisk (*). 


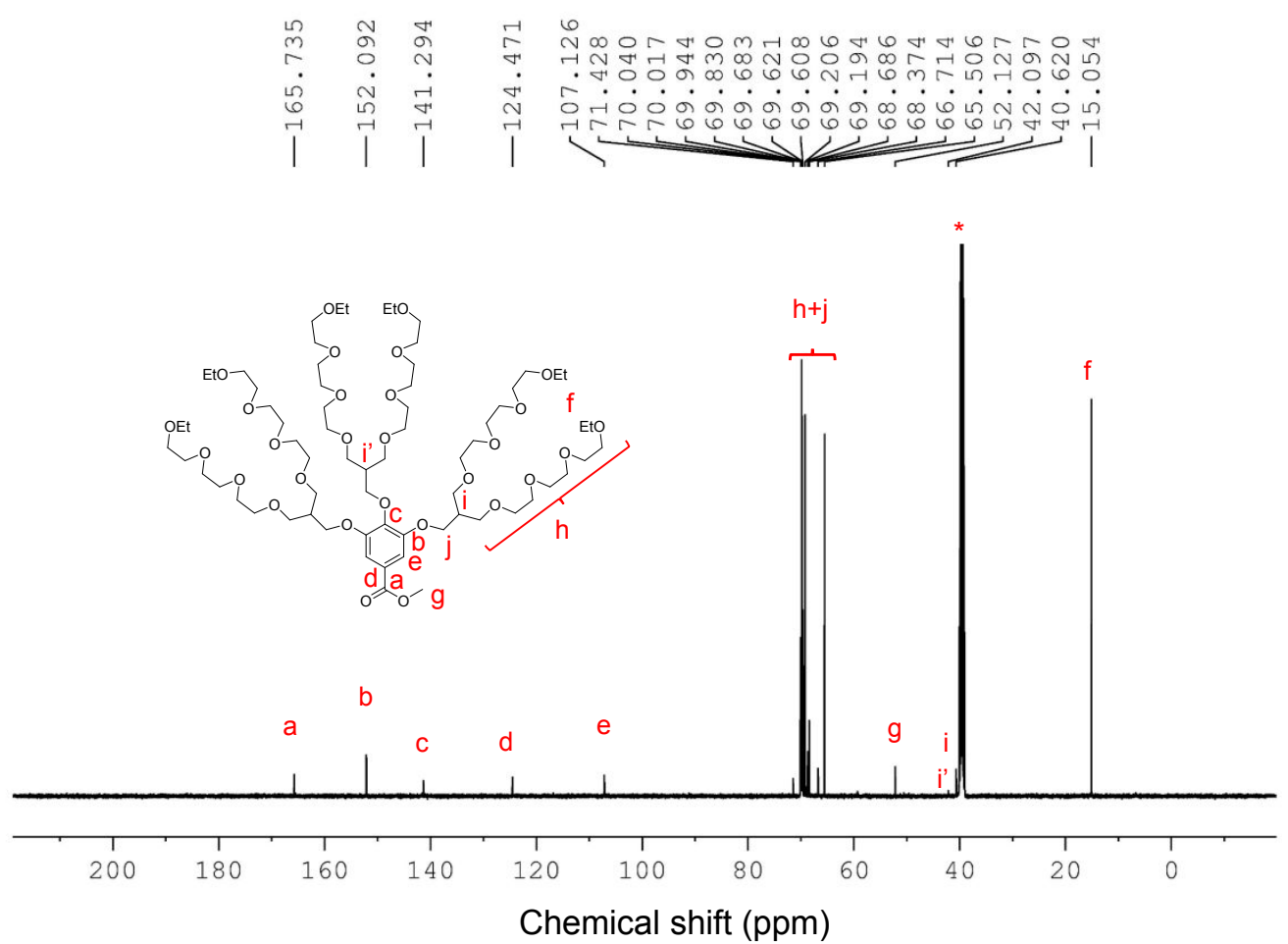

Figure S17. ${ }^{13} \mathrm{C}$ NMR spectrum of $\mathbf{E t ^ { 6 } - O M e}$ in DMSO- $d_{6}$. The solvent peak is marked with asterisk $(*)$.

6-Et-TEG-COOCH3_20200901141203\#12 RT: 0.05 AV: 1 NL: 2.27E8 T: FTMS + p ESI Full ms [200.0000-2000.0000]

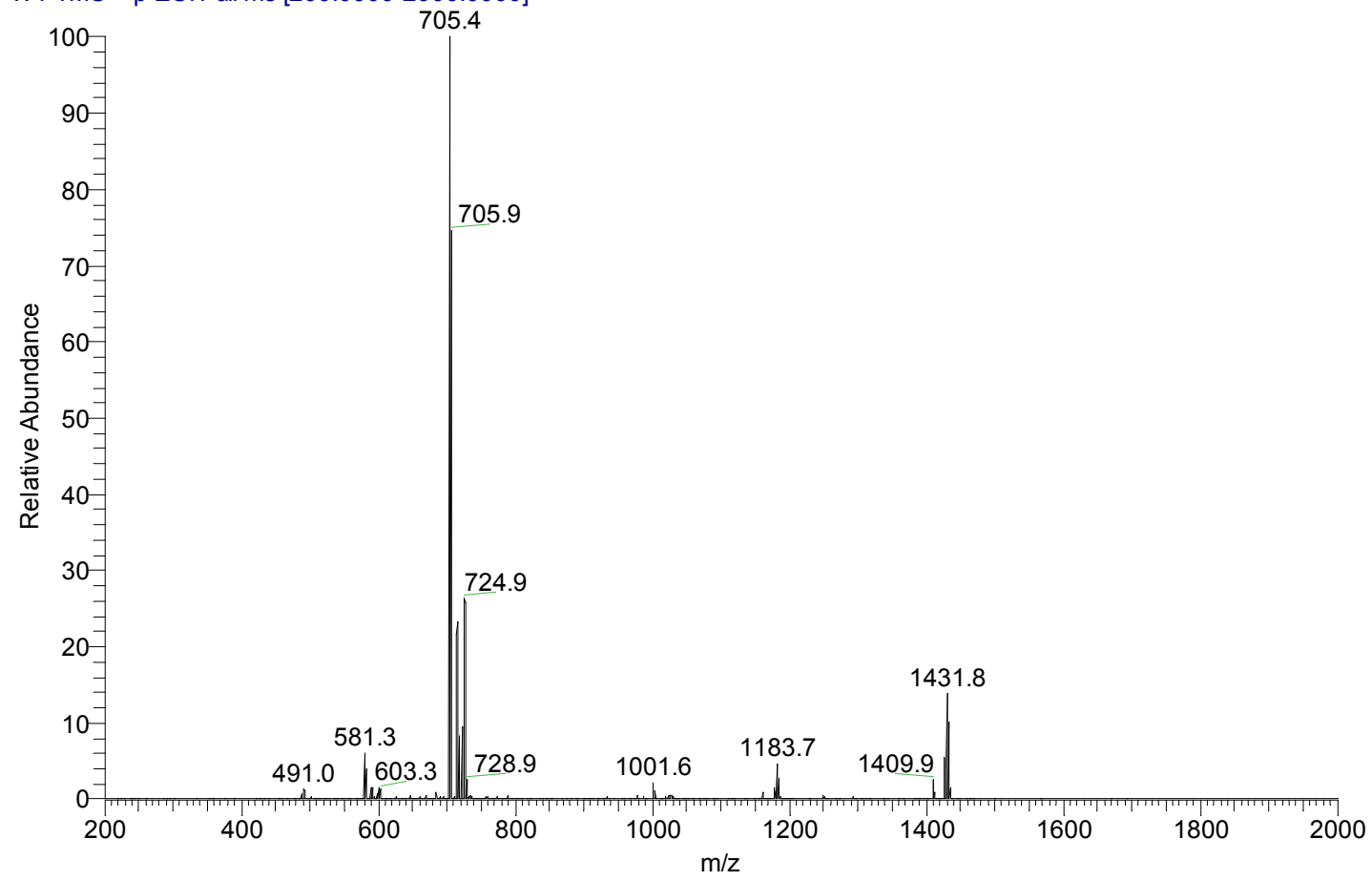

Figure S18. HR-MS spectrum of $\mathbf{E t}^{6}-\mathbf{O M e}$. 


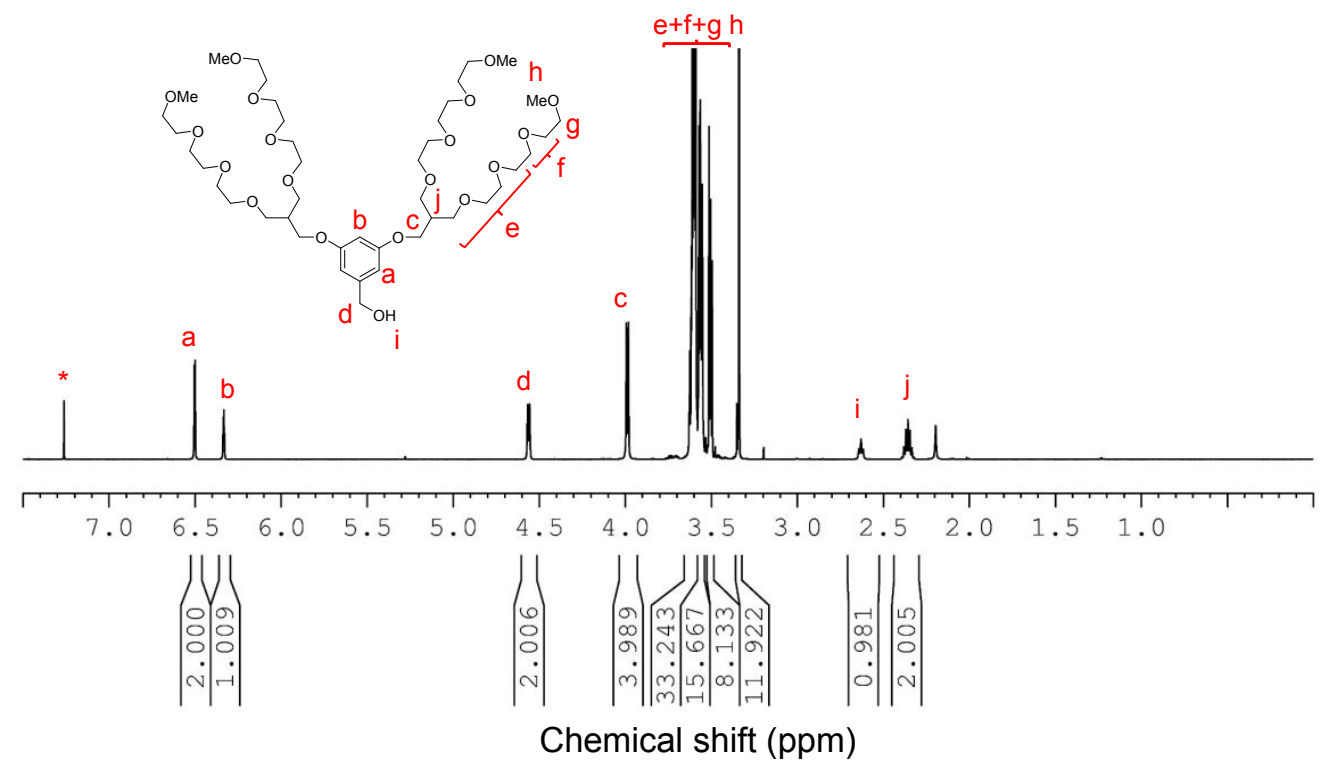

Figure S19. ${ }^{1} \mathrm{H}$ NMR spectrum of $\mathbf{M e}^{4}-\mathbf{O H}$ in $\mathrm{CDCl}_{3}$. The solvent peak is marked with asterisk $(*)$.

$\begin{array}{ll}\infty & \hat{m} \\ 0 & 0 \\ 6 & 0 \\ 0 & \dot{1} \\ 6 & \overrightarrow{1} \\ \overrightarrow{1} & \overrightarrow{1} \\ \mid & \mid\end{array}$
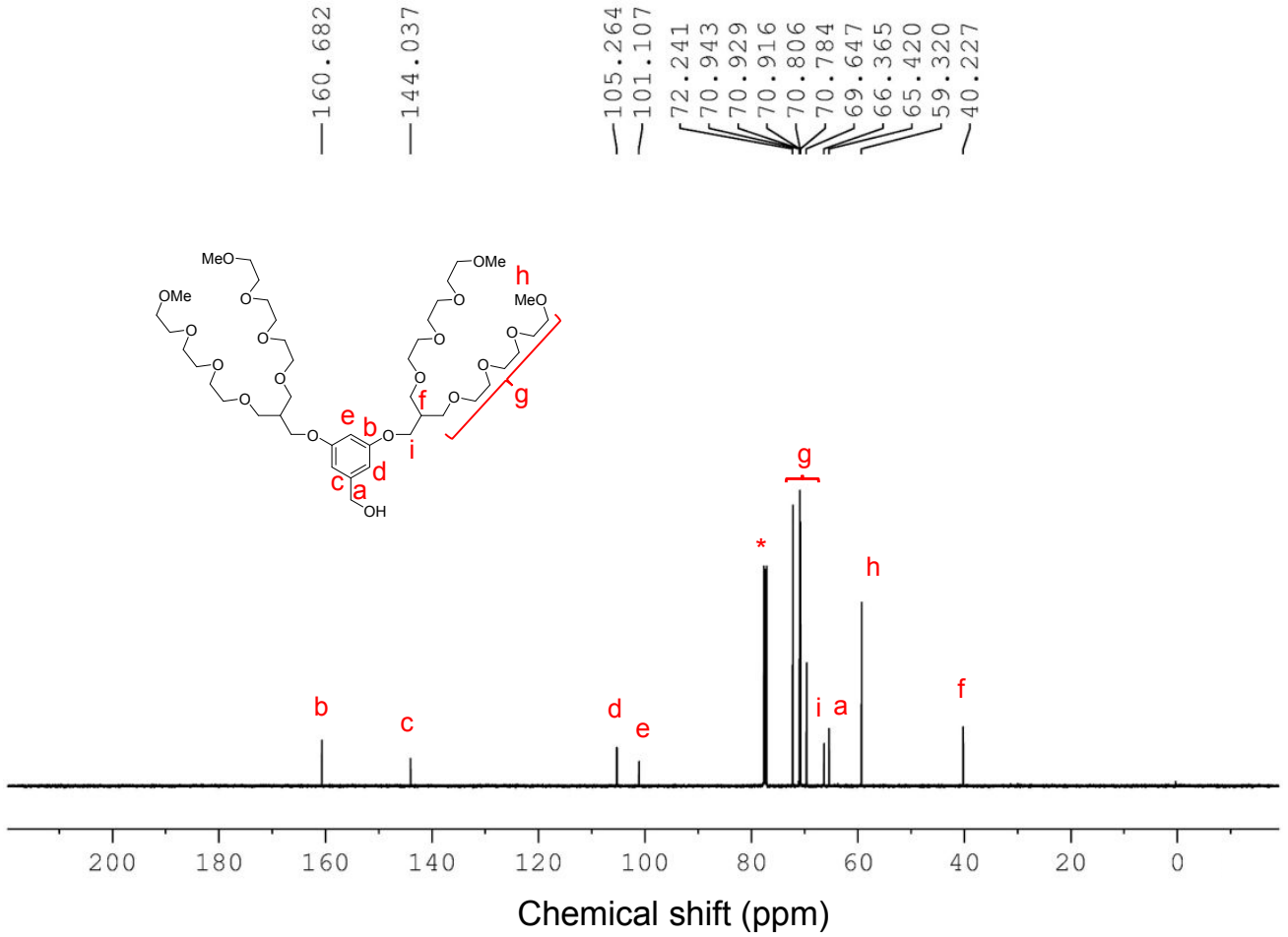

Figure S20. ${ }^{13} \mathrm{C}$ NMR spectrum of $\mathbf{M e}^{4}-\mathbf{O H}$ in $\mathrm{CDCl}_{3}$. The solvent peak is marked with asterisk $(*)$. 
D190055 \#20 RT: 0.30 AV: 1 NL: 1.87E7

T: FTMS + p NSI Full ms [100.00-1500.00]

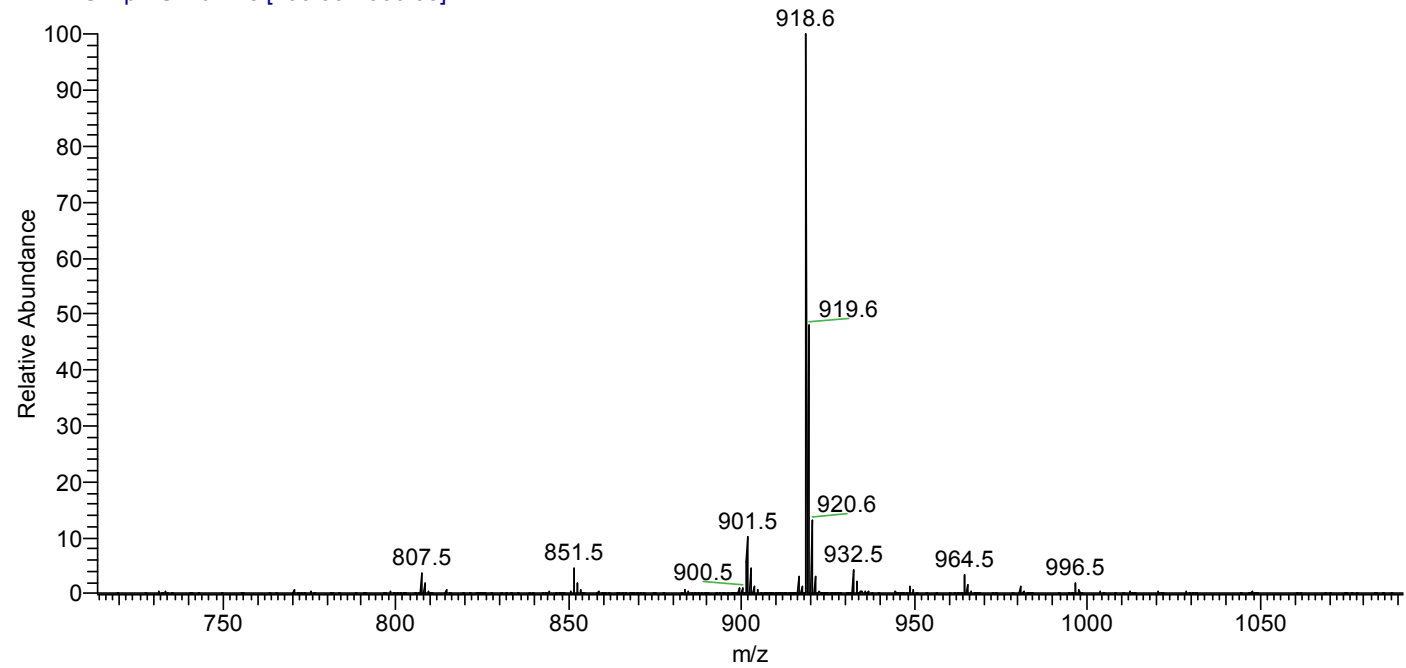

Figure S21. HR-MS spectrum of $\mathbf{M e}^{4}-\mathbf{O H}$.

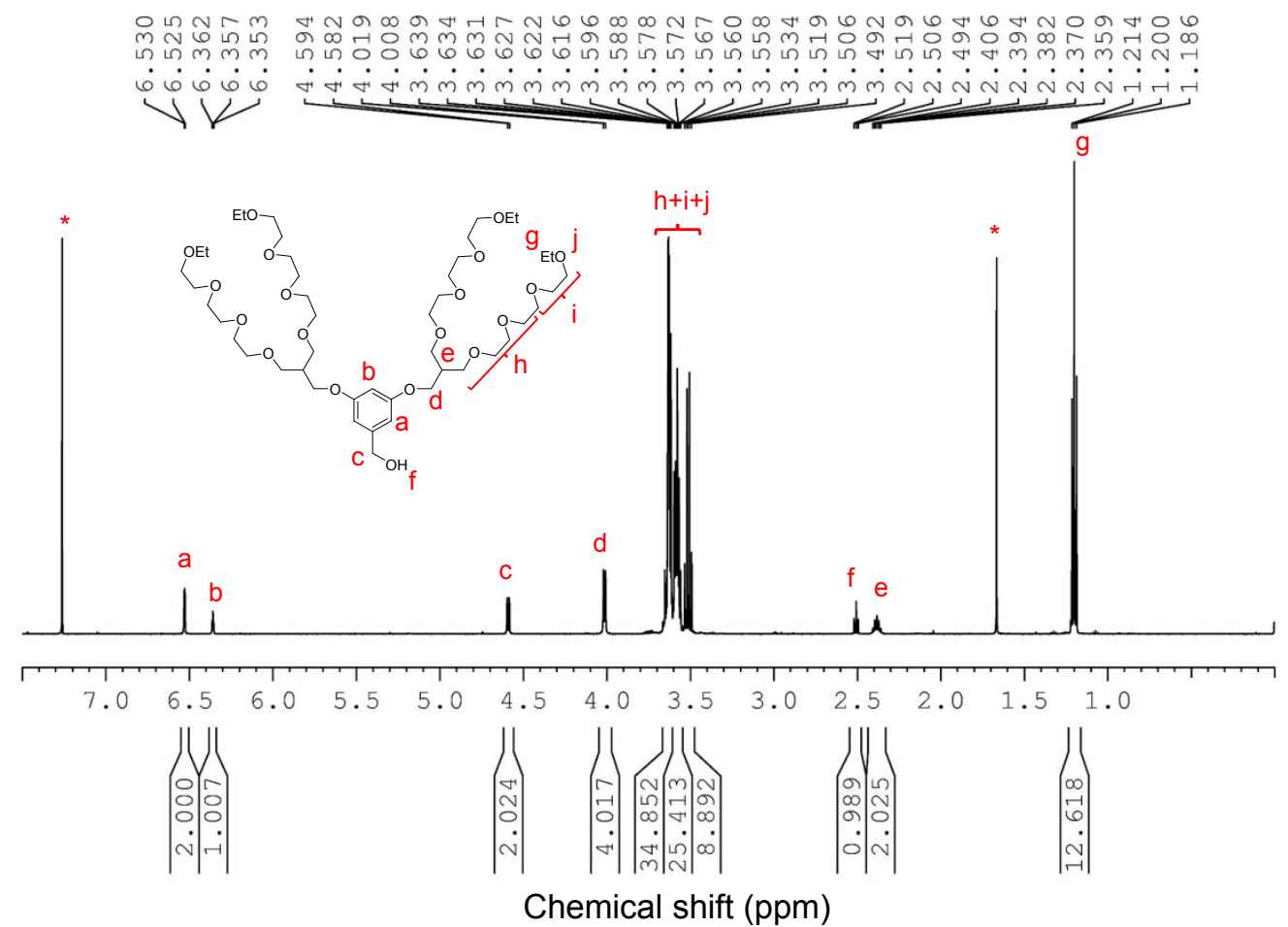

Figure S22. ${ }^{1} \mathrm{H}$ NMR spectrum of $\mathbf{E} \mathbf{t}^{4}-\mathbf{O H}$ in $\mathrm{CDCl}_{3}$. The solvent peak is marked with asterisk $(*)$. 


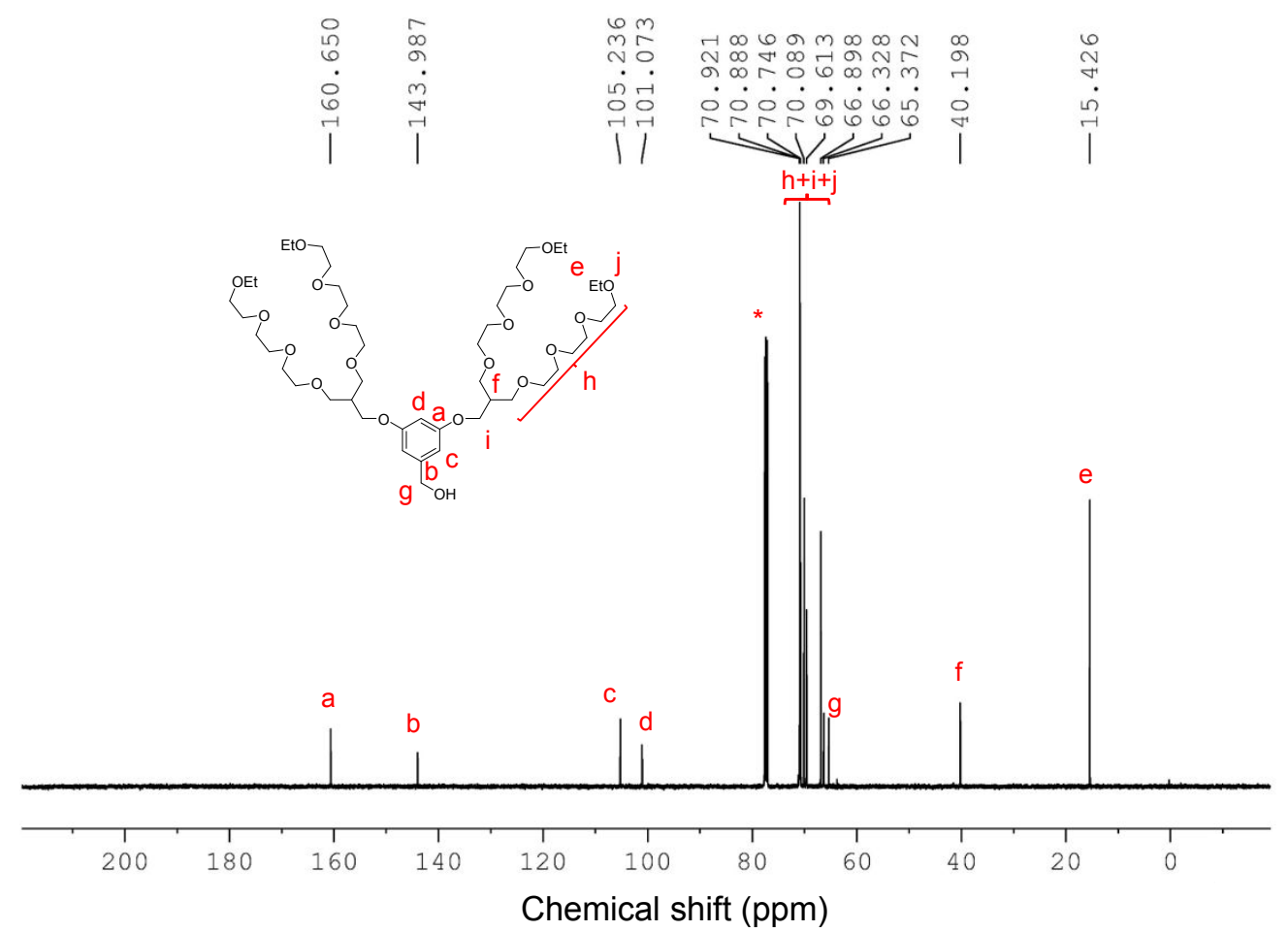

Figure S23. ${ }^{13} \mathrm{C}$ NMR spectrum of $\mathbf{E t} \mathbf{t}^{4}-\mathbf{O H}$ in $\mathrm{CDCl}_{3}$. The solvent peak is marked with asterisk $(*)$.

Et4-OH_20210917150324\#11 RT: 0.09 AV: 1 NL: 7.89E8

T: FTMS + p ESI Full ms [200.0000-2000.0000]

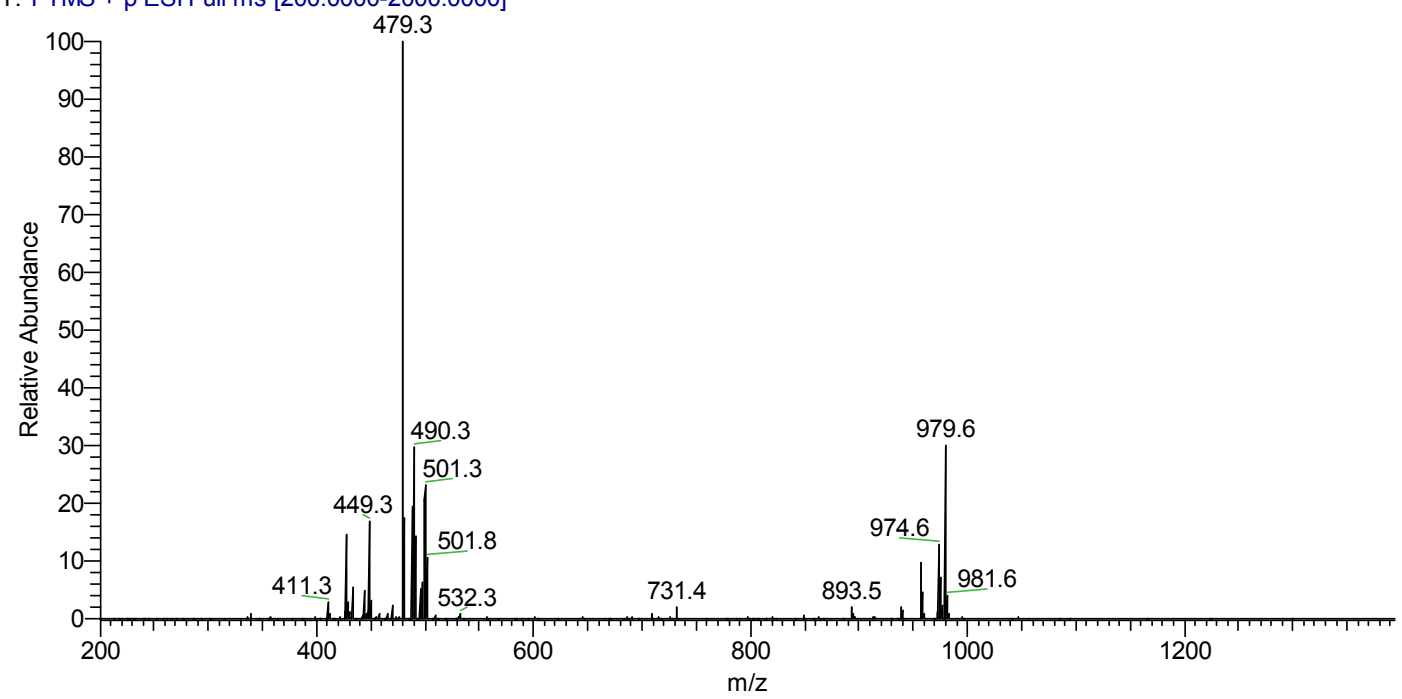

Figure S24. HR-MS spectrum of $\mathbf{E} \mathbf{t}^{4}-\mathbf{O H}$. 


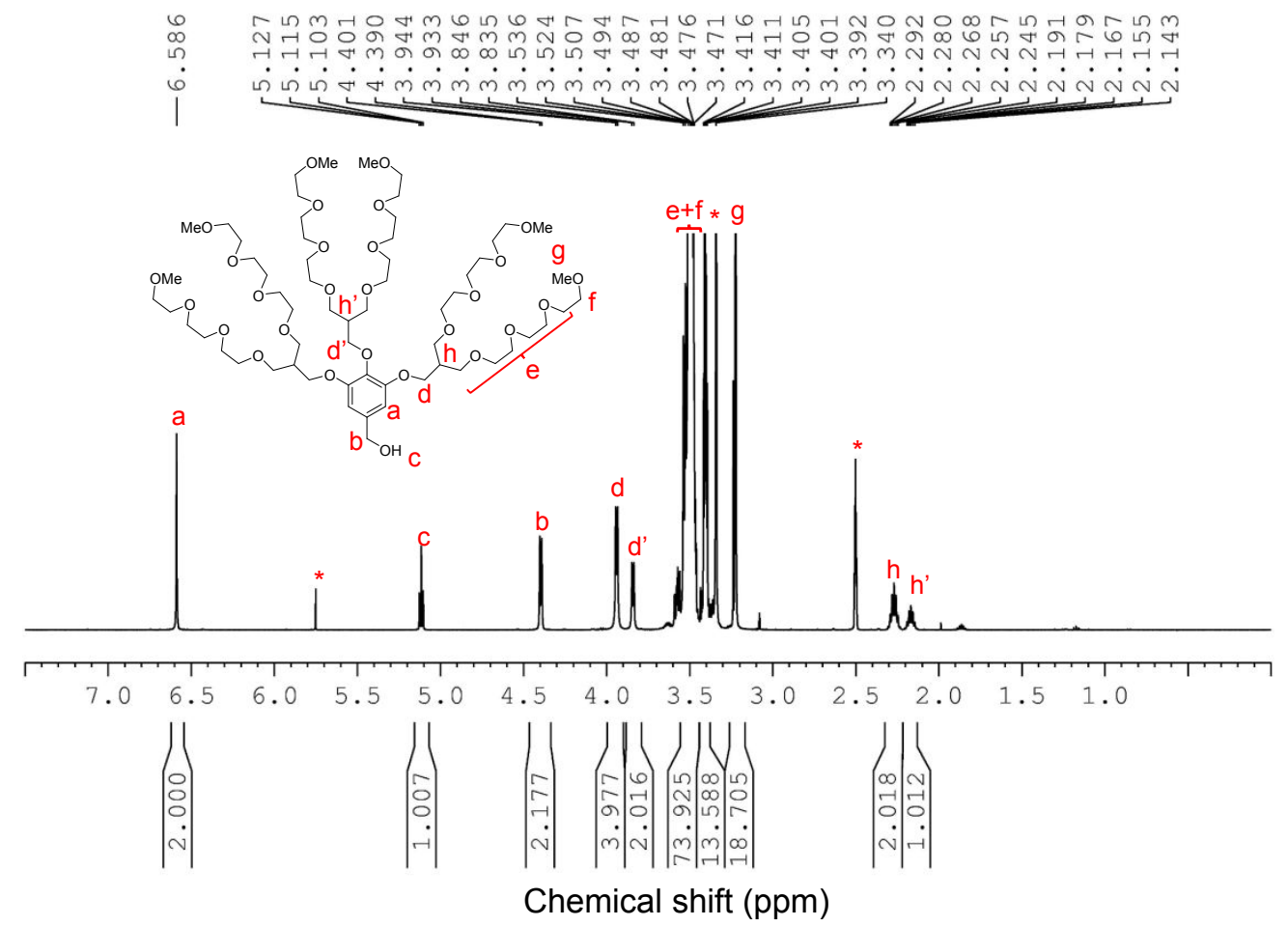

Figure S25. ${ }^{1} \mathrm{H}$ NMR spectrum of $\mathbf{M e}^{6}-\mathrm{OH}$ in DMSO- $d_{6}$. The solvent peak is marked with asterisk $(*)$.

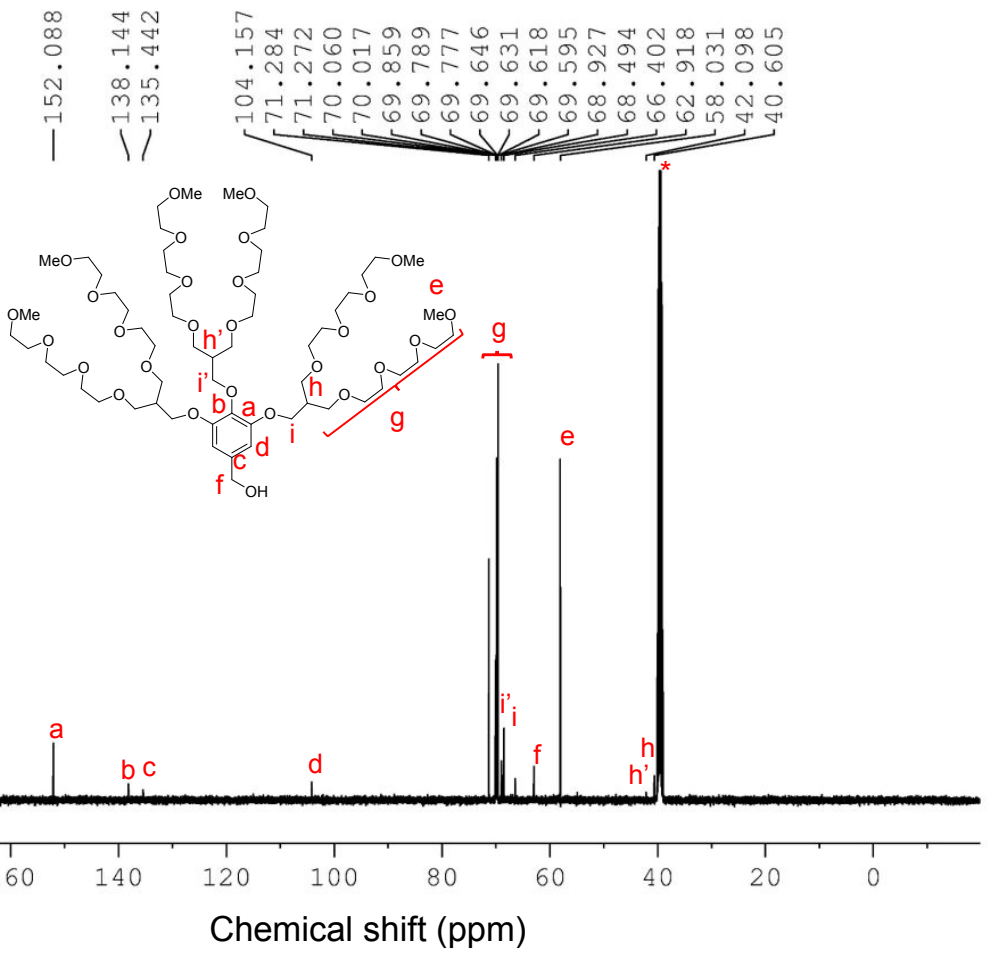

Figure S26. ${ }^{13} \mathrm{C}$ NMR spectrum of $\mathbf{M e}^{6}-\mathbf{O H}$ in DMSO- $d_{6}$. The solvent peak is marked with asterisk $(*)$. 
D190057_181221110036 \#137 RT: 2.12 AV: 1 NL: $1.52 E 5$

T: FTMS + p NSI Full ms [100.00-1500.00]

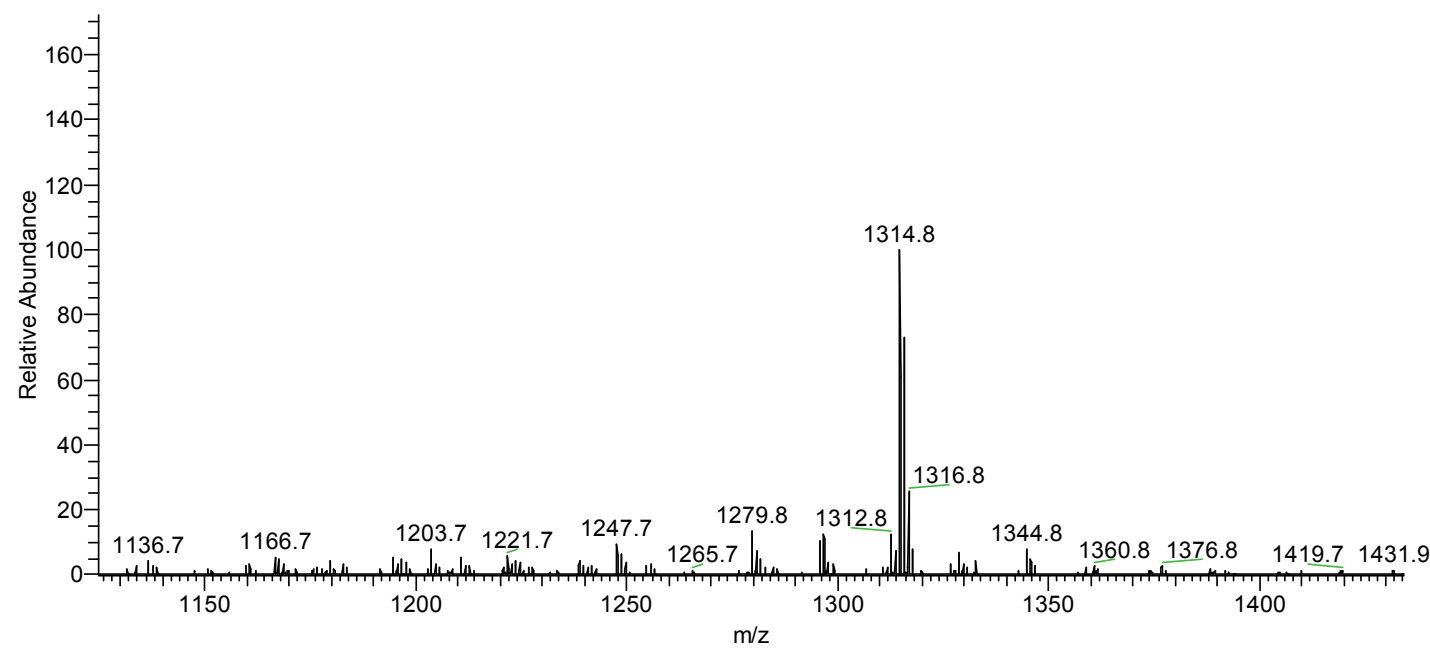

Figure S27. HR-MS spectrum of $\mathbf{M e}^{6}-\mathbf{O H}$.

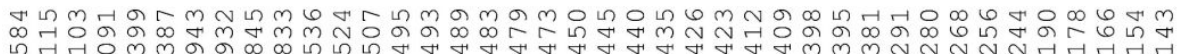

ف

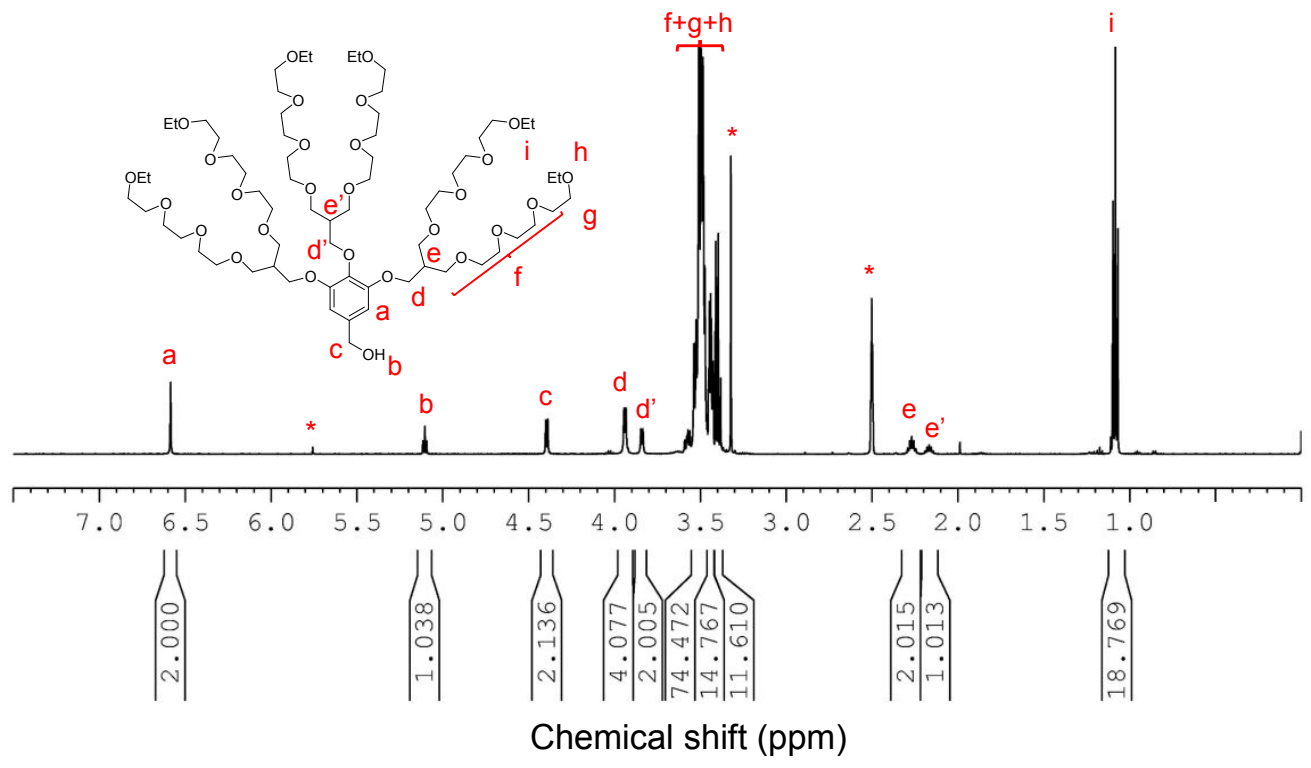

Figure S28. ${ }^{1} \mathrm{H}$ NMR spectrum of $\mathbf{E t}^{6}-\mathbf{O H}$ in DMSO- $d_{6}$. The solvent peak is marked with asterisk $(*)$. 


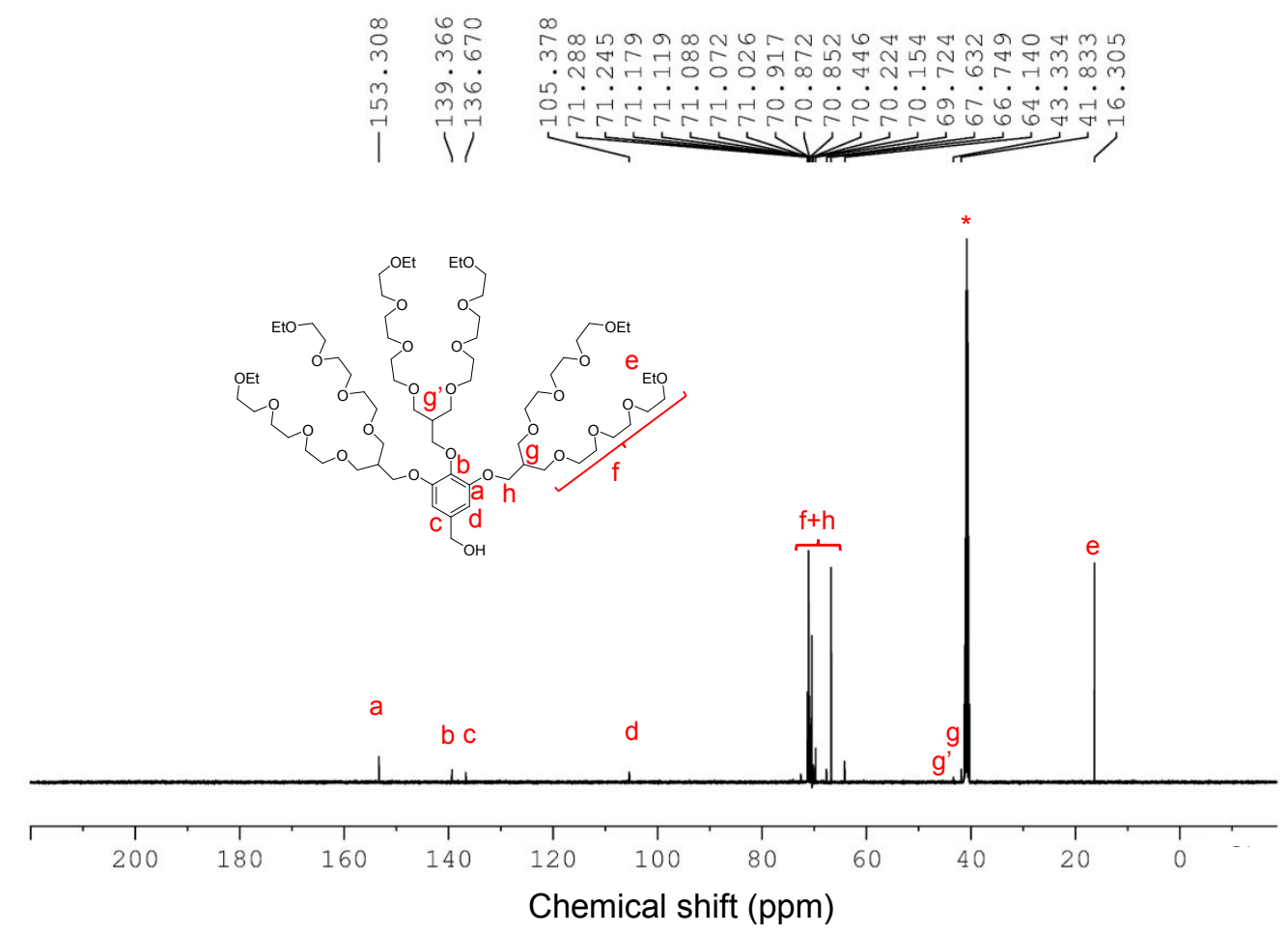

Figure S29. ${ }^{13} \mathrm{C}$ NMR spectrum of $\mathbf{E} \mathbf{t}^{6}-\mathbf{O H}$ in DMSO- $d_{6}$. The solvent peak is marked with asterisk $(*)$.

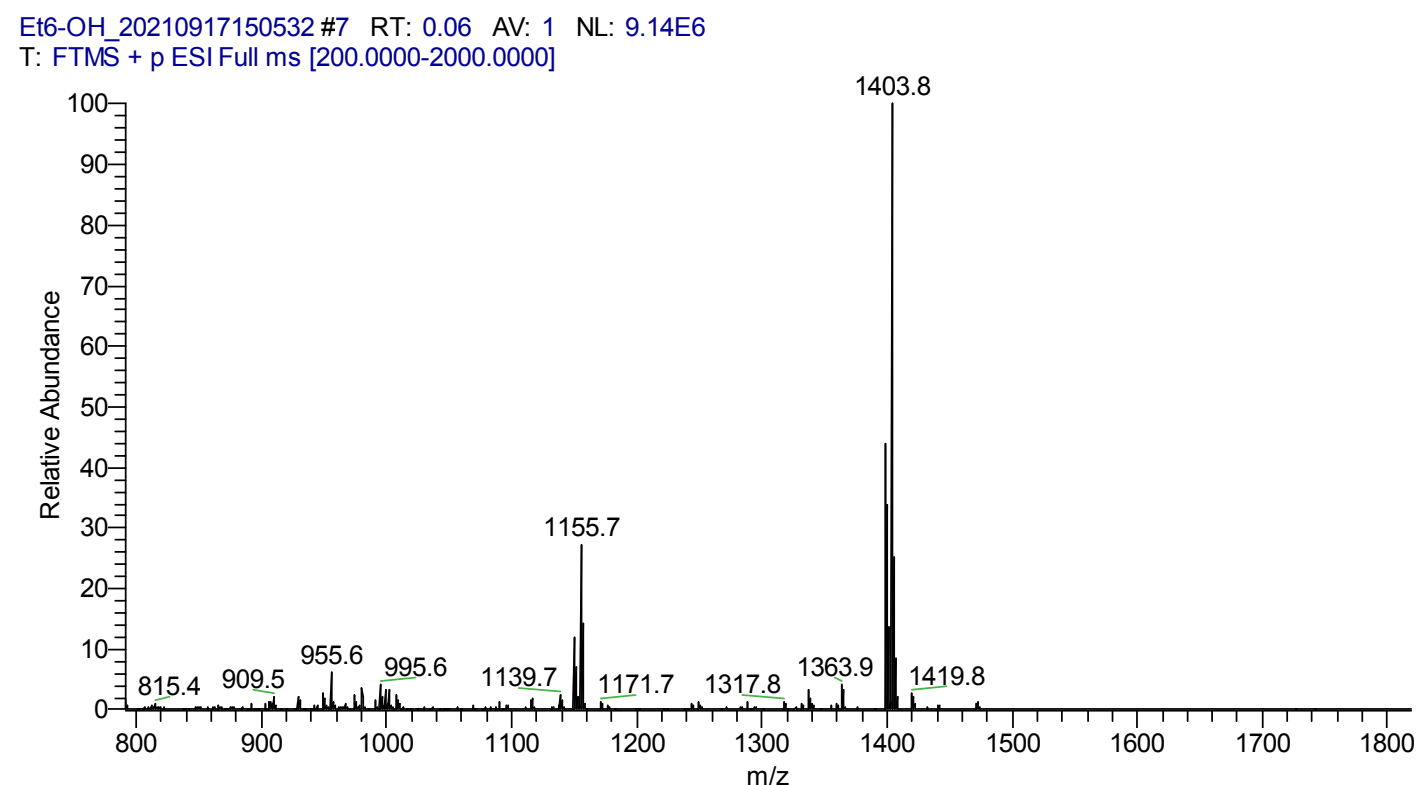

Figure S30. HR-MS spectrum of $\mathbf{E t}^{6}-\mathbf{O H}$. 


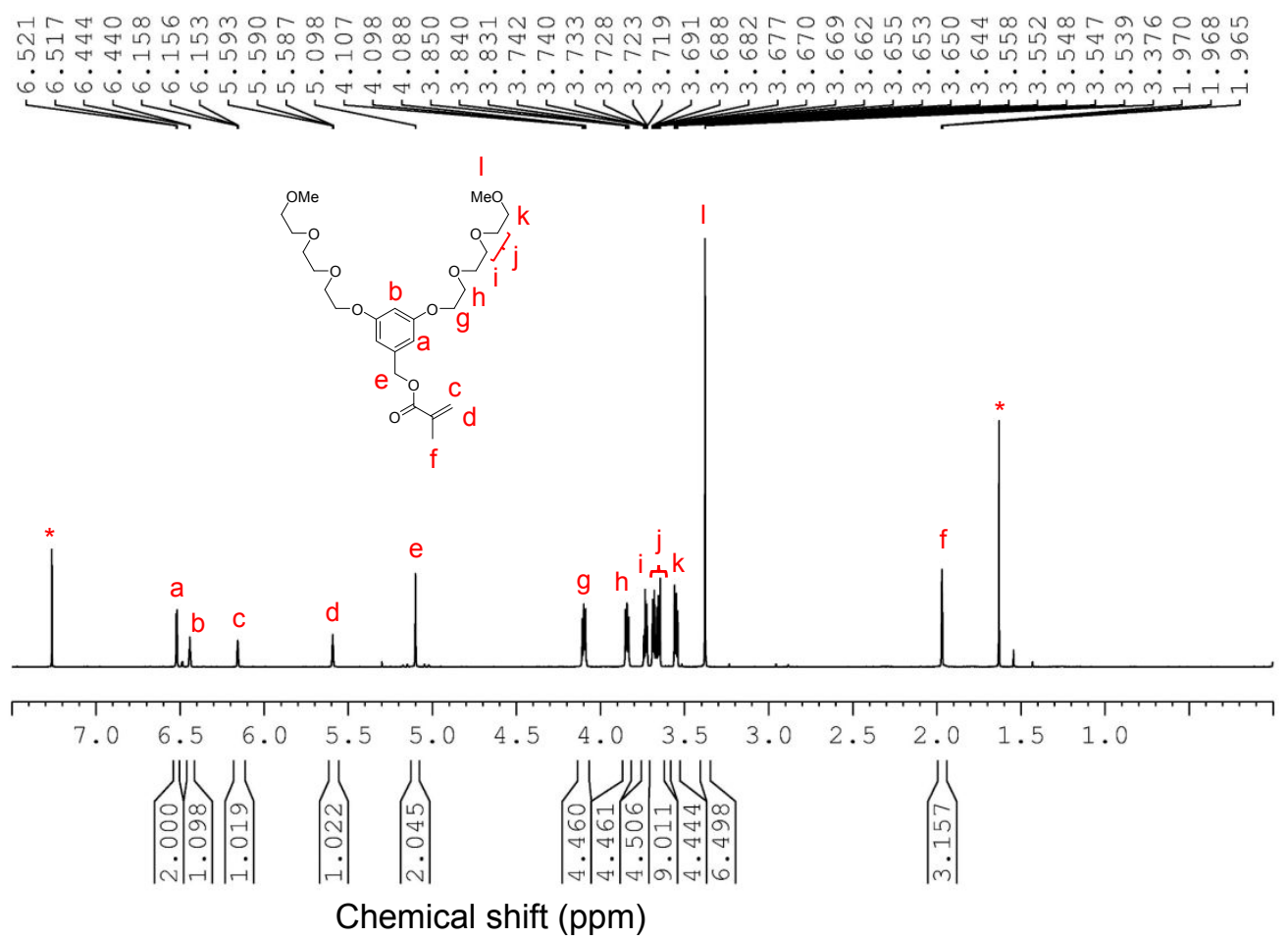

Figure S31. ${ }^{1} \mathrm{H}$ NMR spectrum of $\mathbf{M e}^{2}-\mathbf{M}$ in $\mathrm{CDCl}_{3}$. The solvent peak is marked with asterisk $(*)$.
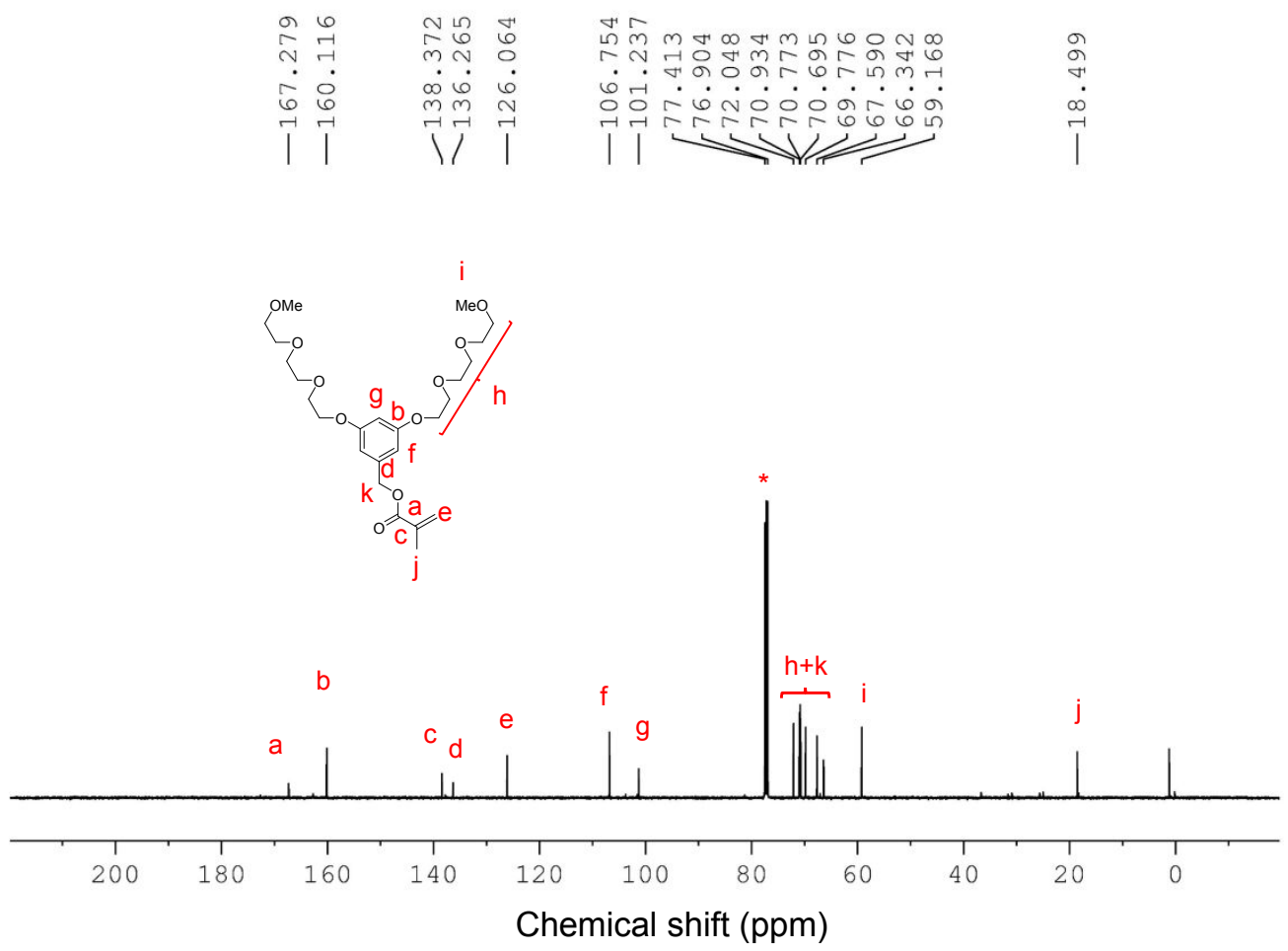

Figure S32. ${ }^{13} \mathrm{C}$ NMR spectrum of $\mathbf{M e}^{2}-\mathbf{M}$ in $\mathrm{CDCl}_{3}$. The solvent peak is marked with asterisk $(*)$. 
Me2-M\#15 RT: 0.12 AV: 1 NL: 4.44E8

T: FTMS + p ESI Full ms [100.0000-1000.0000]

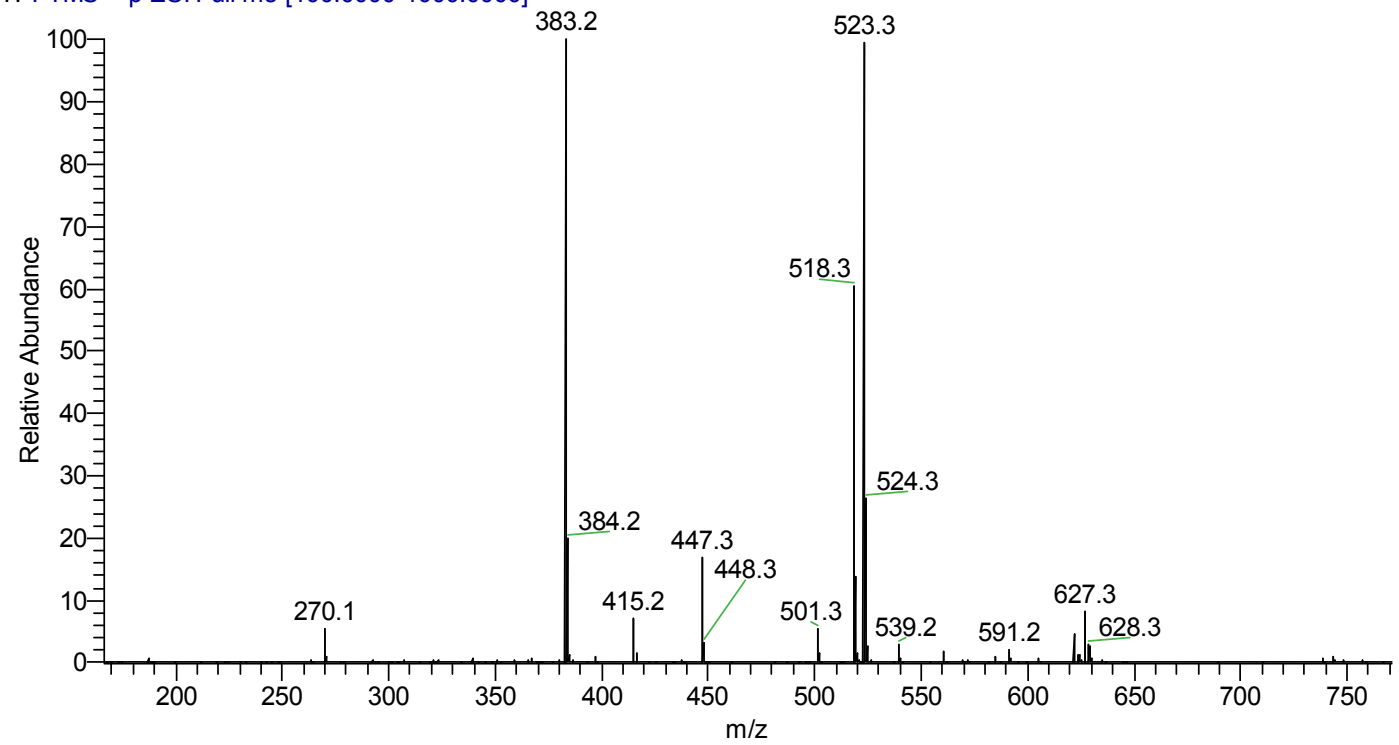

Figure S33. HR-MS spectrum of $\mathbf{M e}^{2}-\mathbf{M}$.

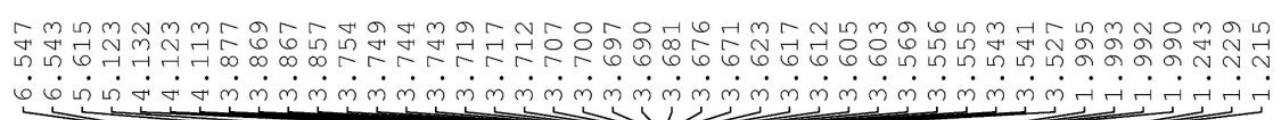

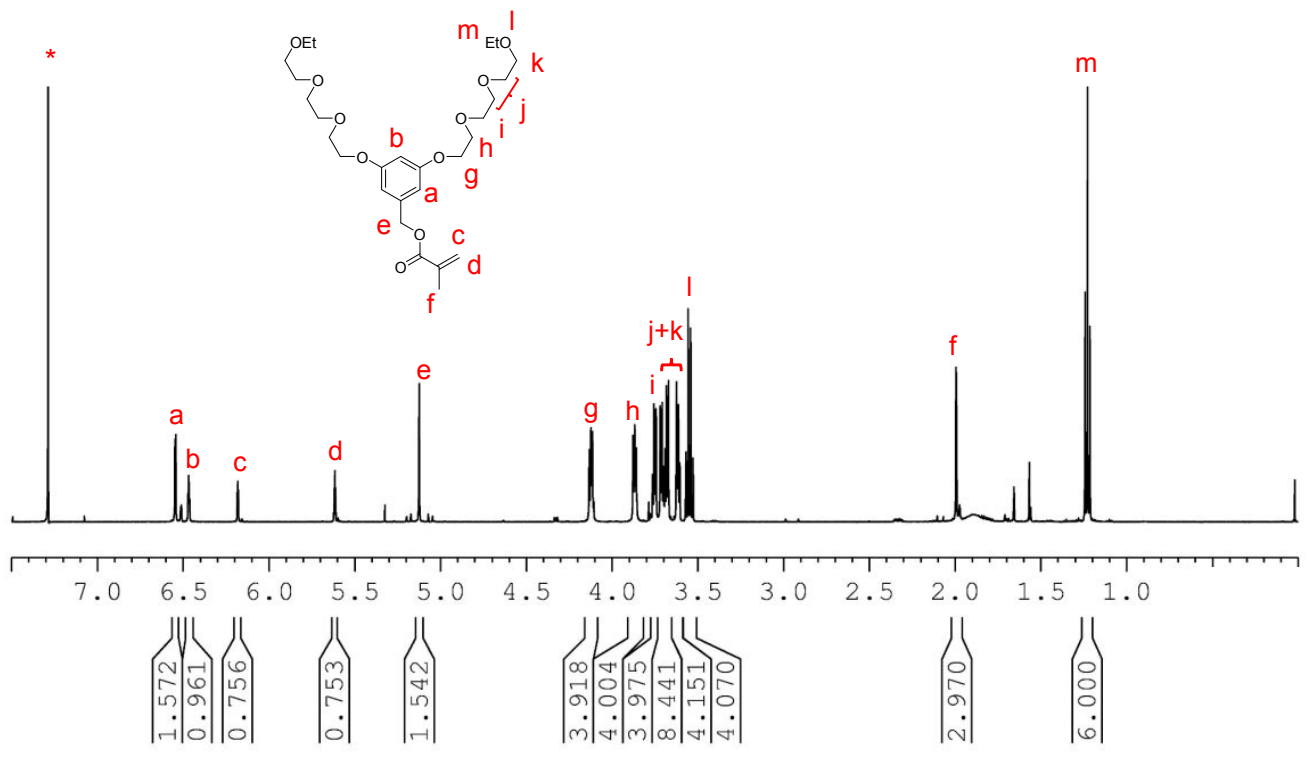

Chemical shift (ppm)

Figure S34. ${ }^{1} \mathrm{H}$ NMR spectrum of $\mathbf{E t}^{2}-\mathbf{M}$ in $\mathrm{CDCl}_{3}$. The solvent peak is marked with asterisk $(*)$. 


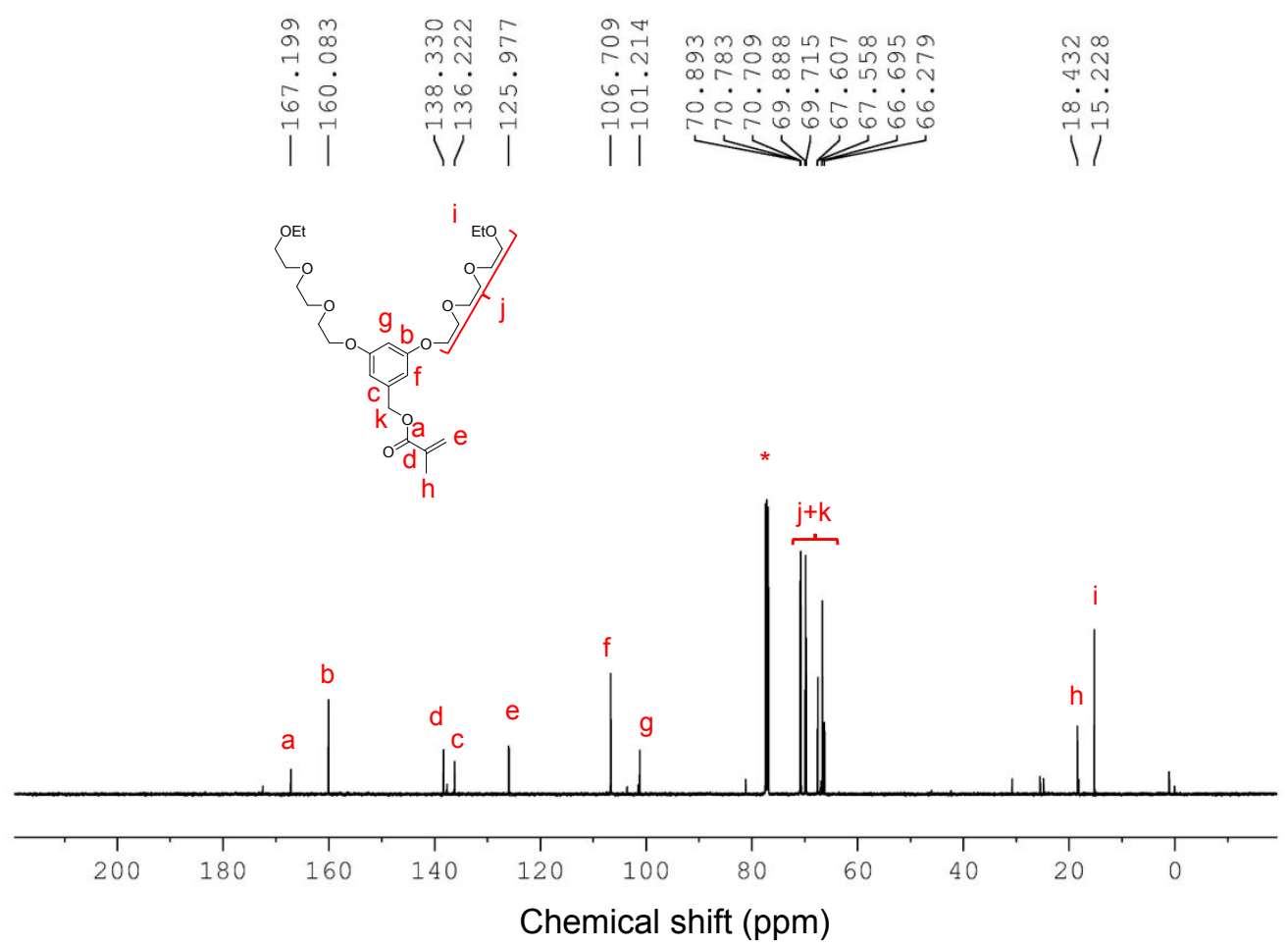

Figure S35. ${ }^{13} \mathrm{C}$ NMR spectrum of $\mathbf{E t}^{2}-\mathbf{M}$ in $\mathrm{CDCl}_{3}$. The solvent peak is marked with asterisk $(*)$.

Et2-M\#13 RT: 0.11 AV: 1 NL: 9.01E8

T: FTMS + p ESI Full ms [100.0000-1000.0000]

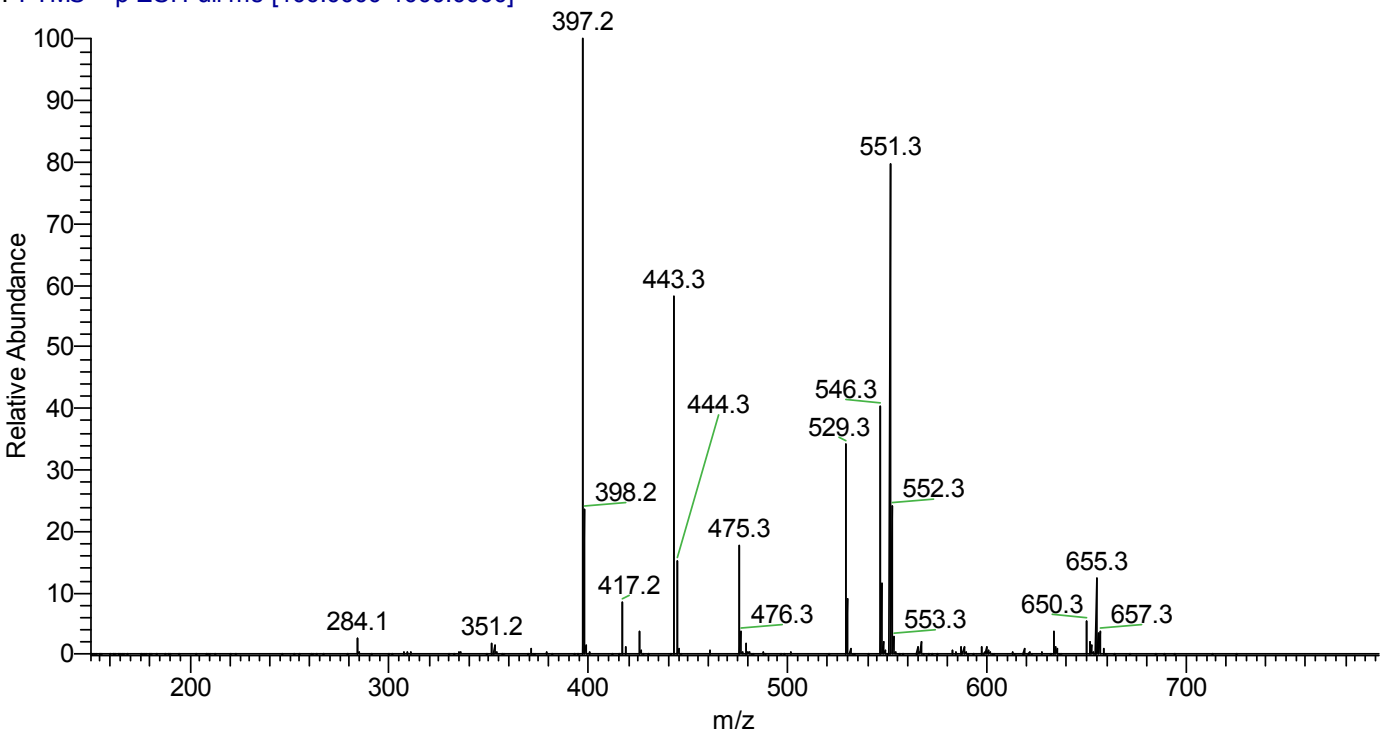

Figure S36. HR-MS spectrum of $\mathbf{E t}^{2}-\mathbf{M}$. 


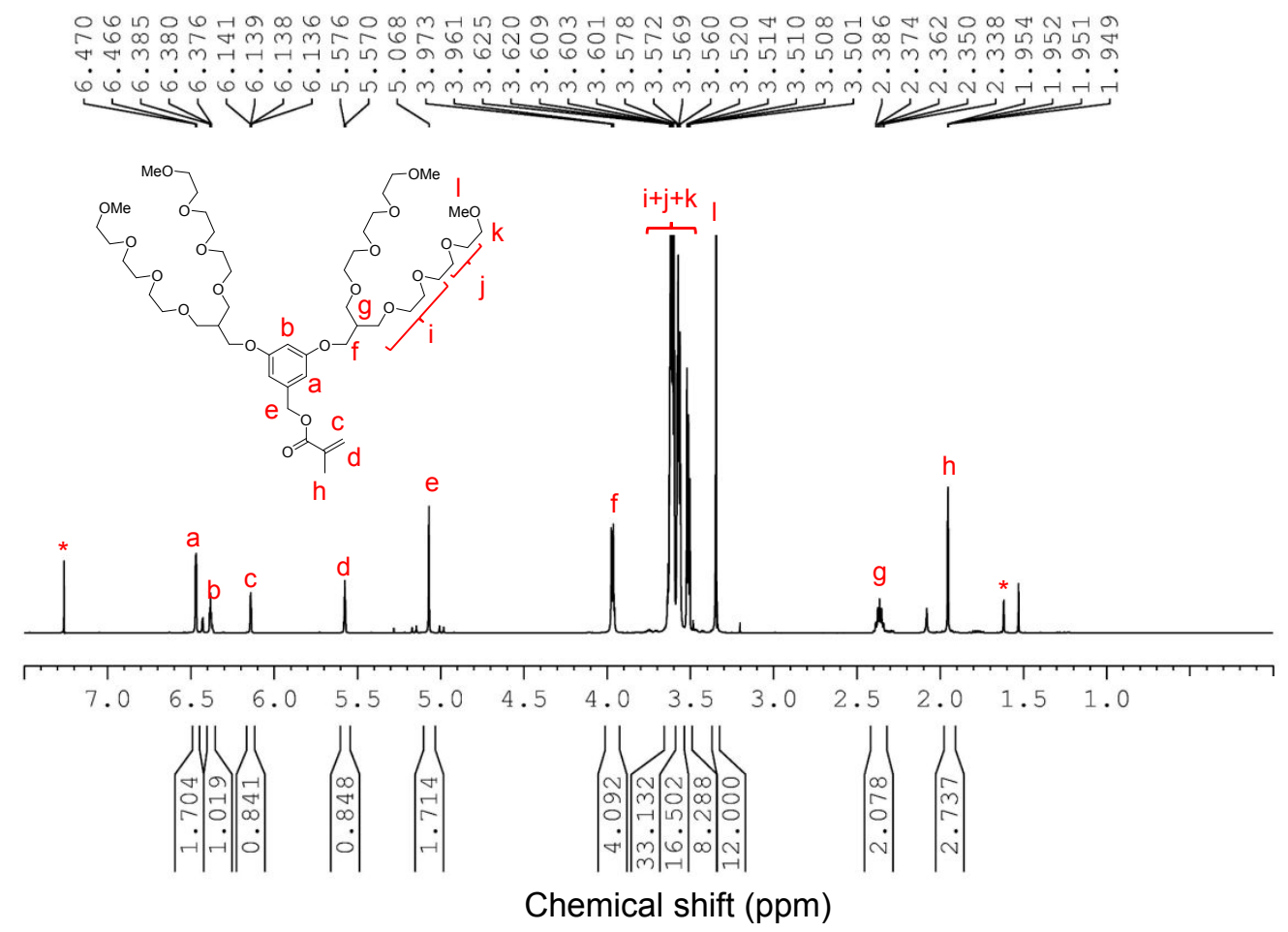

Figure S37. ${ }^{1} \mathrm{H}$ NMR spectrum of $\mathbf{M e}^{4}-\mathbf{M}$ in $\mathrm{CDCl}_{3}$. The solvent peak is marked with asterisk $(*)$.
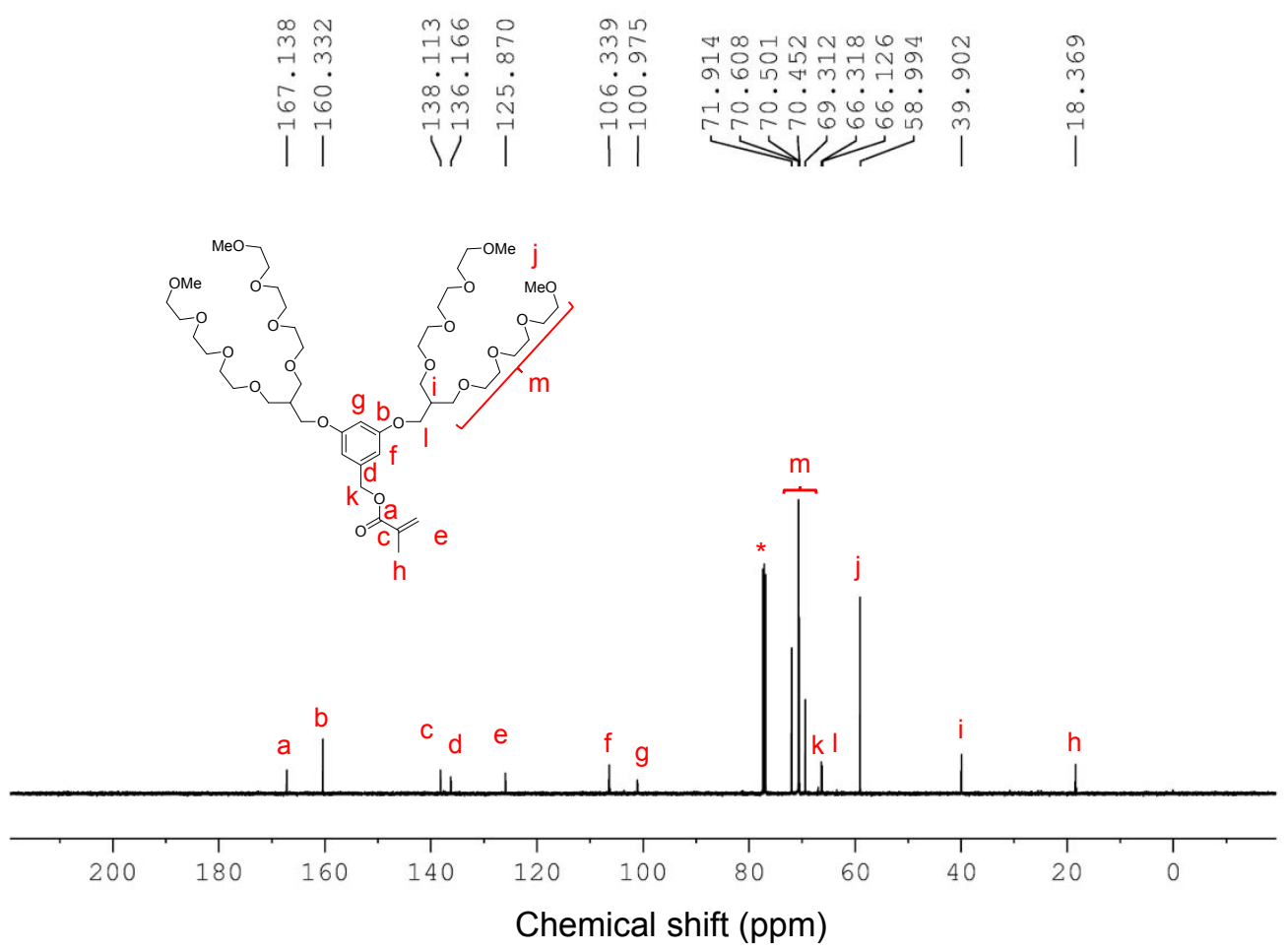

Figure S38. ${ }^{13} \mathrm{C}$ NMR spectrum of $\mathbf{M e}^{4}-\mathbf{M}$ in $\mathrm{CDCl}_{3}$. The solvent peak is marked with asterisk $(*)$. 
Me4-M_20210917145910 \#11 RT: 0.09 AV: 1 NL: 9.19E8

T: FTMS + p ESI Full ms [100.0000-1500.0000]

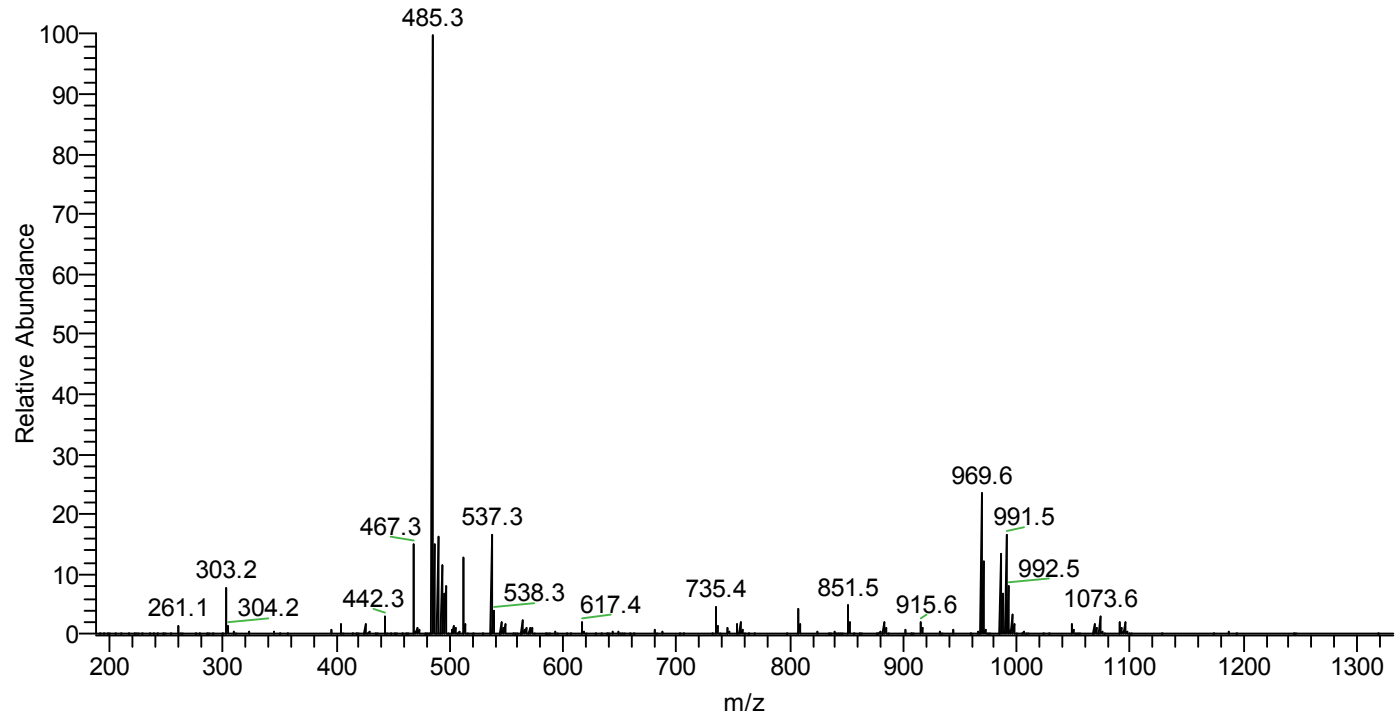

Figure S39. HR-MS spectrum of $\mathbf{M e}^{4}-\mathbf{M}$.
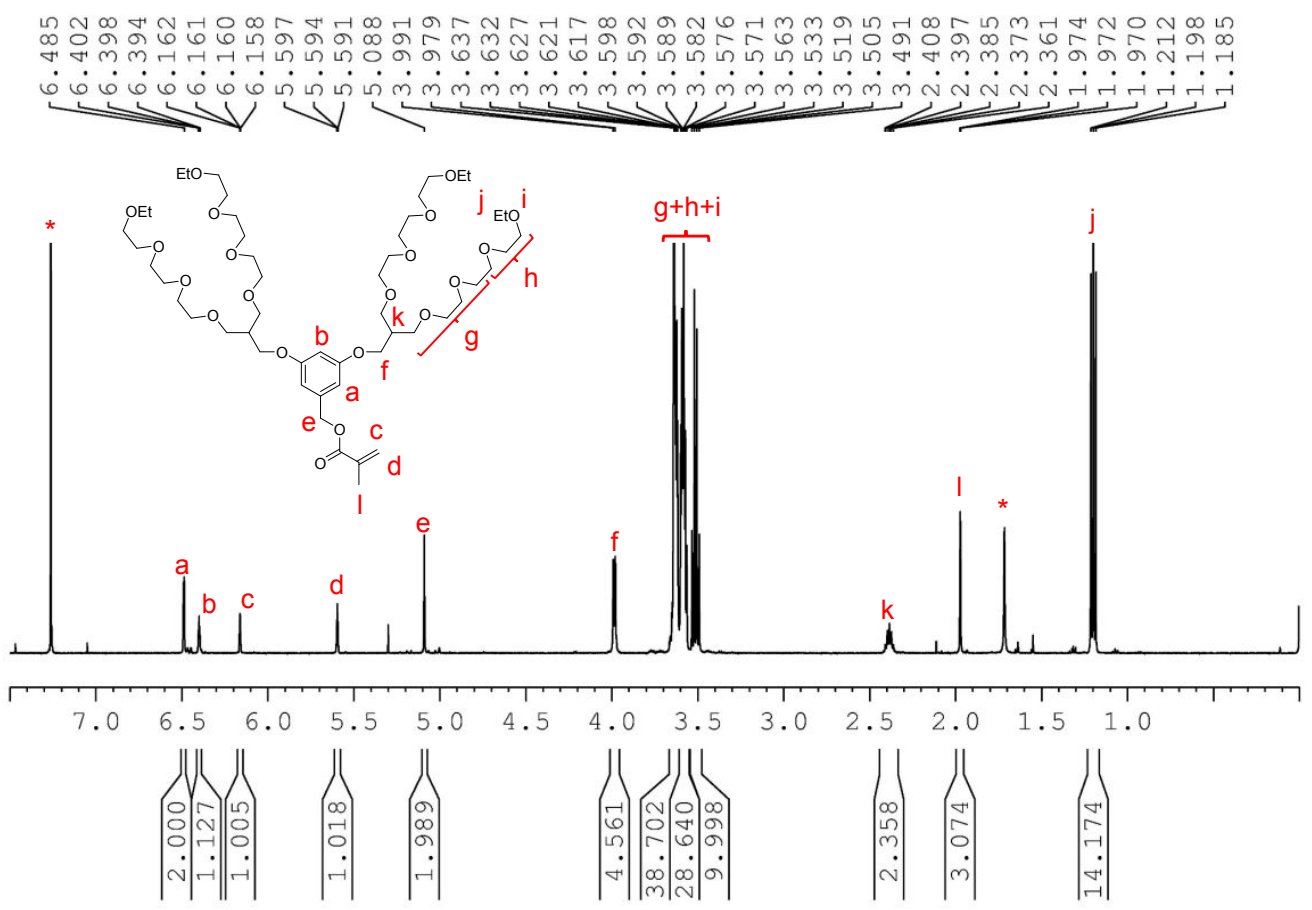

Chemical shift (ppm)

Figure S40. ${ }^{1} \mathrm{H}$ NMR spectrum of $\mathbf{E t}^{4}-\mathbf{M}$ in $\mathrm{CDCl}_{3}$. The solvent peak is marked with asterisk $(*)$. 


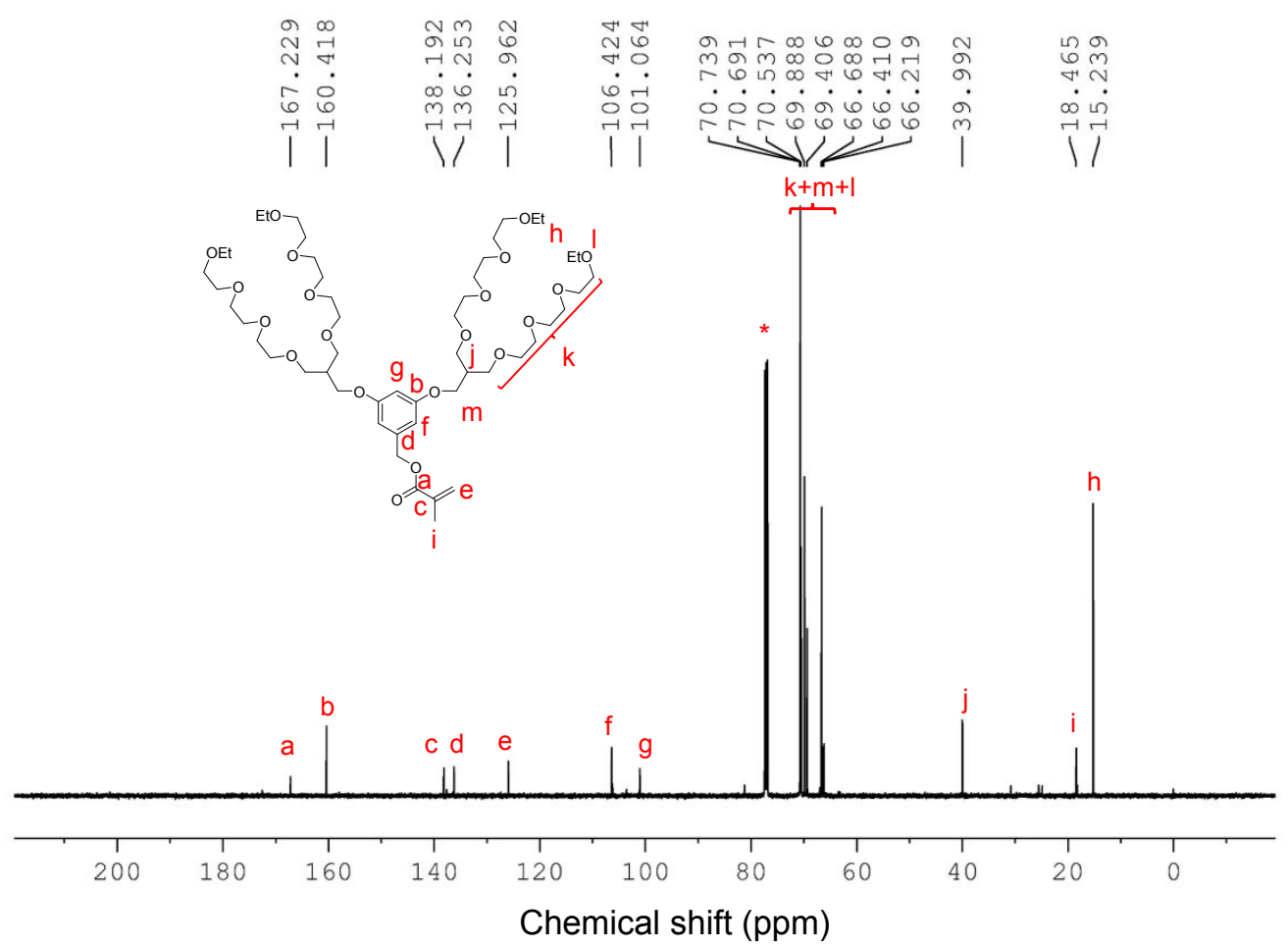

Figure S41. ${ }^{13} \mathrm{C}$ NMR spectrum of $\mathbf{E t}^{4}-\mathbf{M}$ in $\mathrm{CDCl}_{3}$. The solvent peak is marked with asterisk $(*)$.

Et4-M 20210917150736 \#7 RT: 0.06 AV: 1 NL: $1.40 E 8$

T: FTMS + p ESI Full ms [200.0000-2000.0000]
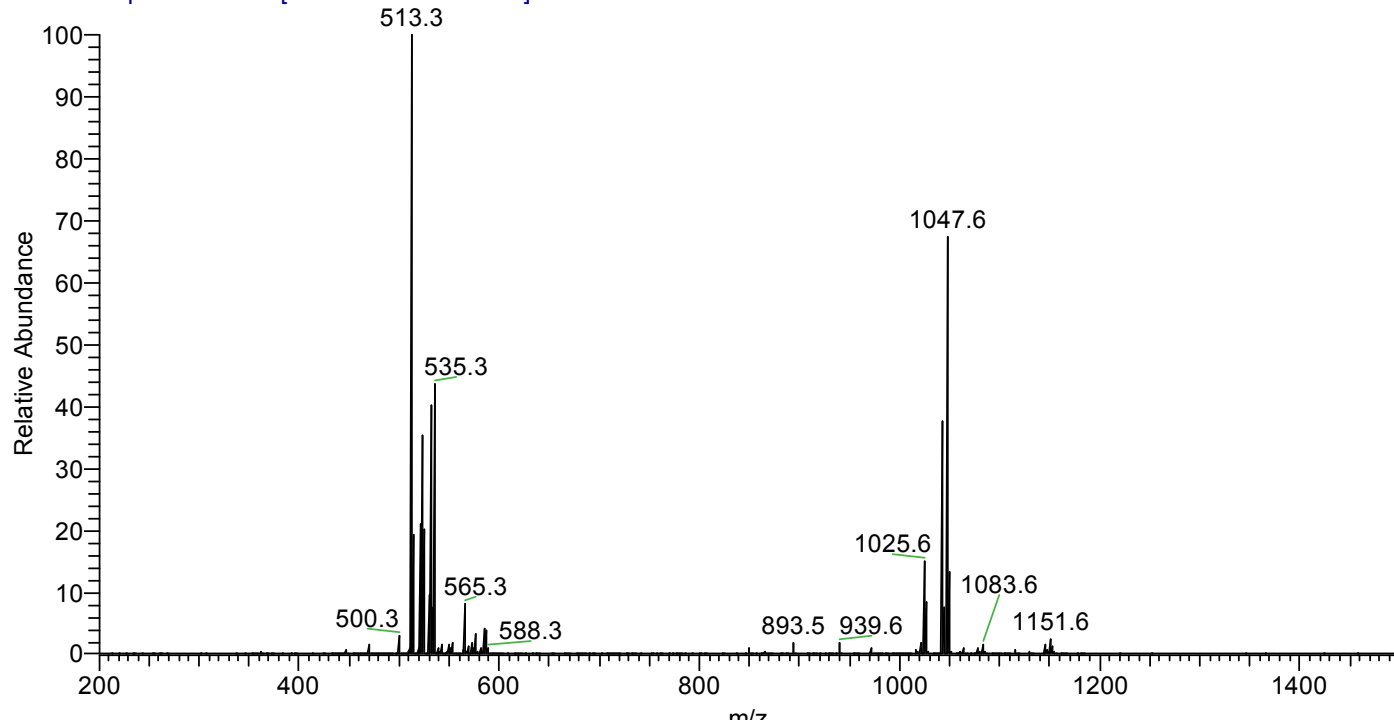

Figure S42. HR-MS spectrum of $\mathbf{E t}^{4}$-M. 


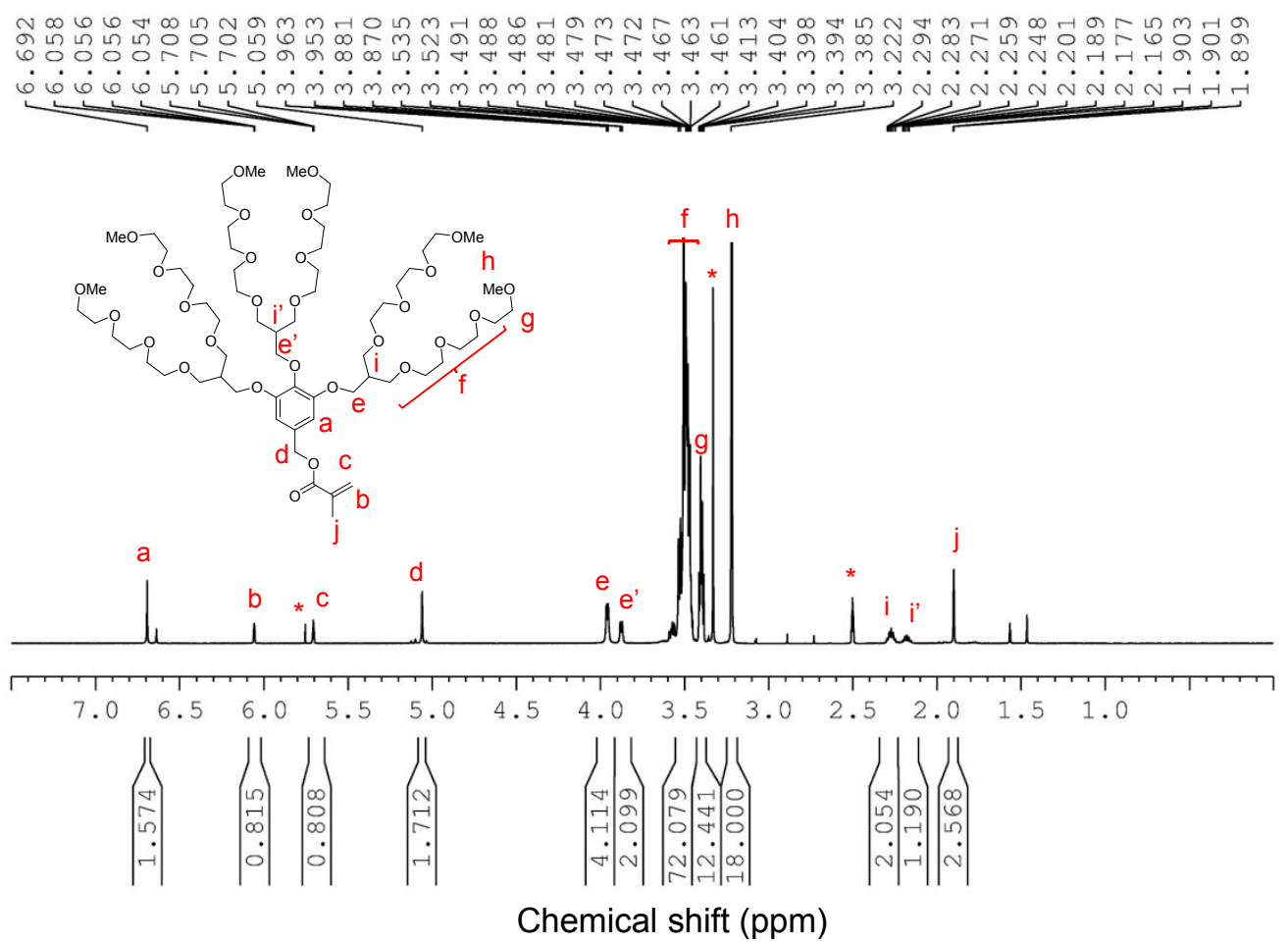

Figure S43. ${ }^{1} \mathrm{H}$ NMR spectrum of $\mathbf{M e}^{6}-\mathbf{M}$ in DMSO- $d_{6}$. The solvent peak is marked with asterisk $(*)$.
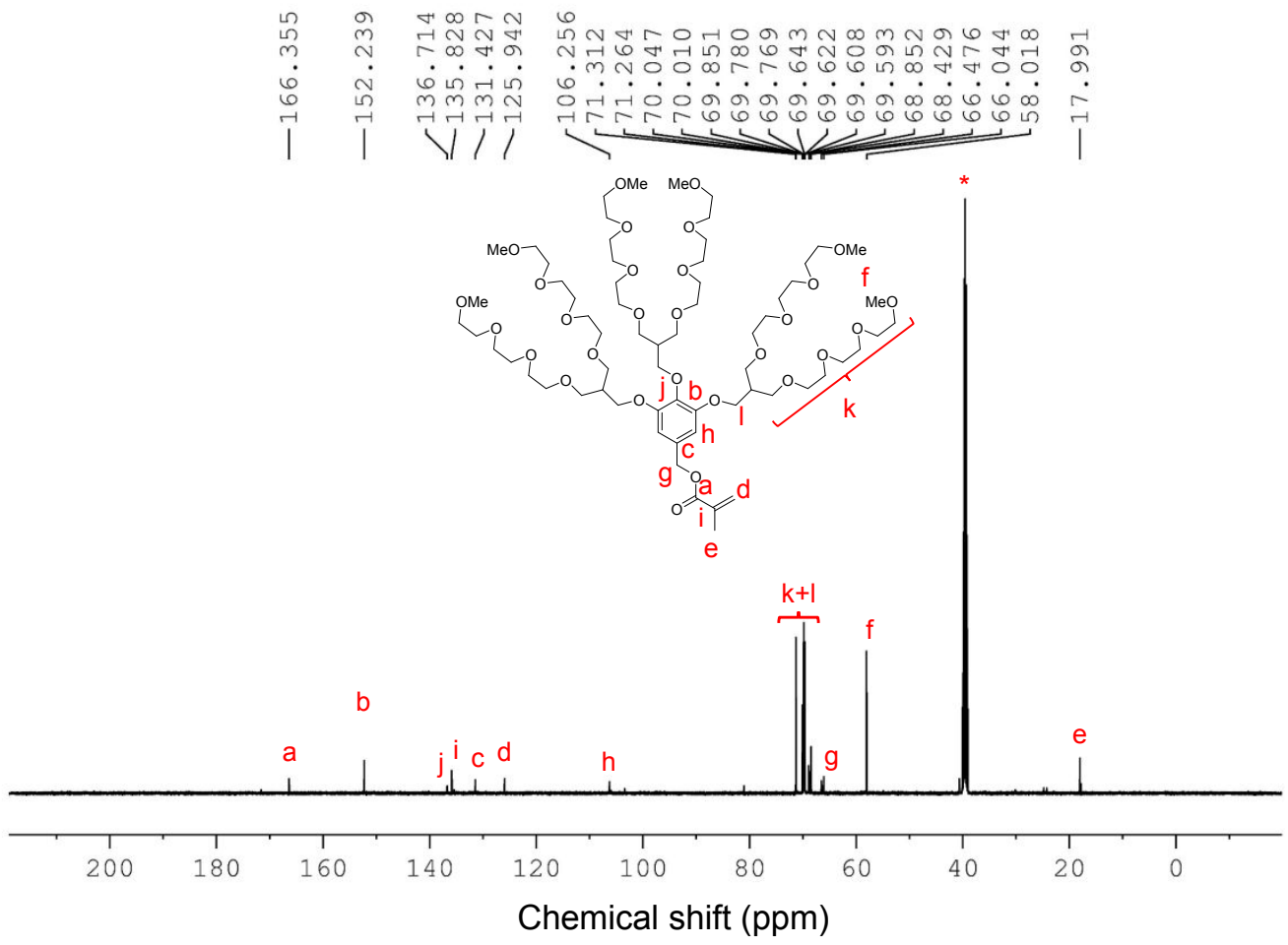

Figure S44. ${ }^{13} \mathrm{C}$ NMR spectrum of $\mathbf{M e}^{6}-\mathbf{M}$ in DMSO- $d_{6}$. The solvent peak is marked with asterisk $(*)$. 


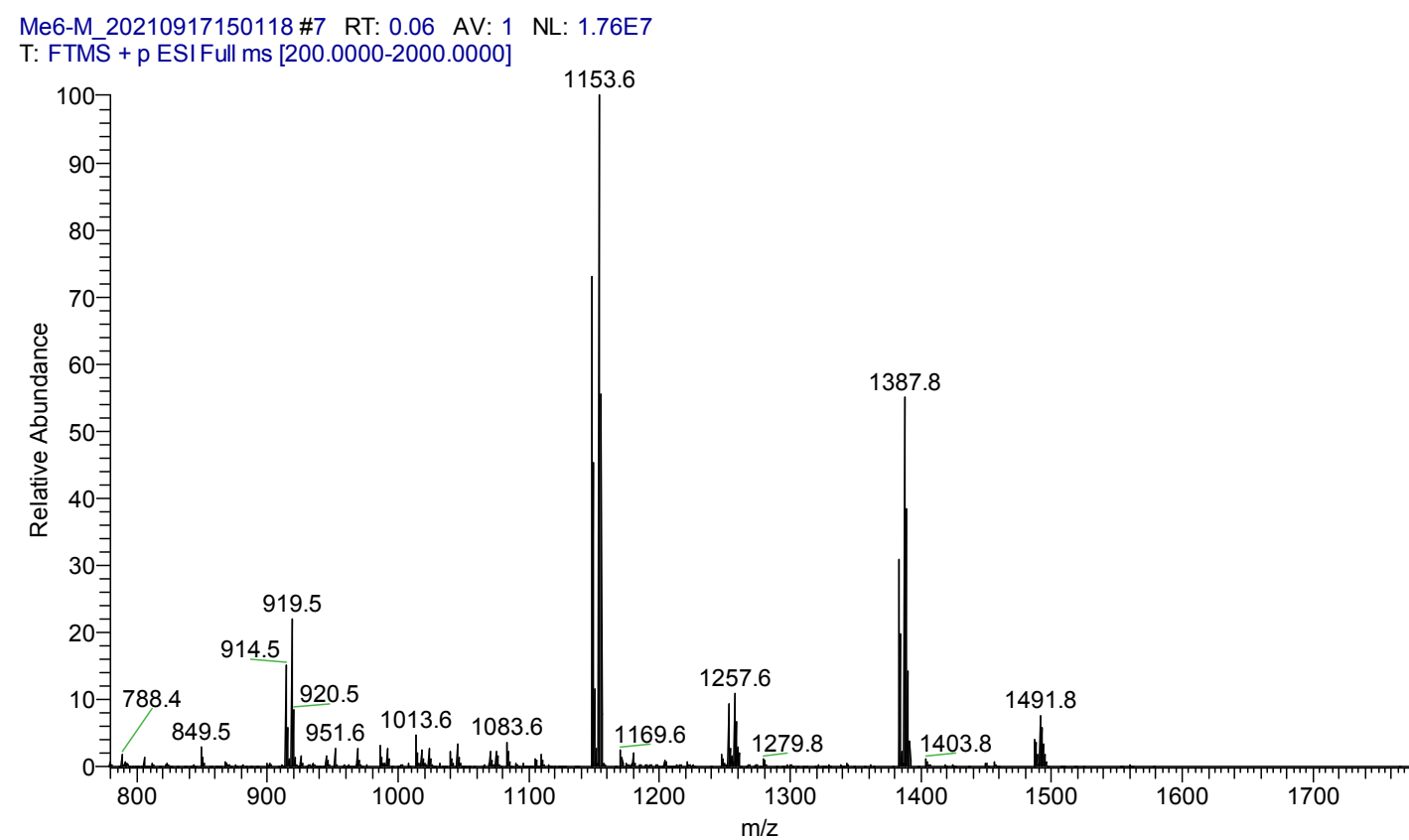

Figure S45. HR-MS spectrum of $\mathbf{M e}^{\mathbf{6}}-\mathbf{M}$.

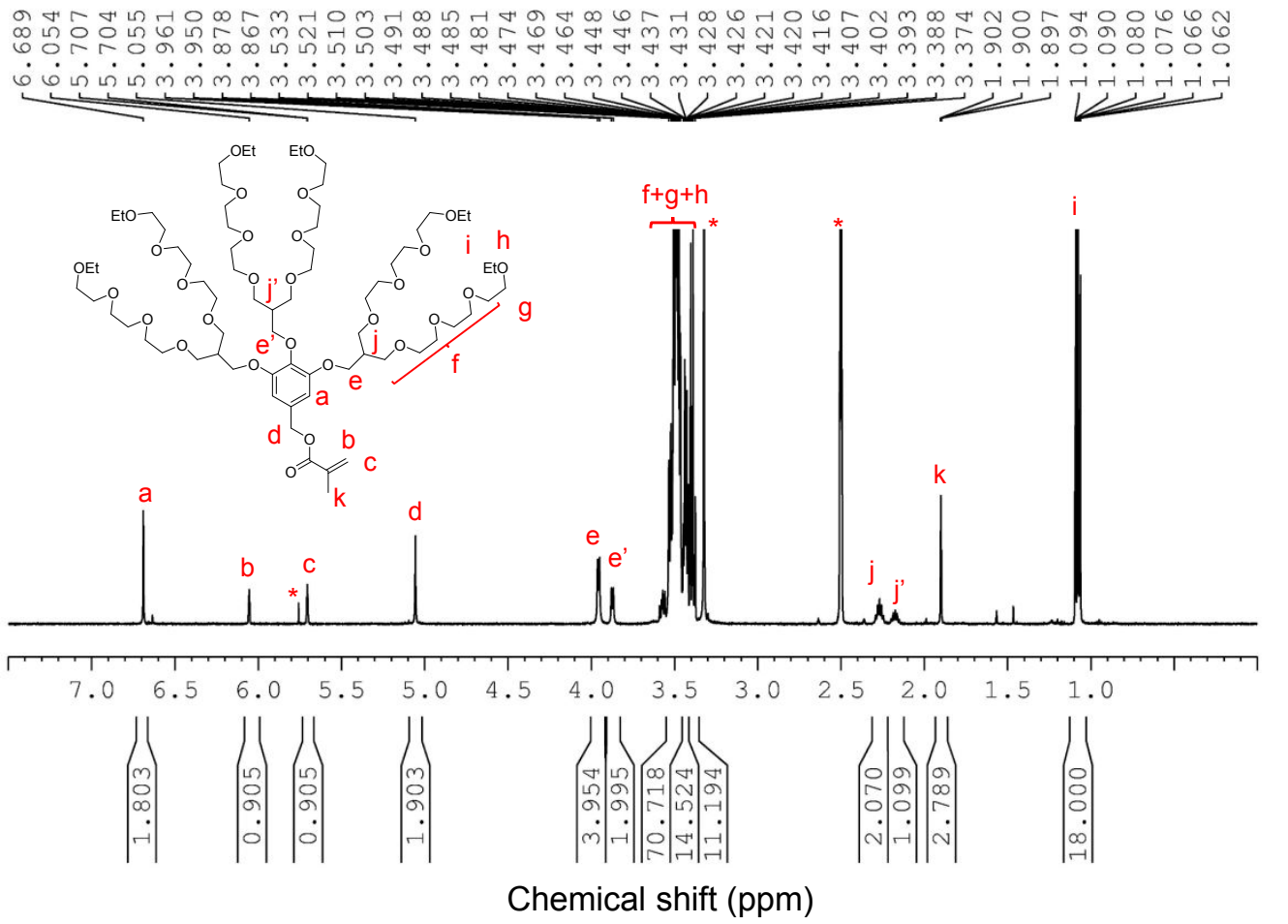

Figure S46. ${ }^{1} \mathrm{H}$ NMR spectrum of $\mathbf{E} \mathbf{t}^{6}-\mathbf{M}$ in DMSO- $d_{6}$. The solvent peak is marked with asterisk $(*)$. 


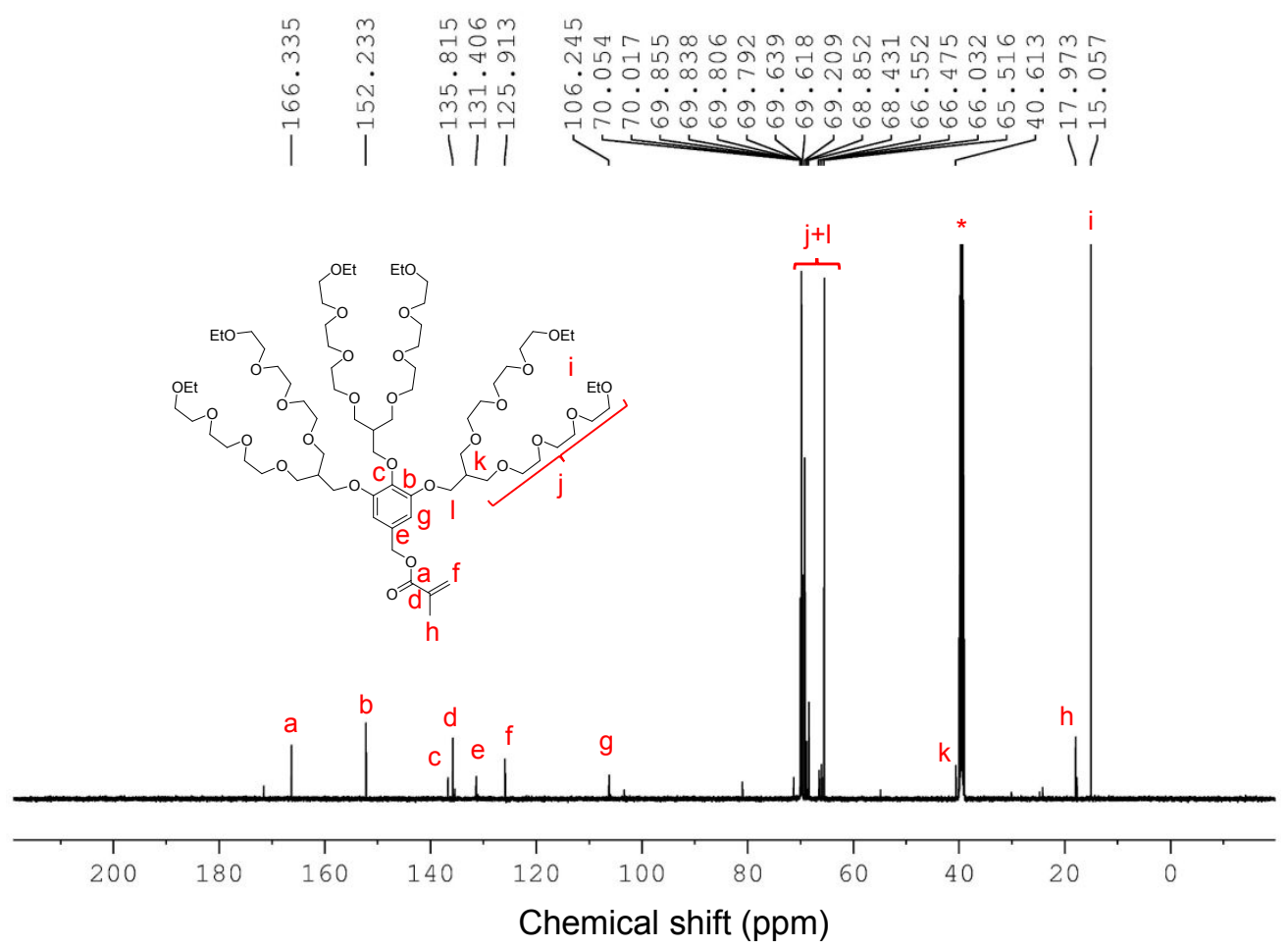

Figure S47. ${ }^{13} \mathrm{C}$ NMR spectrum of $\mathbf{E} \mathbf{t}^{6}-\mathbf{M}$ in DMSO- $d_{6}$. The solvent peak is marked with asterisk $(*)$.

Et6-M_20210917150942 \#8 RT: 0.06 AV: 1 NL: 1.55E8

T: FTMS + p ESI Full ms [200.0000-2000.0000]

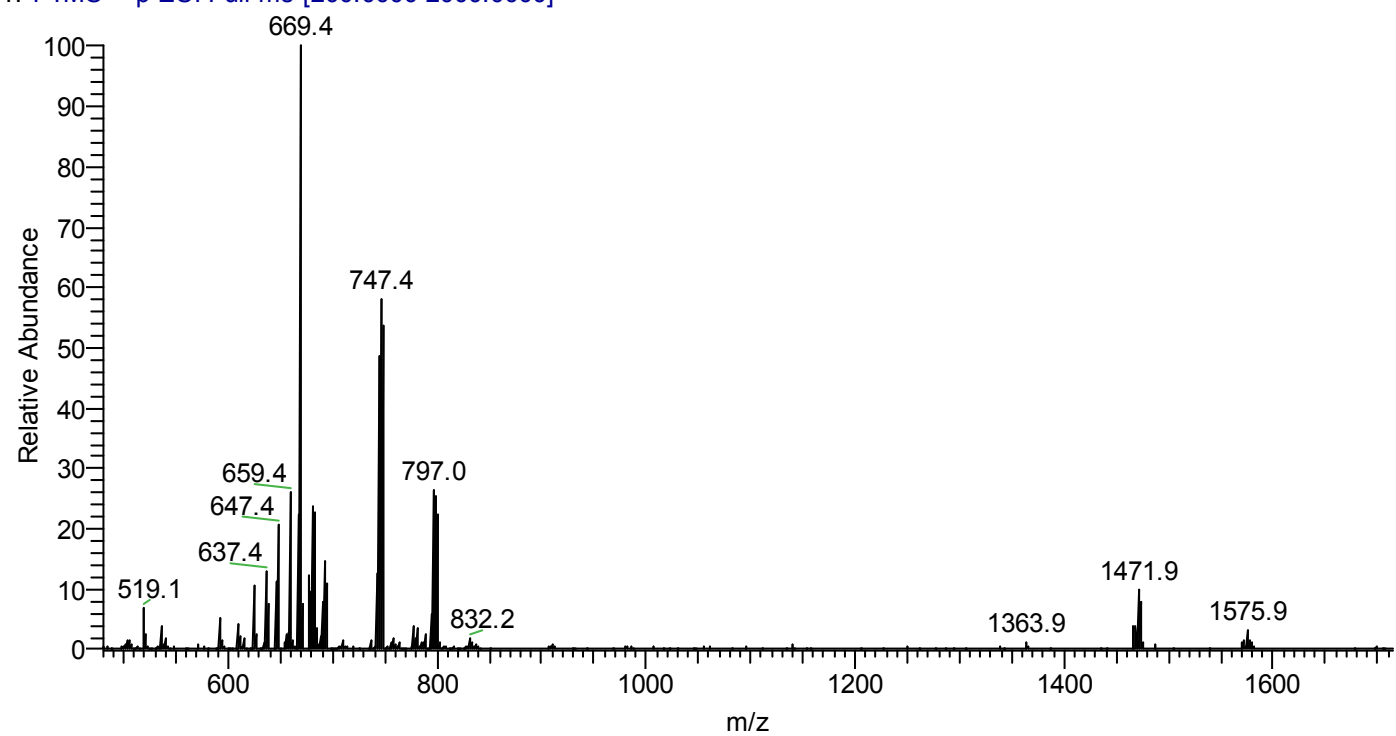

Figure S48. HR-MS spectrum of $\mathbf{E t}^{\mathbf{6}}-\mathbf{M}$. 


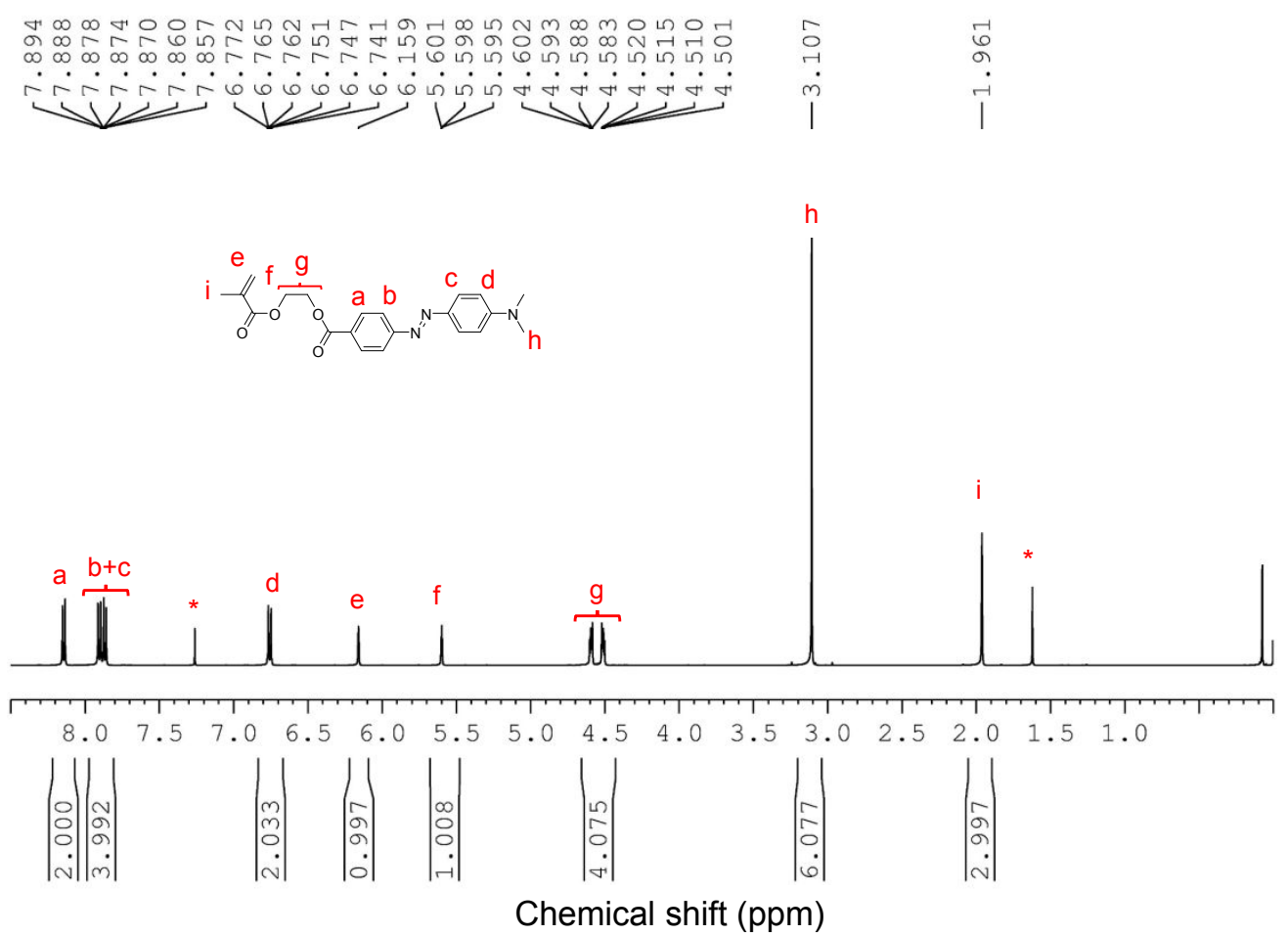

Figure S49. ${ }^{1} \mathrm{H}$ NMR spectrum of $\mathbf{M M R}$ in $\mathrm{CDCl}_{3}$. The solvent peak is marked with asterisk (*).

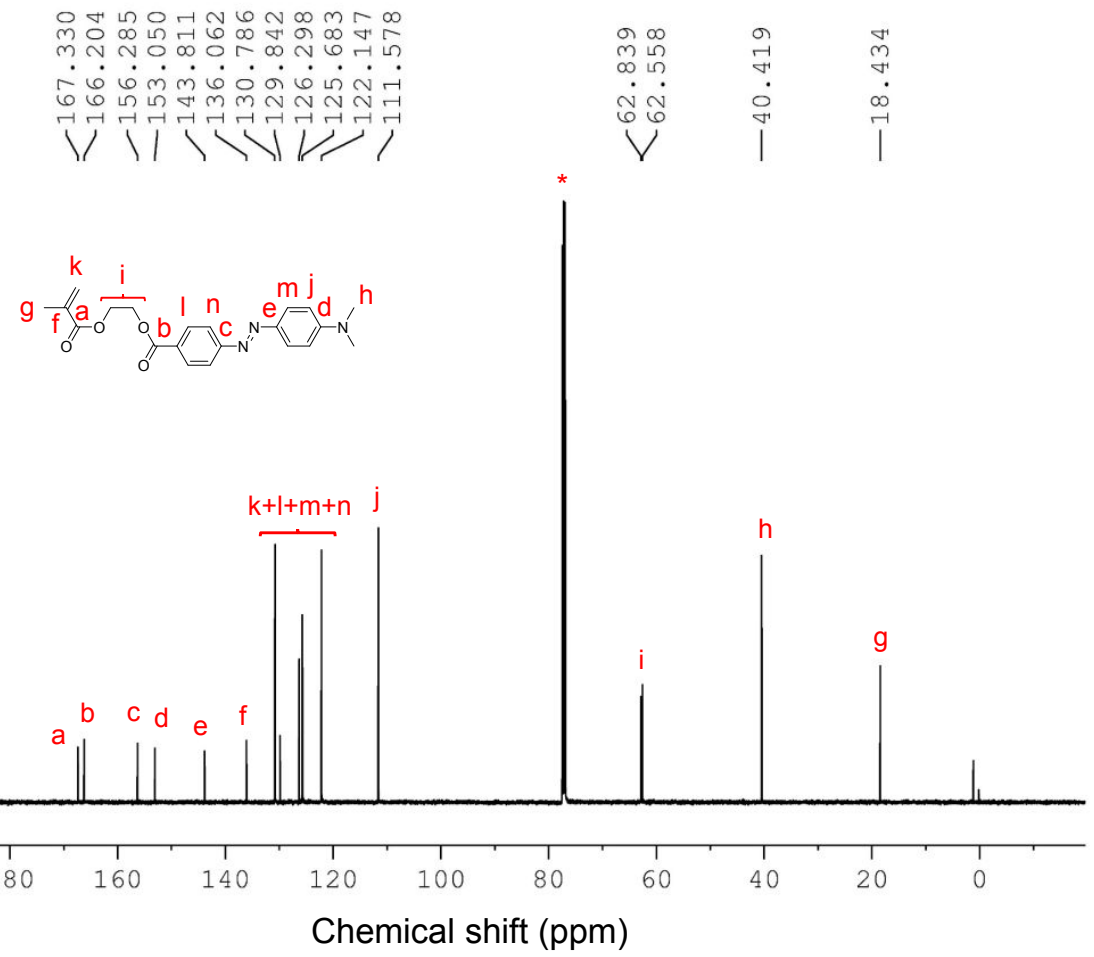

Figure S50. ${ }^{13} \mathrm{C}$ NMR spectrum of $\mathbf{M M R}$ in $\mathrm{CDCl}_{3}$. The solvent peak is marked with asterisk $(*)$. 
MMR \#10 RT: $0.08 \quad$ AV: 1 NL: $2.17 E 8$

T: FTMS + p ESI Full ms [100.0000-1000.0000]

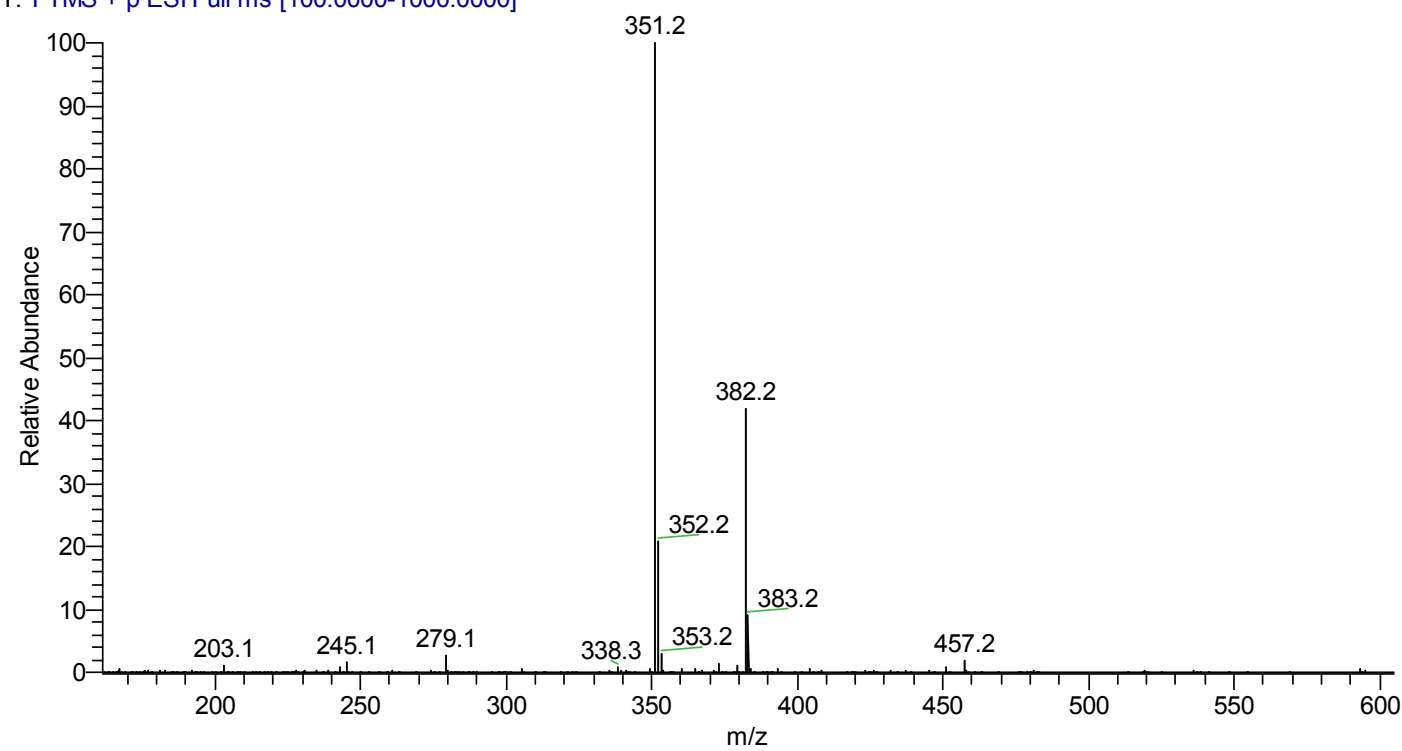

Figure S51. HR-MS spectrum of MMR.

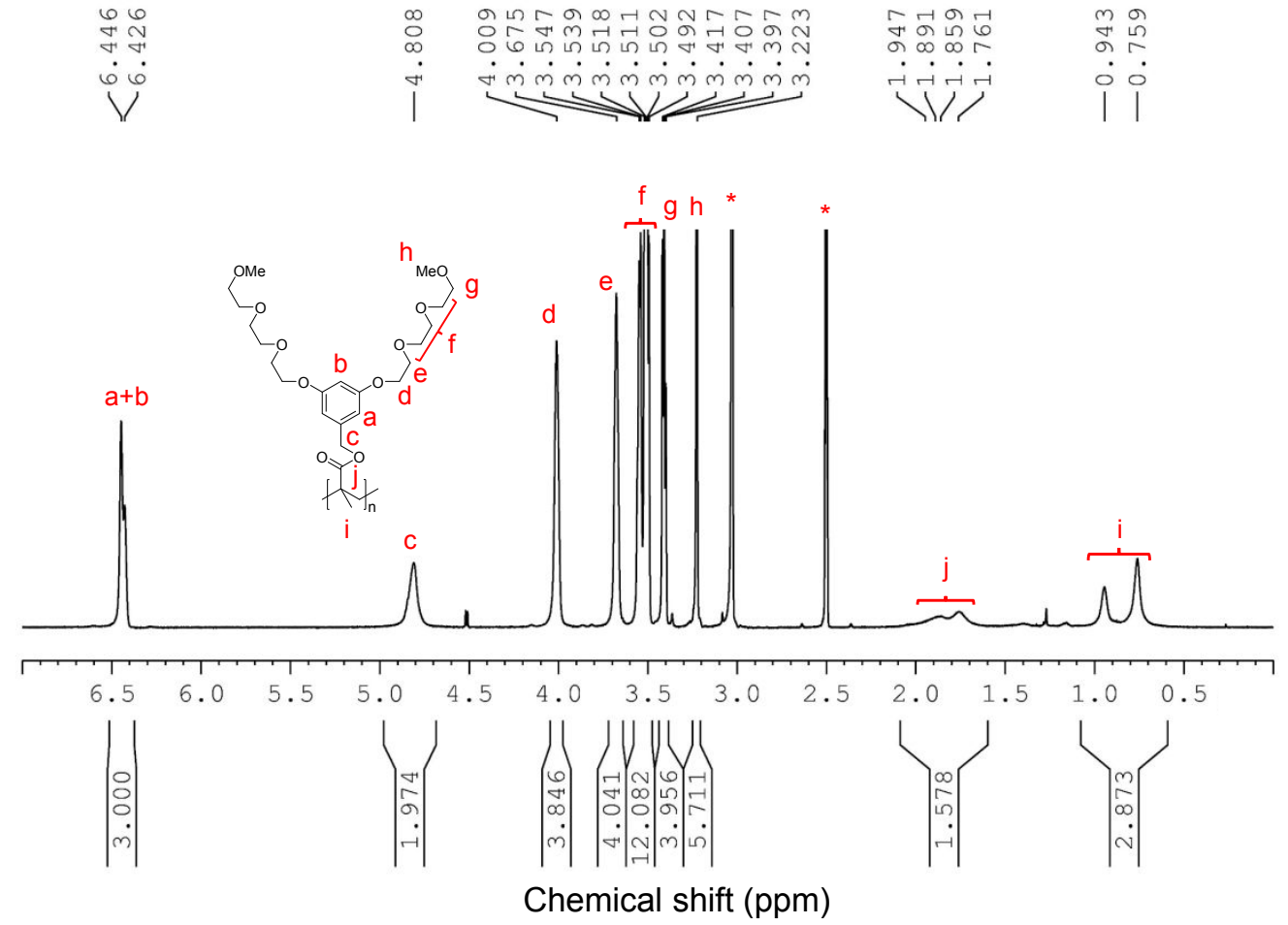

Figure S52 ${ }^{1} \mathrm{H}$ NMR spectrum of Me $\mathbf{M e}^{2}-\mathbf{P G 1}$ in DMSO- $d_{6}$ at $80{ }^{\circ} \mathrm{C}$. The solvent peak is marked with asterisk $(*)$. 


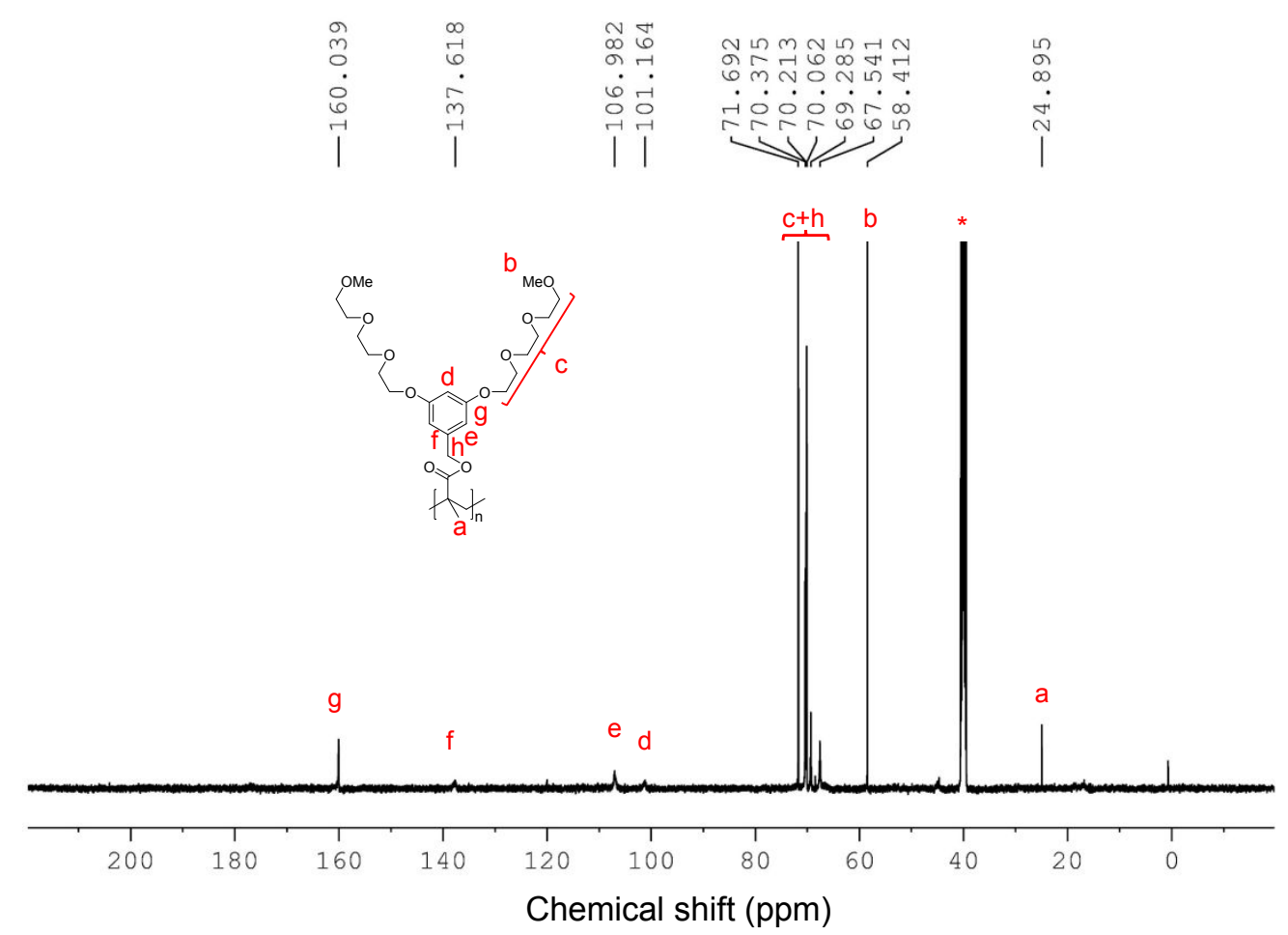

Figure S53 ${ }^{13} \mathrm{C}$ NMR spectrum of $\mathbf{M e}^{2}-\mathrm{PG} 1$ in DMSO- $d_{6}$. The solvent peak is marked with asterisk (*).

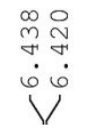
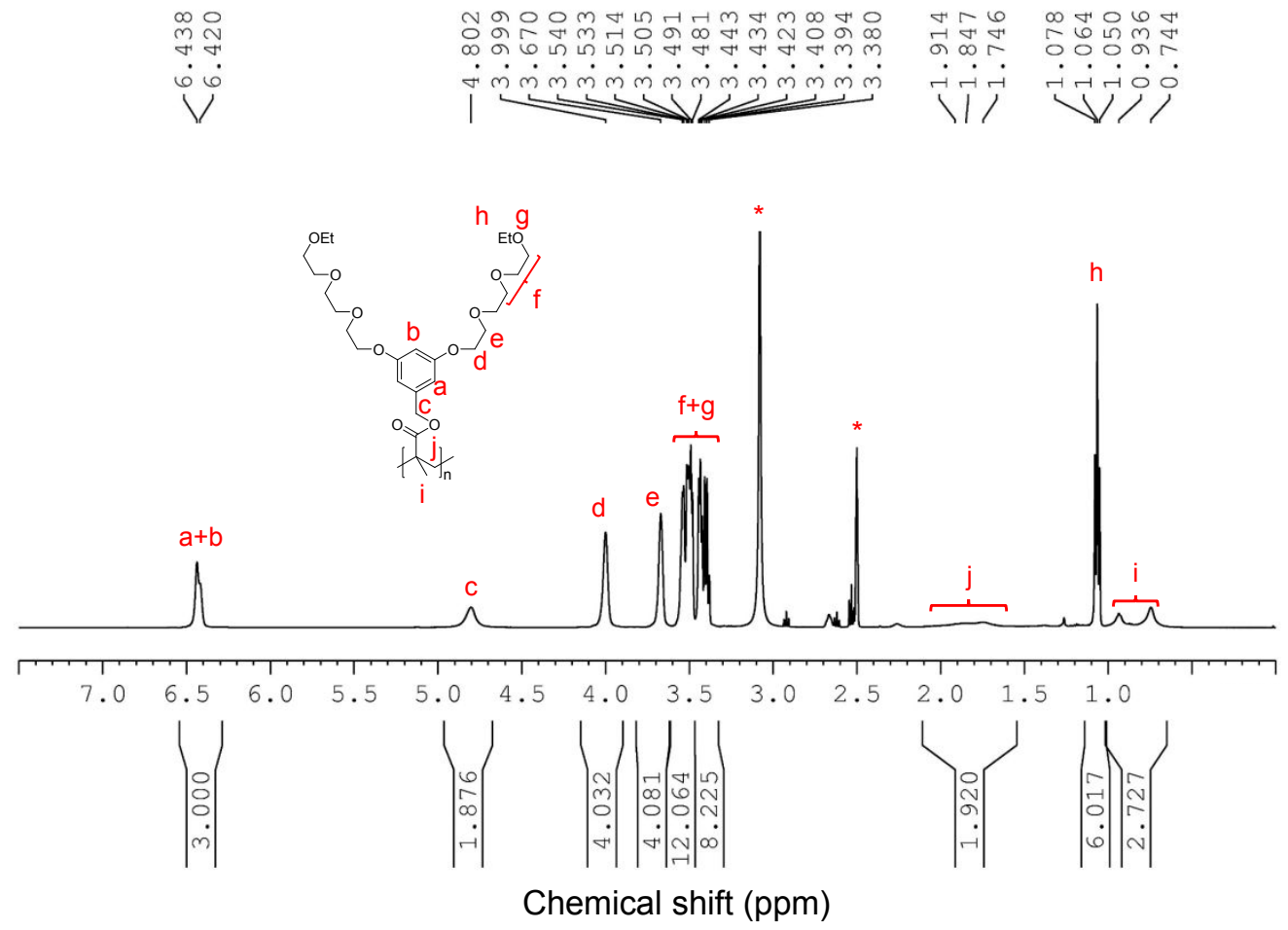

Figure S54 ${ }^{1} \mathrm{H}$ NMR spectrum of $\mathbf{E t} \mathbf{t}^{2}$-PG1 in DMSO- $d_{6}$ at $80{ }^{\circ} \mathrm{C}$. The solvent peak is marked with asterisk (*). 


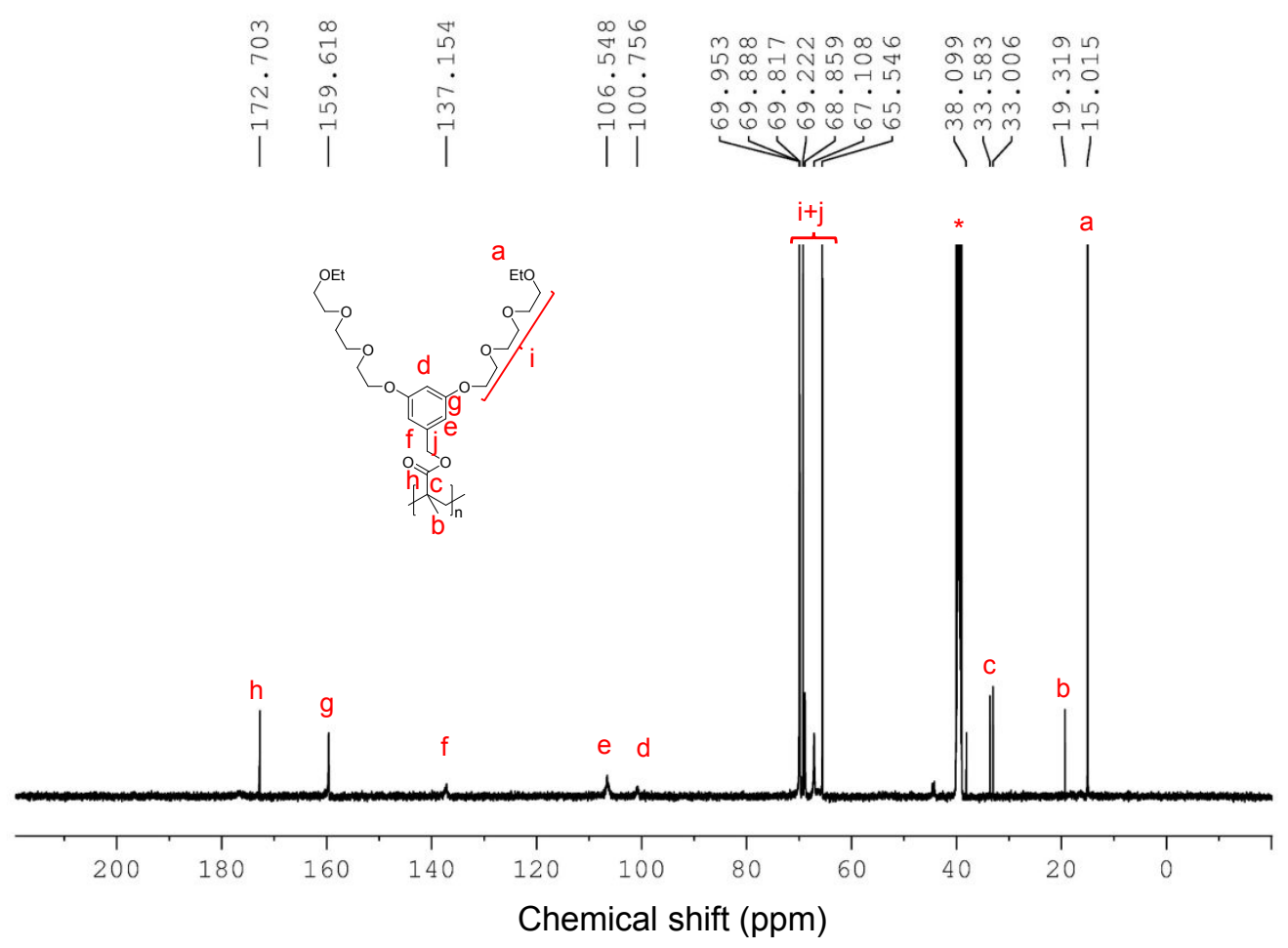

Figure $\mathbf{S 5 5}{ }^{13} \mathrm{C}$ NMR spectrum of $\mathbf{E t}^{2}-\mathbf{P G 1}$ in DMSO- $d_{6}$. The solvent peak is marked with asterisk $(*)$.

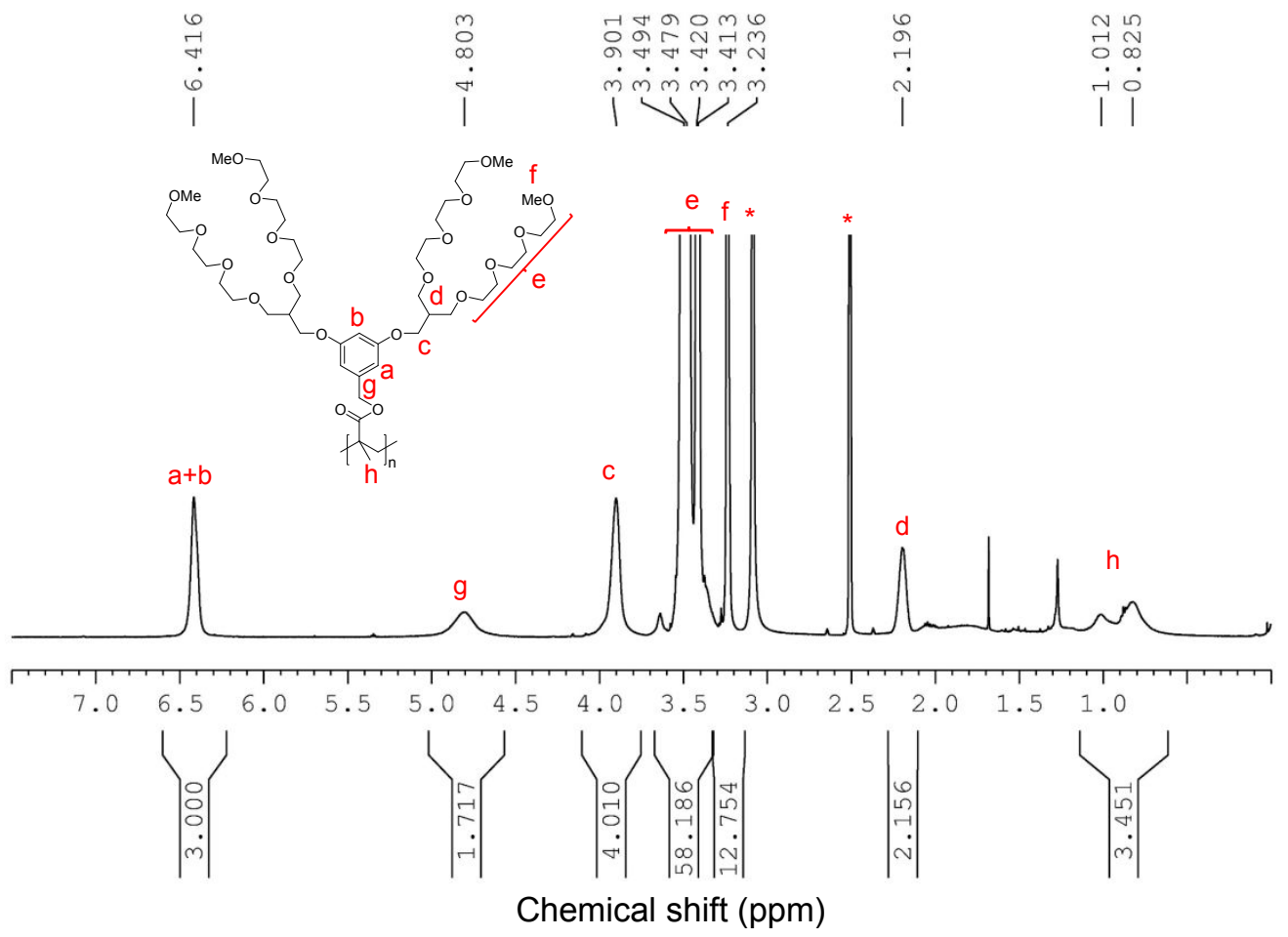

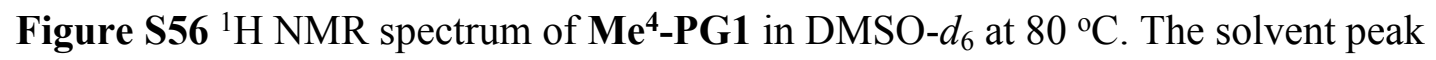
is marked with asterisk $(*)$. 


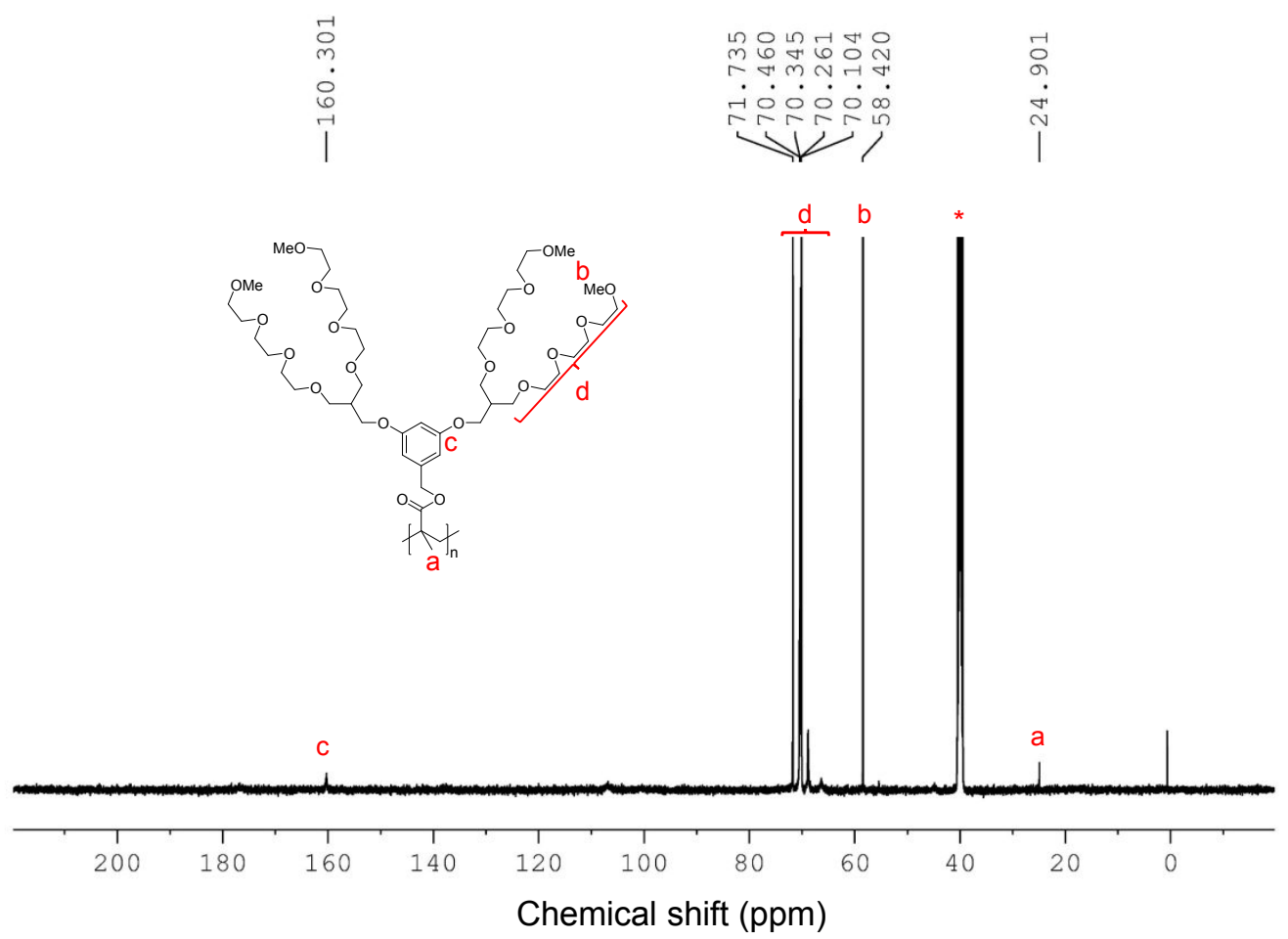

Figure S57 ${ }^{13} \mathrm{C}$ NMR spectrum of $\mathbf{M e}^{4}-\mathrm{PG} 1$ in DMSO- $d_{6}$. The solvent peak is marked with asterisk (*).
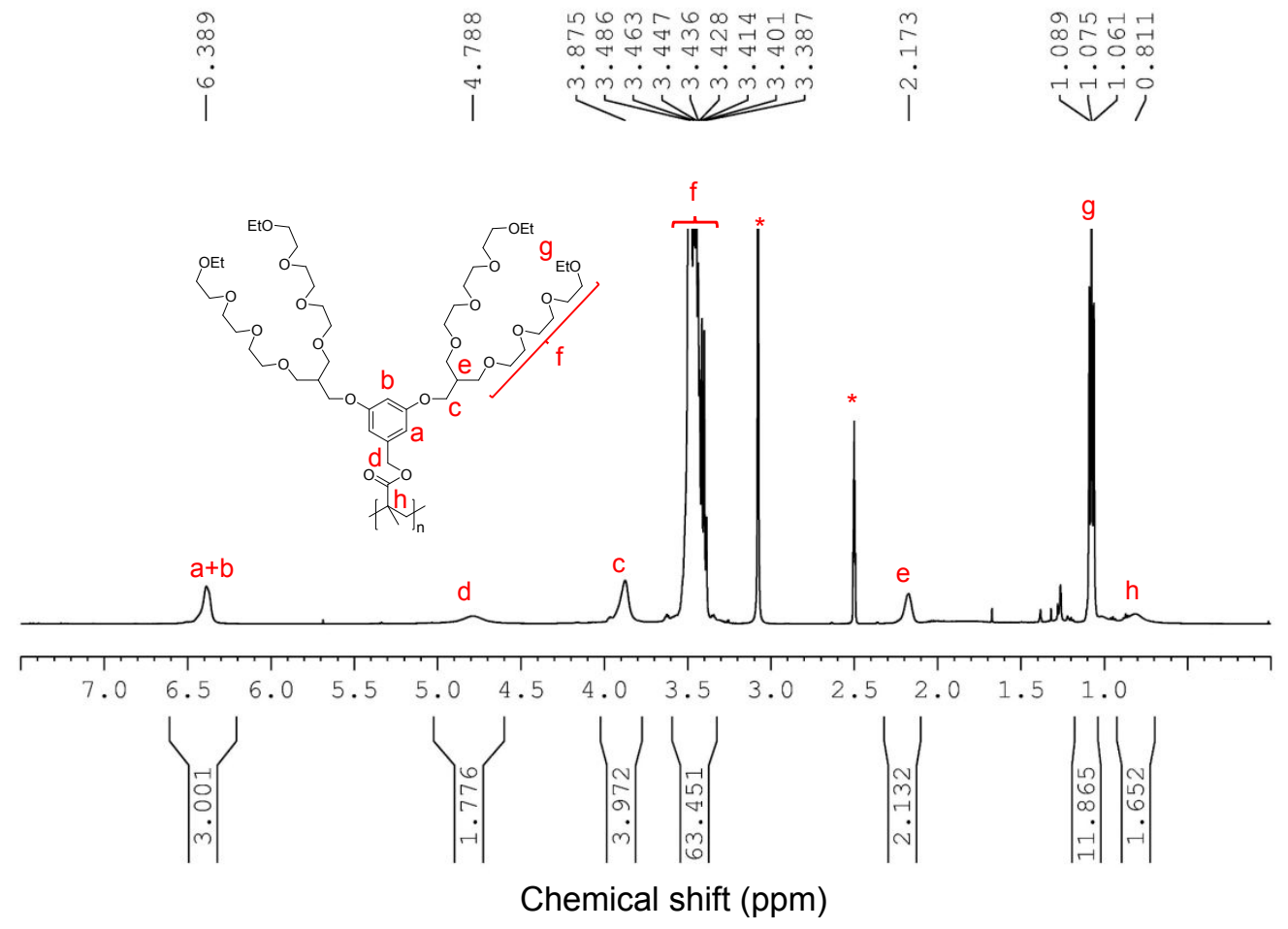

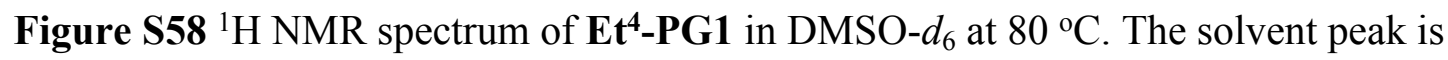
marked with asterisk $(*)$. 


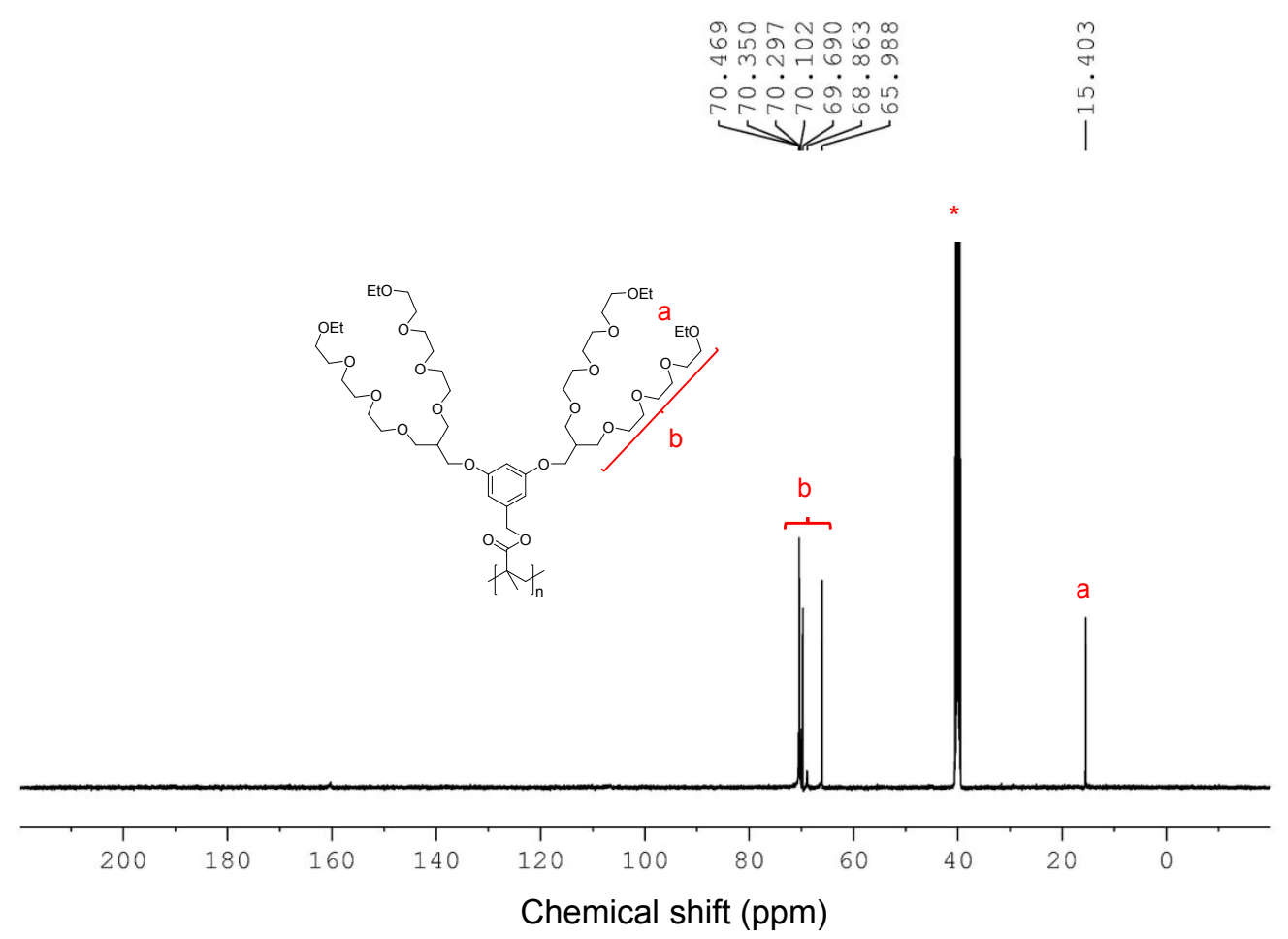

Figure S59 ${ }^{13} \mathrm{C}$ NMR spectrum of $\mathbf{E t} \mathbf{t}^{4}$-PG1 in DMSO- $d_{6}$. The solvent peak is marked with asterisk $(*)$.

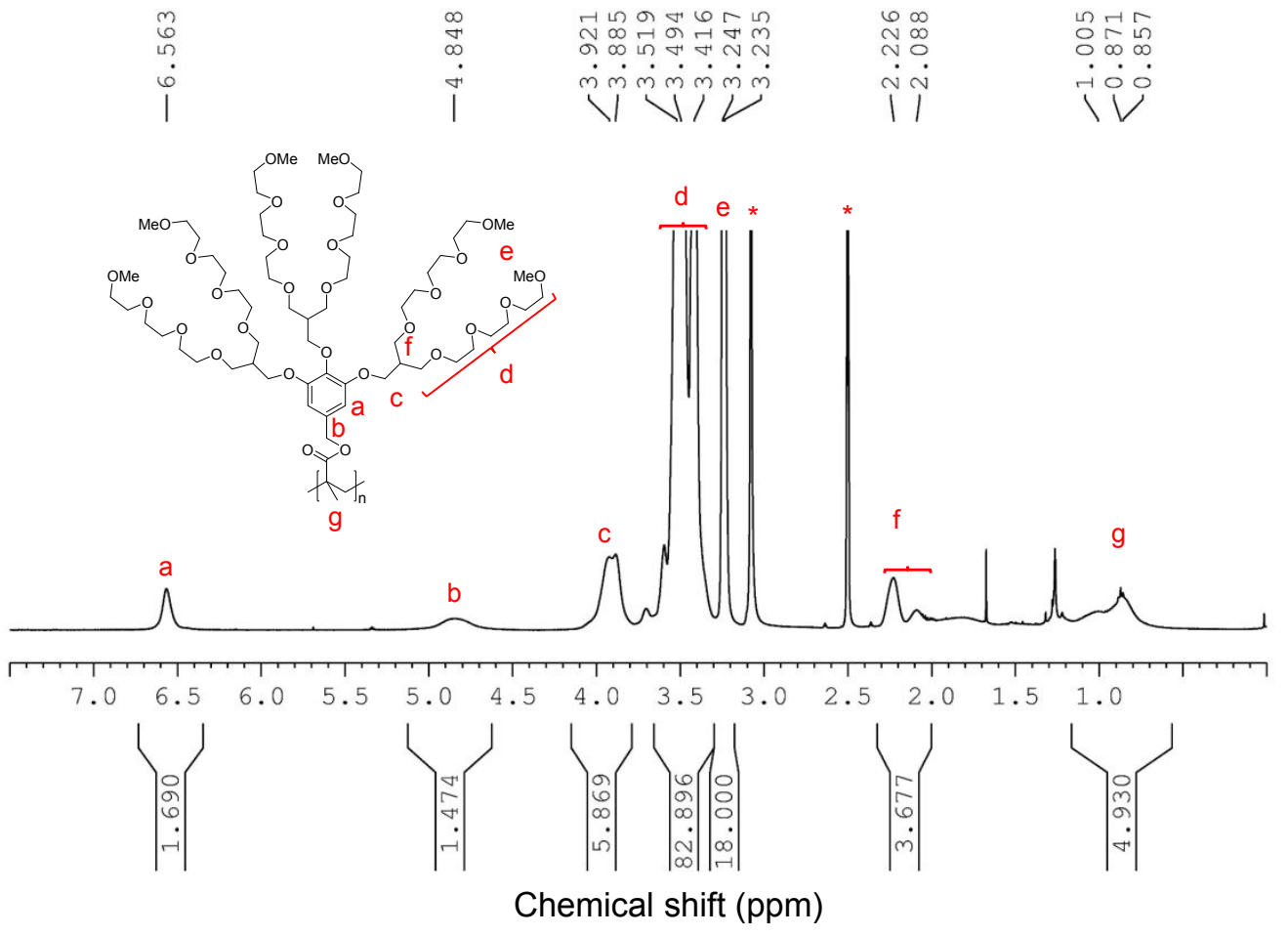

Figure S60 ${ }^{1} \mathrm{H}$ NMR spectrum of Me-PG1 in DMSO- $d_{6}$ at $80{ }^{\circ} \mathrm{C}$. The solvent peak is marked with asterisk $(*)$. 


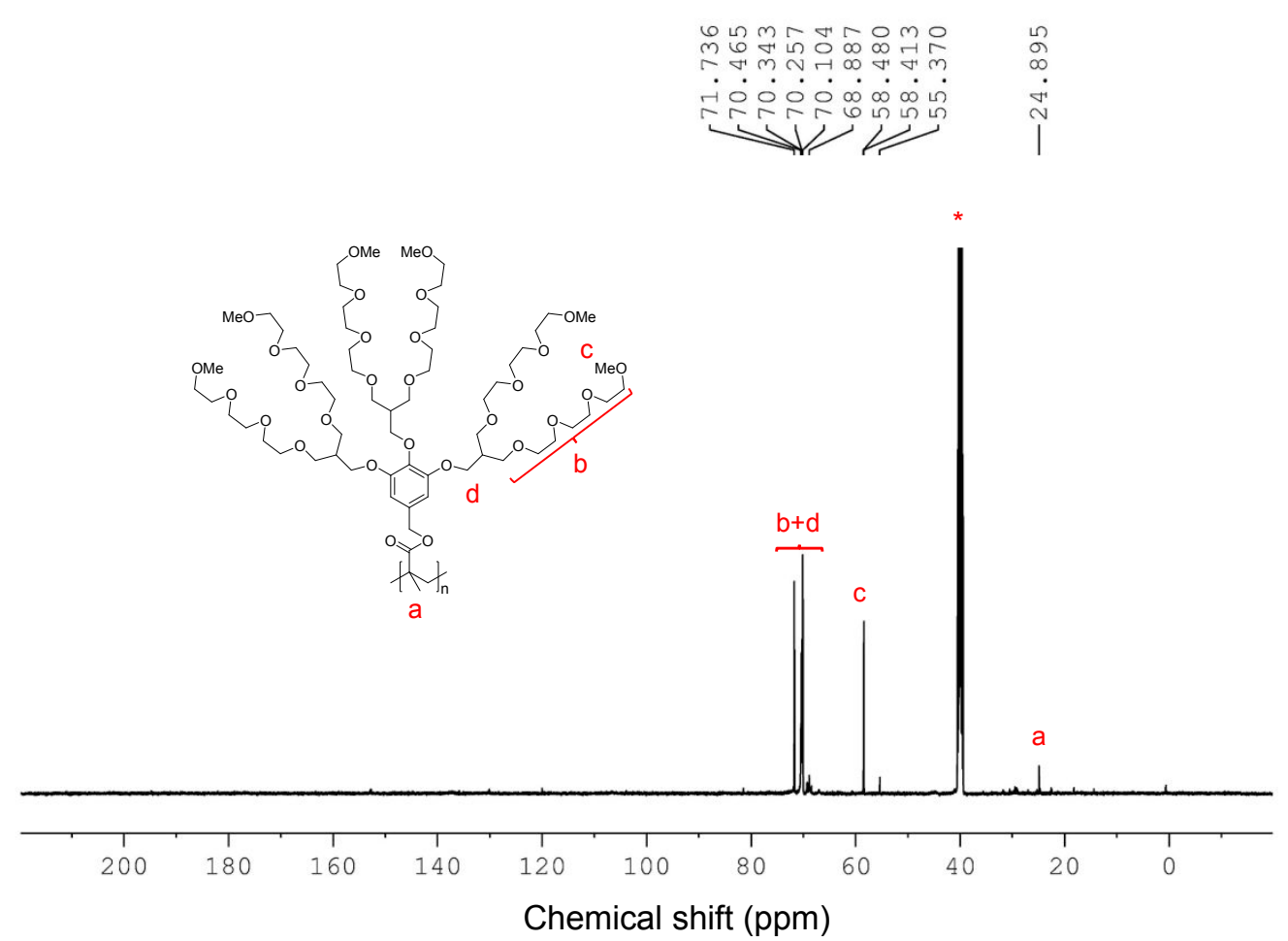

Figure S61 ${ }^{13} \mathrm{C}$ NMR spectrum of $\mathbf{M e}^{6}-\mathrm{PG1}$ in DMSO- $d_{6}$. The solvent peak is marked with asterisk (*).

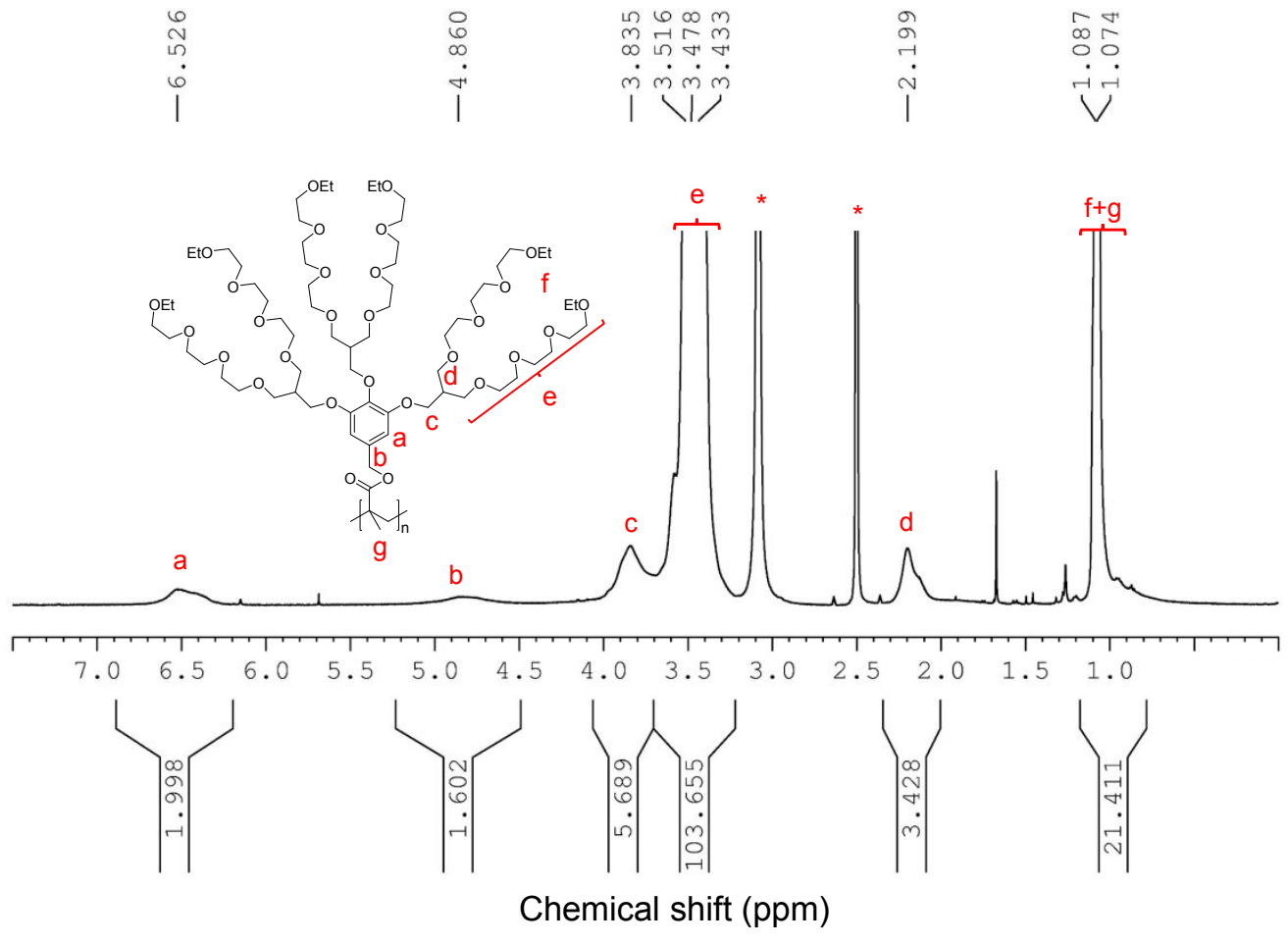

Figure S62. ${ }^{1} \mathrm{H}$ NMR spectrum of Et $\mathbf{t}^{6}-\mathbf{P G 1}$ in DMSO- $d_{6}$ at $80{ }^{\circ} \mathrm{C}$. The solvent peak is marked with asterisk $(*)$. 


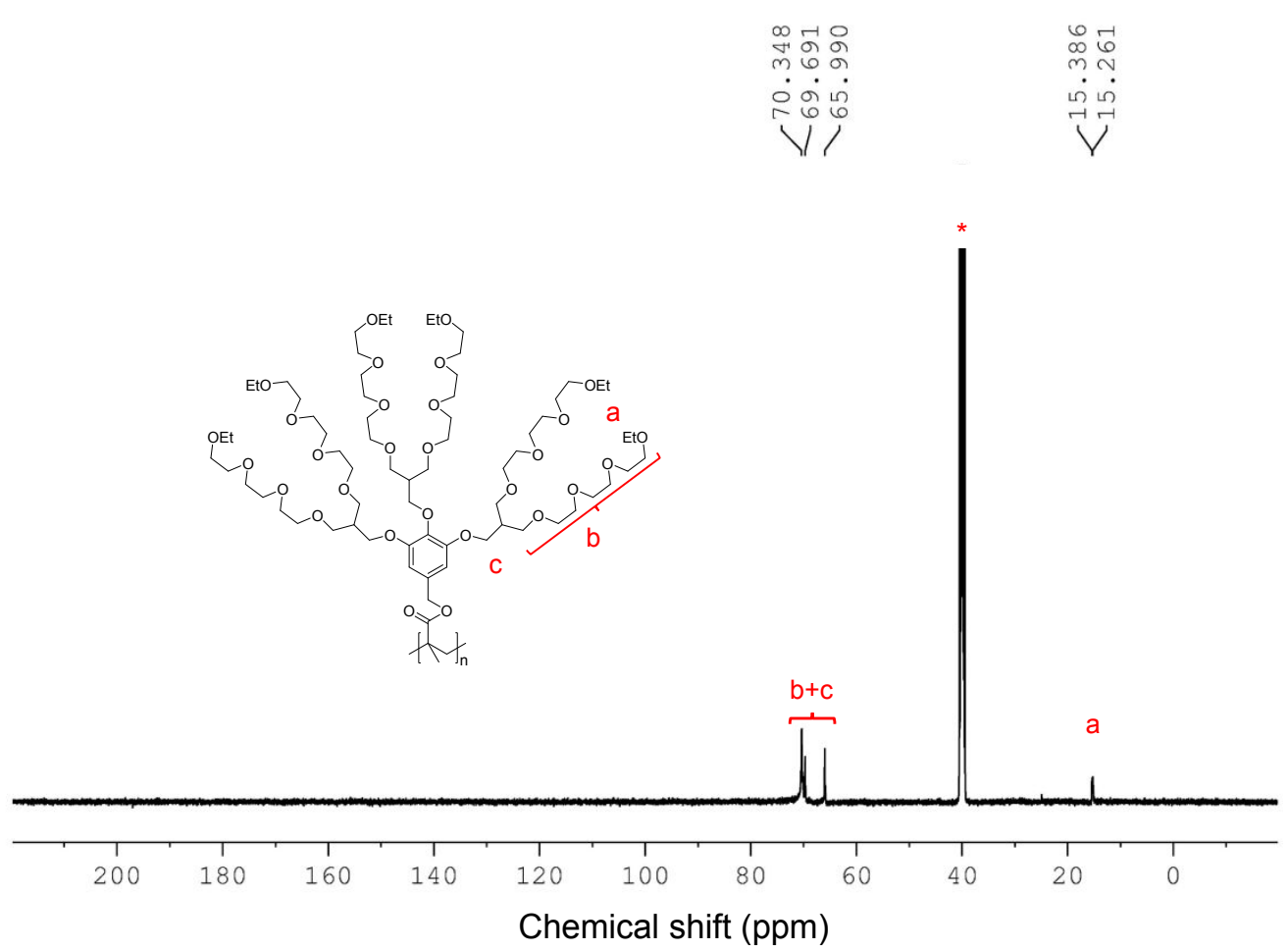

Figure S63. ${ }^{13} \mathrm{C}$ NMR spectrum of $\mathbf{E t} \mathbf{t}^{6}-\mathbf{P G 1}$ in DMSO- $d_{6}$. The solvent peak is marked with asterisk (*).

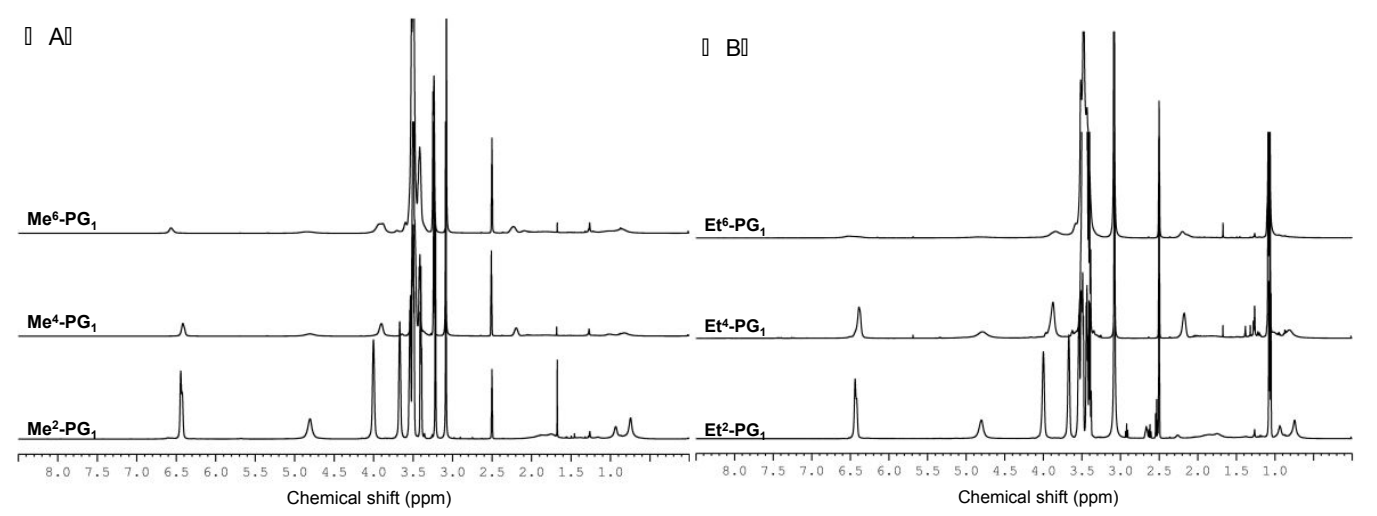

Figure S64. ${ }^{1} \mathrm{H}$ NMR spectrum of different dendronized polymers in DMSO- $d_{6}$ at $80{ }^{\circ} \mathrm{C}$. 


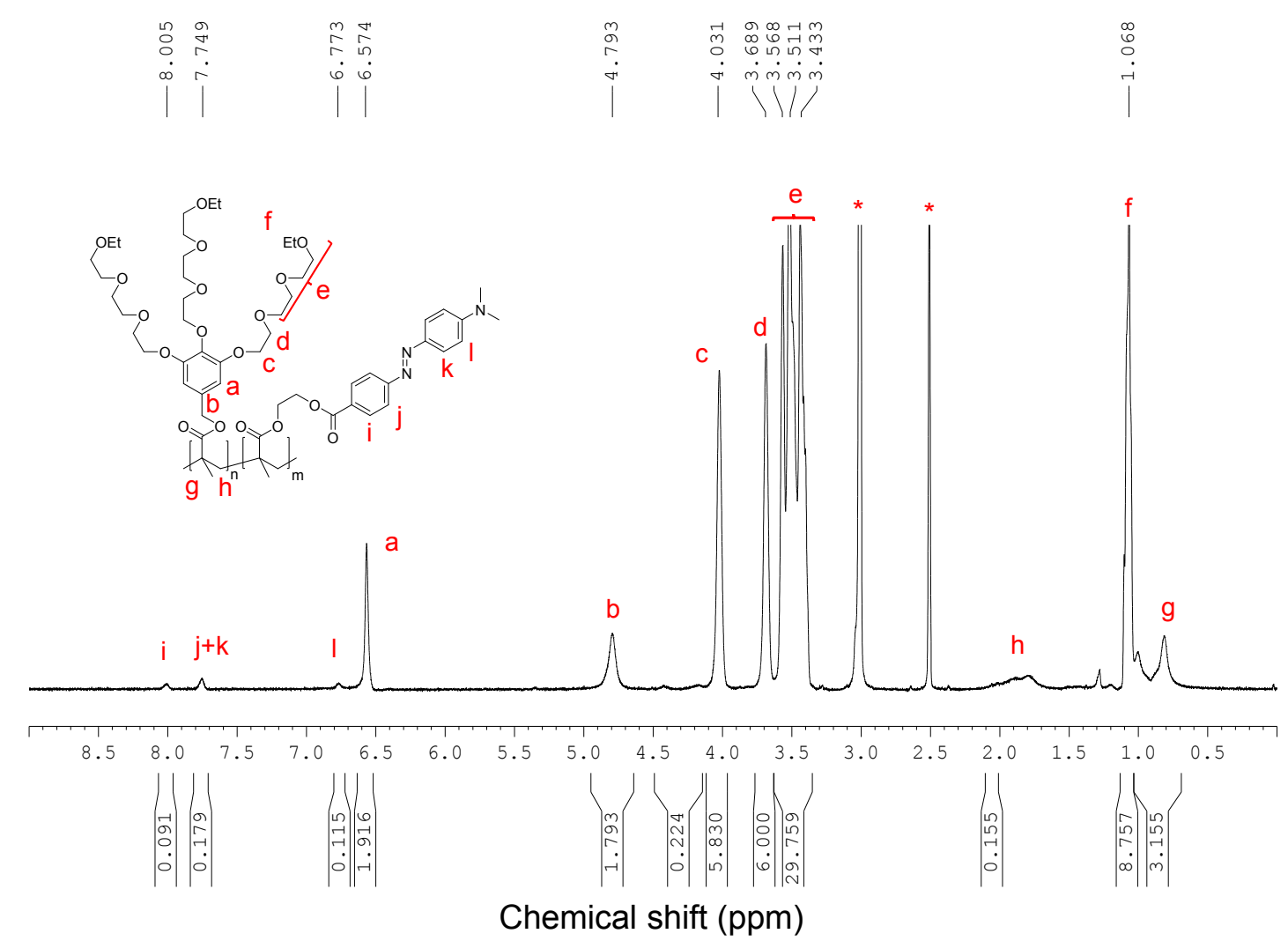

Figure S65. ${ }^{1} \mathrm{H}$ NMR spectrum of Et $\mathbf{t}^{3}$-PG1MR in DMSO- $d_{6}$ at $80{ }^{\circ} \mathrm{C}$. The solvent peak is marked with asterisk $(*)$.

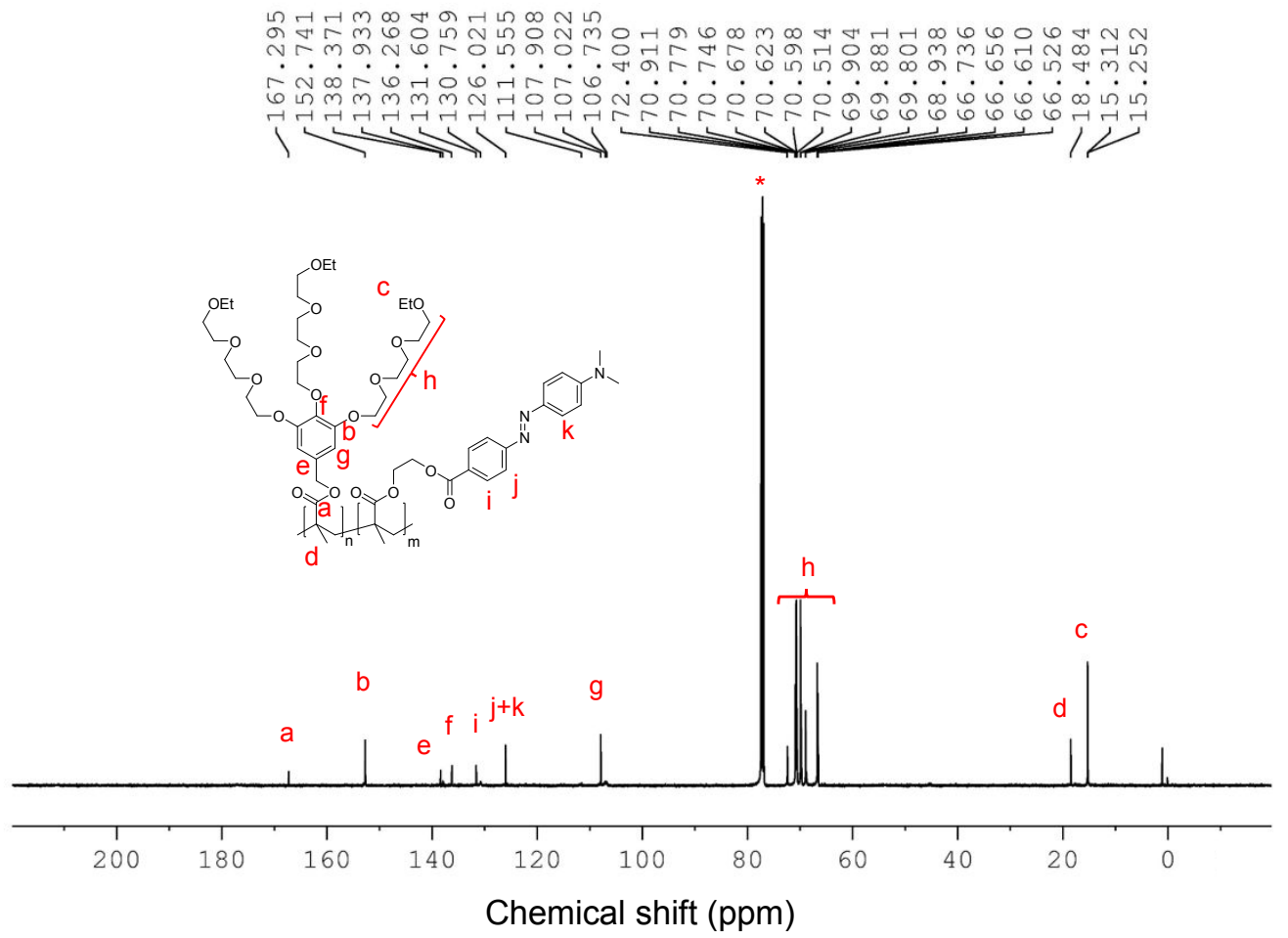

Figure S66. ${ }^{13} \mathrm{C}$ NMR spectrum of $\mathbf{E t}^{3}-\mathbf{P G 1 M R}$ in $\mathrm{CDCl}_{3}$. The solvent peak is marked with asterisk $(*)$. 


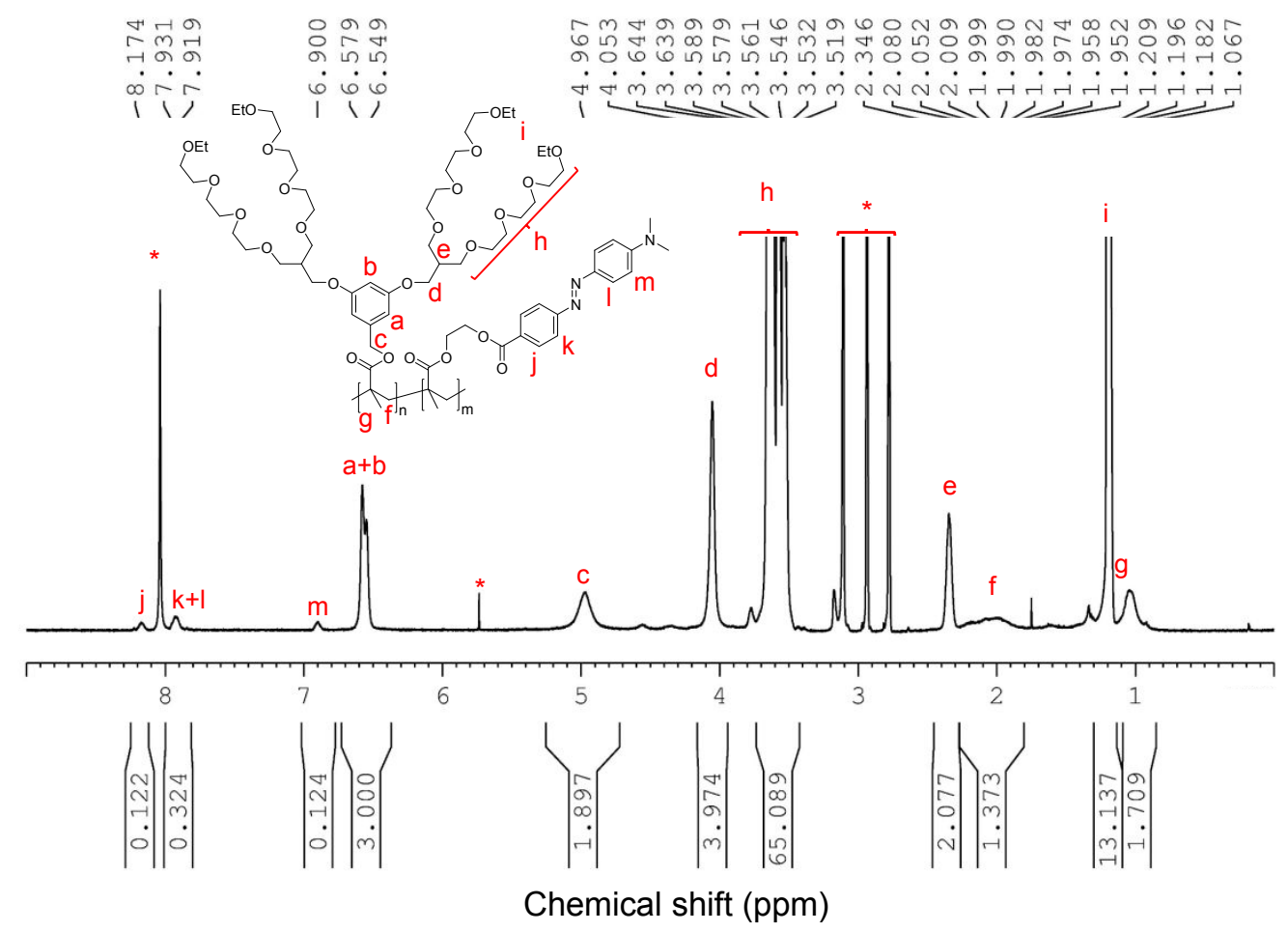

Figure S67. ${ }^{1} \mathrm{H}$ NMR spectrum of Et $\mathbf{t}^{4}-\mathrm{PG1MR}$ in DMF- $d_{7}$ at $80^{\circ} \mathrm{C}$. The solvent peak is marked with asterisk $(*)$.

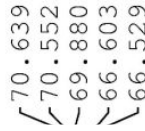

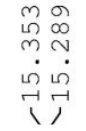

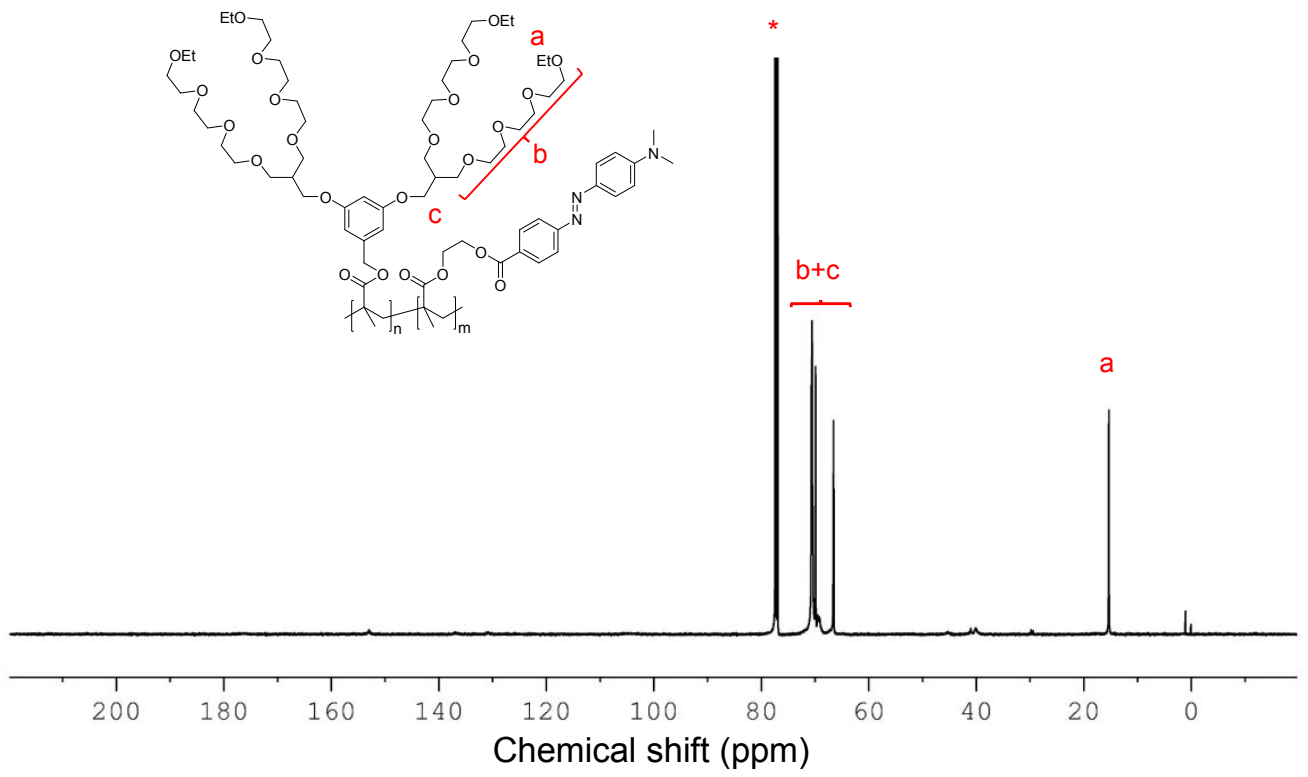

Figure S68. ${ }^{13} \mathrm{C}$ NMR spectrum of $\mathbf{E t}^{4}-\mathbf{P G 1 M R}$ in $\mathrm{CDCl}_{3}$. The solvent peak is marked with asterisk $(*)$. 


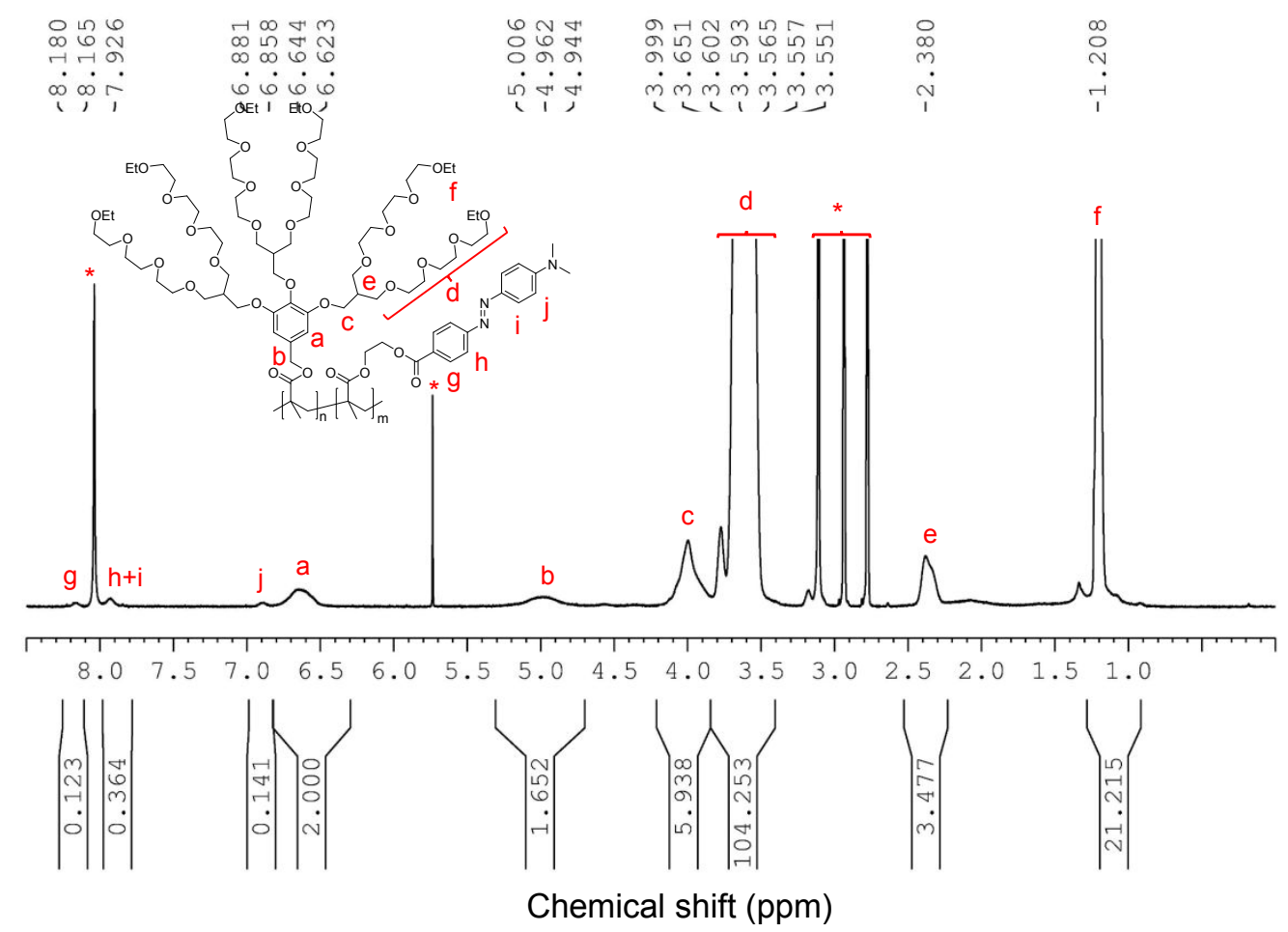

Figure S69. ${ }^{1} \mathrm{H}$ NMR spectrum of Et $\mathbf{t}^{6}-\mathrm{PG1MR}$ in DMF- $d_{7}$ at $80^{\circ} \mathrm{C}$. The solvent peak is marked with asterisk $(*)$.

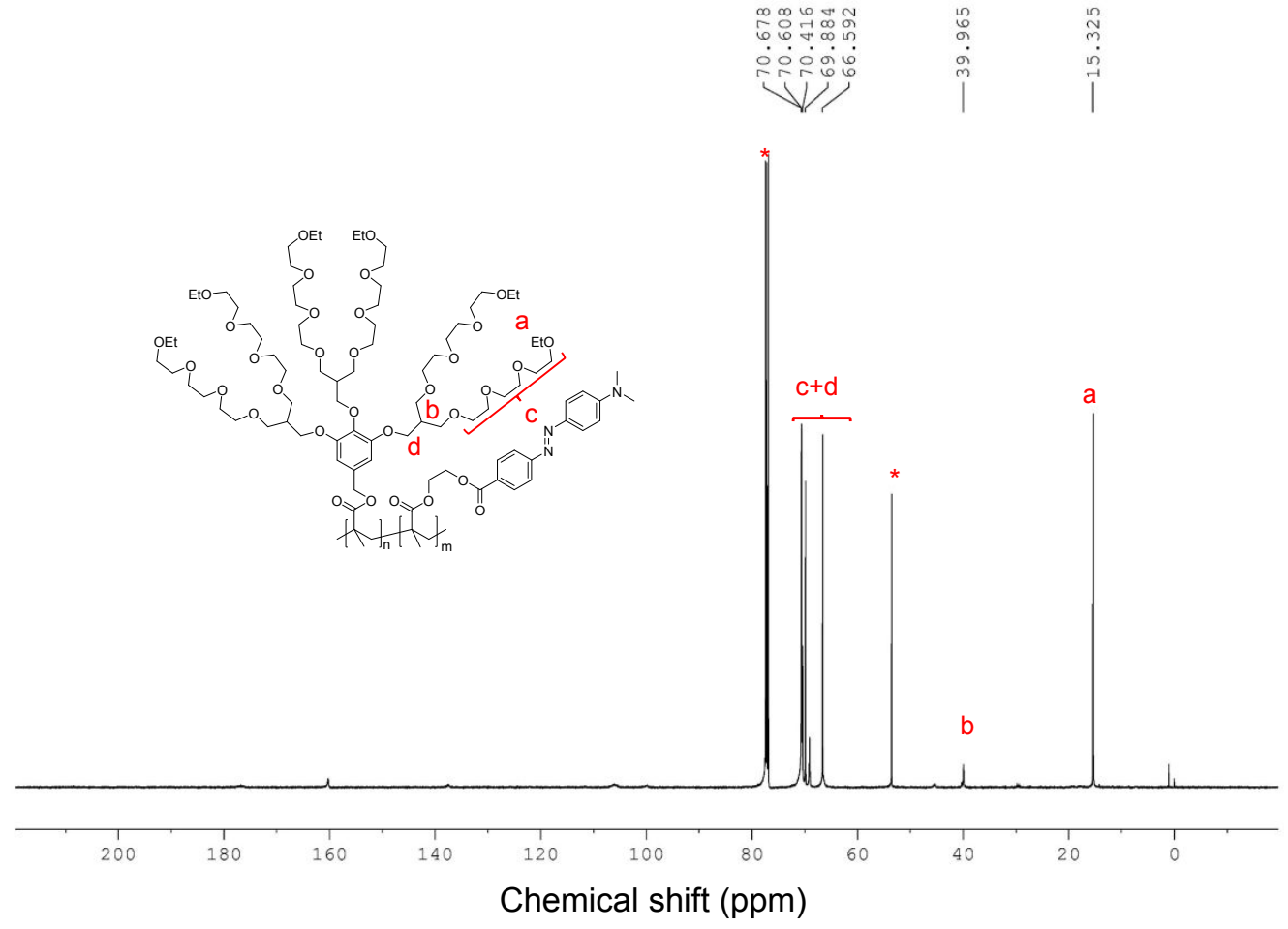

Figure S70. ${ }^{13} \mathrm{C}$ NMR spectrum of $\mathbf{E t}^{6}-\mathbf{P G 1 M R}$ in $\mathrm{CDCl}_{3}$. The solvent peak is marked with asterisk (*). 


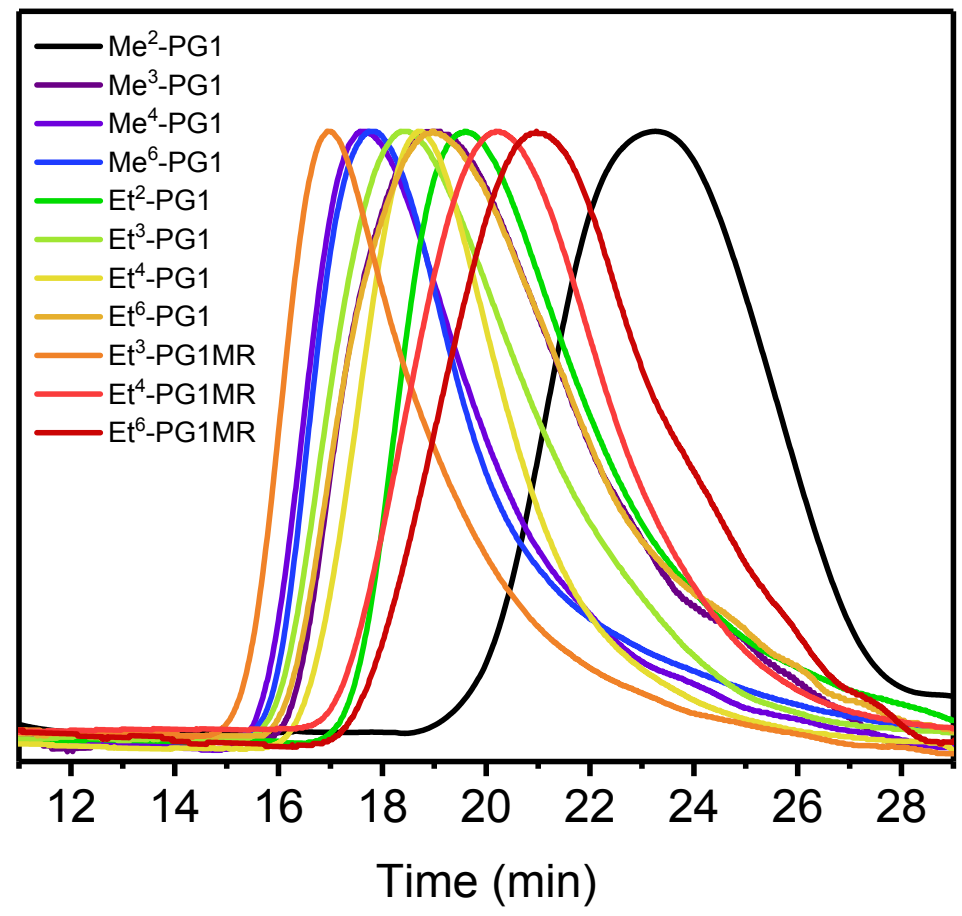

Figure S71. GPC elution curves of dendronized polymers.

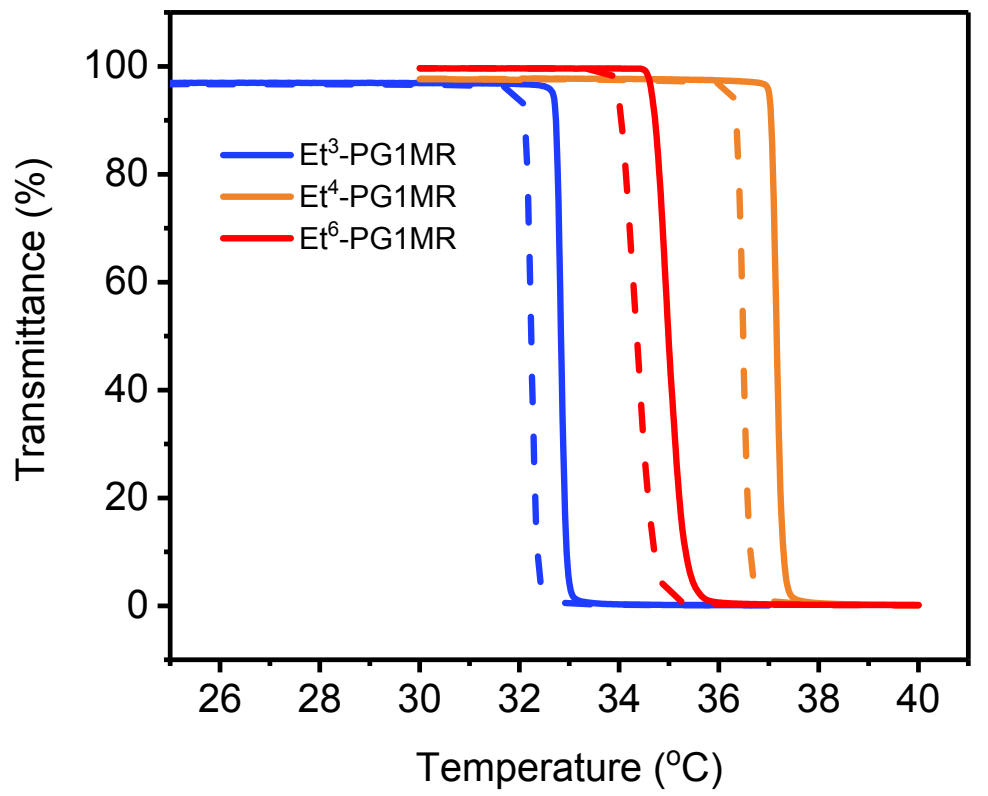

Figure S72. Plots of transmittance $v s$ temperature for $0.25 \mathrm{wt} \%$ aqueous solutions of copolymers. Heating and cooling rate $=0.2{ }^{\circ} \mathrm{C} / \mathrm{min}$. 

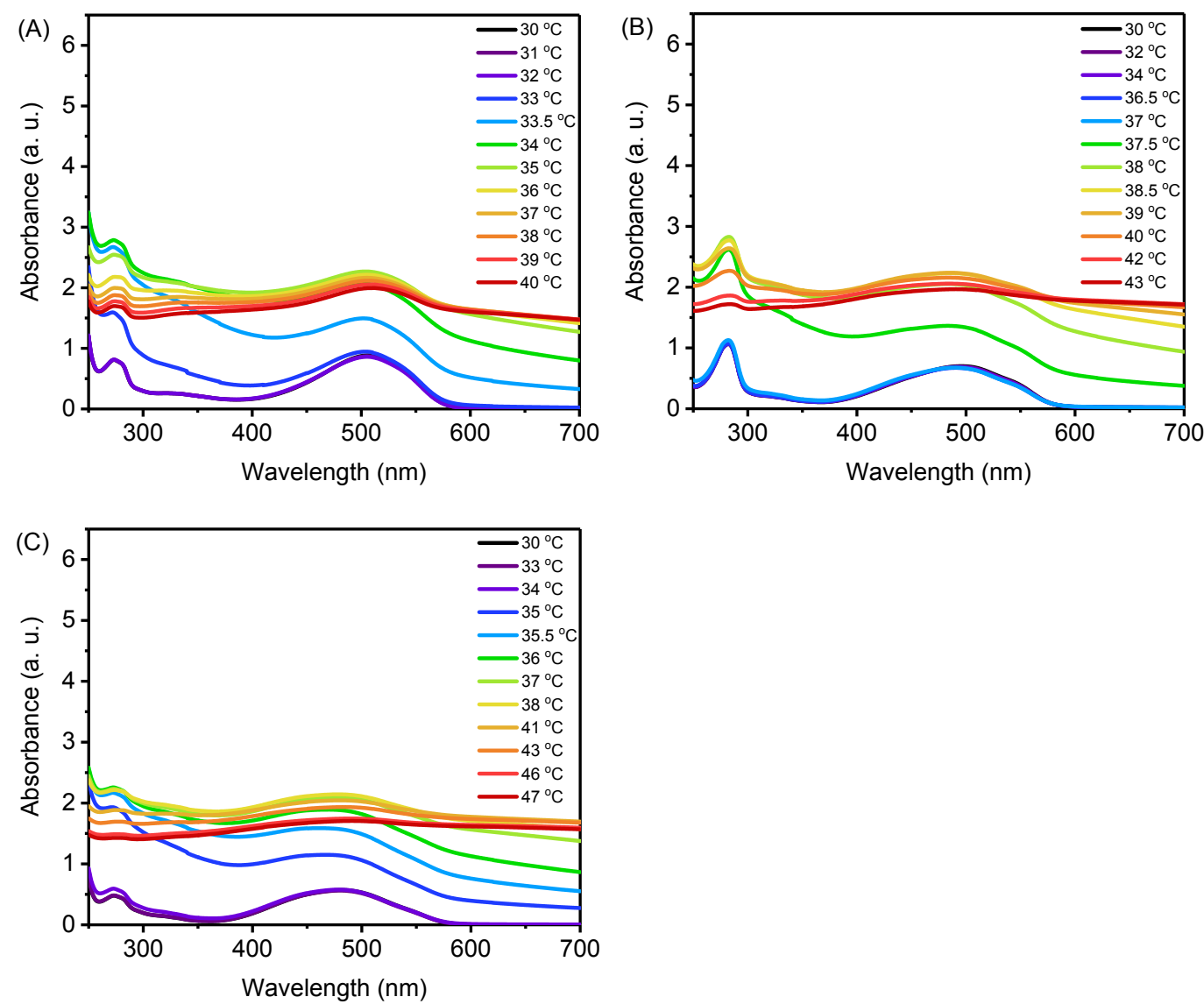

Figure S73 Temperature-varied UV/vis spectra for $\mathbf{E t}^{\mathbf{3}}$-PG1MR (A), Et $\mathbf{t}^{4}$-PG1MR (B), Et ${ }^{6}$-PG1MR (C).
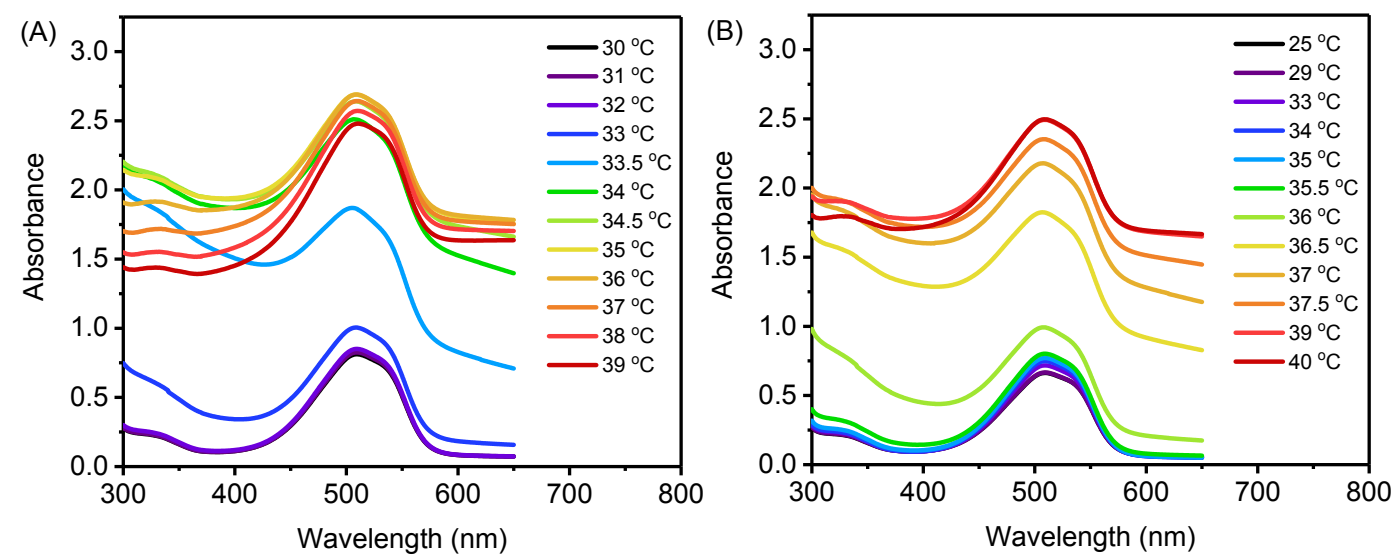


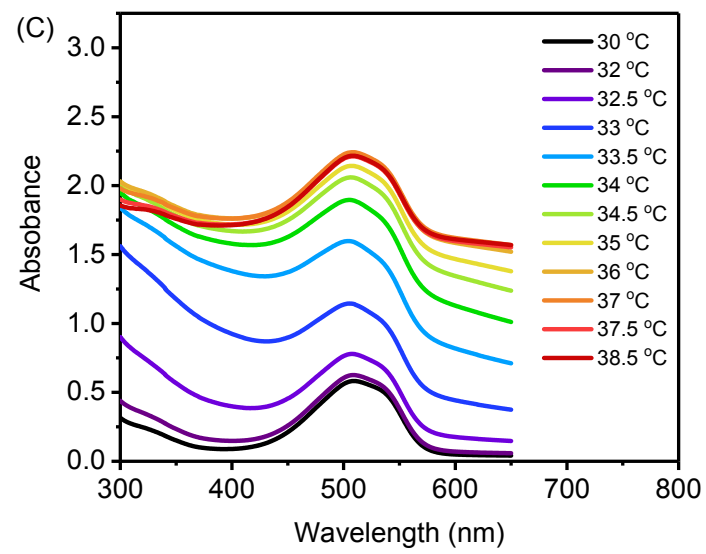

Figure S74. Temperature-varied UV/vis spectra for $\mathbf{E t}^{3}$-PG1@MR (A), Et $\mathbf{t}^{4}$ PG1@MR (B), Et ${ }^{6}-P G 1 @ M R(C)$.
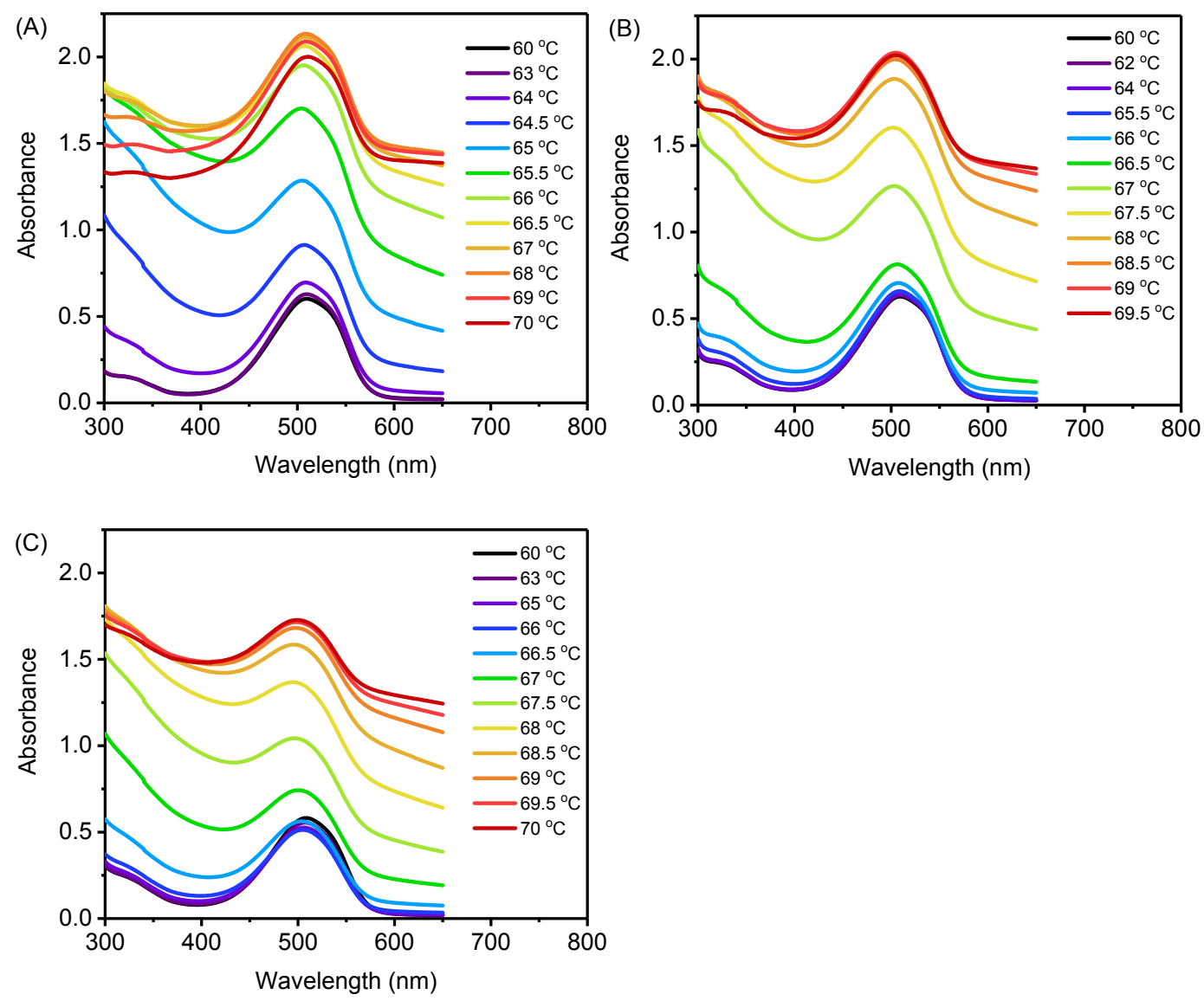

Figure S75. Temperature-varied UV/vis spectra for Me $\mathbf{3}^{3}$-PG1@MR (A), Me $\mathbf{M}^{4}$ PG1@MR (B), Me'-PG1@MR (C). 